\title{
Hypervalent iodine(III) reagents in organic synthesis
}

\author{
Viktor V. Zhdankin \\ Department of Chemistry and Biochemistry, University of Minnesota Duluth, \\ Duluth, Minnesota 55812, USA \\ E-mail:vzhdanki@d.umn.edu
}

\begin{abstract}
This review summarizes the chemistry of hypervalent iodine(III) compounds with emphasis of their synthetic applications. The preparation and reactions of (difluoroiodo)arenes, (dichloroiodo)arenes, iodosylarenes, [bis(acyloxy)iodo]arenes, and aryliodine(III) organosulfonates are overviewed. Application of these reagents allows mild and highly selective oxidative transformations in a facile and environmentally friendly manner. Some of these useful transformations can be carried out using organoiodine(III) compounds as catalysts or recyclable reagents.
\end{abstract}

Keywords: Hypervalent iodine, oxidation, (difluoroiodo)benzene, (dichloroiodo)benzene, iodosylbenzene, (diacetoxyiodo)benzene, [hydroxy(tosyloxy)]iodobenzene, catalysis, recyclable reagents

\section{Contents}

1. Introduction

2. Classification and General Structural Features of Organic Iodine(III) Compounds

3. Preparation of Hypervalent Iodine(III) Compounds

3.1. (Difluoroiodo)arenes

3.2. (Dichloroiodo)arenes

3.3. Iodosylarenes

3.4. [Bis(acyloxy)iodo]arenes

3.5. Aryliodine(III) Organosulfonates

4. Halogenations using Hypervalent Iodine(III) Reagents

4.1. Fluorinations

4.2. Chlorinations

4.3. Brominations and Iodinations

5. Oxidative Transformations of Organic Substrates 
5.1. Oxidation of alcohols

5.2. Oxidative functionalization of carbonyl compounds, alkenes, and arenes

5.3. Oxidative rearrangements and fragmentations

5.4. Oxidative dearomatization of phenolic substrates

5.5. Oxidative coupling of aromatic substrates

5.6. Radical rearrangements

5.7. Thiocyanations, azidations, arylselenations, and aryltellurations

5.8. Transition metal catalyzed reactions

6. Hypervalent Iodine Compounds as Catalysts and Reusable Reagents

6.1. Catalytic utilization of hypervalent iodine reagents

6.2. Polymer-supported and recyclable hypervalent iodine reagents

7. Conclusion and Outlook

Acknowledgements

References

\section{Introduction}

In the past decade, the organic chemistry of iodine has experienced a rapid development. This growing interest in iodine compounds is mainly due to the mild and highly selective oxidizing properties of hypervalent iodine reagents, combined with their benign environmental character and commercial availability. Organic iodine(III) and iodine(V) derivatives are now routinely used in organic synthesis as reagents for various selective oxidative transformations of complex organic molecules. Several reviews, books and book chapters, some comprehensive, but most dealing with specific aspects of polyvalent organoiodine chemistry, have been published just in the last 5-6 years. ${ }^{1}$ Particularly noteworthy was the publication of commemorative issue of ARKIVOC honoring Prof. Anastasios Varvoglis, in which 22 research articles and accounts covered all key areas of hypervalent iodine chemistry. ${ }^{2 a}$ In 2006 , we have published a review in ARKIVOC on the synthetic applications of pentavalent iodine compounds, including 2iodoxybenzoic acid (IBX), Dess-Martin periodinane (DMP), and new pseudocyclic derivatives of 2-iodoxybenzoic acid. ${ }^{2 b}$ The purpose of the present review is to summarize the chemistry of hypervalent iodine(III) compounds with emphasis on recent synthetic applications; literature coverage is through the end of 2008.

\section{Classification and General Structural Features of Organic Iodine(III) Compounds}

Organic iodine(III) compounds are commonly classified by the type of ligands attached to the iodine atom. ${ }^{\text {b-d }}$ The following general classes of iodine(III) compounds have found broad 
application in organic synthesis: (difluoroiodo)arenes $\mathbf{1}$, (dichloroiodo)arenes $\mathbf{2}$, iodosylarenes $\mathbf{3}$, [bis(acyloxy)iodo]arenes 4, aryliodine(III) organosulfonates $\mathbf{5}$, five-membered iodine heterocycles (benziodoxoles 6 and benziodazoles 7), iodonium salts $\mathbf{8}$, iodonium ylides $\mathbf{9}$, and iodonium imides 10 (Scheme 1). (Difluoroiodo)arenes $\mathbf{1}$ and (dichloroiodo)arenes $\mathbf{2}$ are effective fluorinating and chlorinating reagents, respectively. Iodosylarenes $\mathbf{3}$, aryliodine(III) carboxylates 4 and organosulfonates $\mathbf{5}$ in general are strong oxidizing agents and have found widespread application as reagents for oxygenation and oxidative functionalization of organic substrates. The most important and commercially available representatives of aryliodine(III) carboxylates are (diacetoxyiodo)benzene $\mathrm{PhI}(\mathrm{OAc})_{2}$, which has several commonly used abbreviations, such as DIB, PID, PIDA (phenyliodine diacetate), IBD, or IBDA (iodosobenzene diacetate), and [bis(trifluoroacetoxy)iodo]benzene $\mathrm{PhI}\left(\mathrm{OCOCF}_{3}\right)_{2}$, abbreviated as BTI or PIFA [(phenyliodine bis(trifluoroacetate)]. In this review, the abbreviations DIB and BTI will be used. The most important representative of aryliodine(III) organosulfonates, the commercially available [hydroxy(tosyloxy)iodo]benzene $\mathrm{PhI}(\mathrm{OH}) \mathrm{OTs}$, is abbreviated as HTIB and is also known as Koser's reagent.

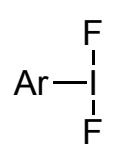

1

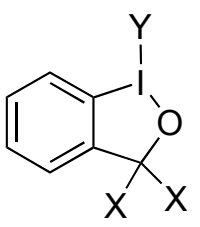

6

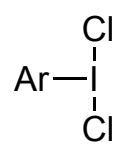

2
$(\mathrm{ArlO})_{\mathrm{n}}$

3

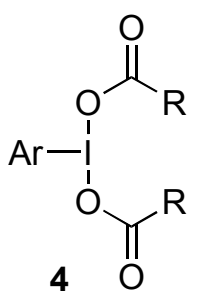

$\operatorname{Ar}-I_{\mathrm{I}}^{+} \mathrm{X}^{-}$

8<smiles>[R]OS(=O)(O)=[Ni]</smiles>

5

$\mathrm{X}=\mathrm{Me}, \mathrm{CF}_{3}$ or $2 \mathrm{X}=\mathrm{O}$;

$\mathrm{Y}=\mathrm{OH}, \mathrm{OAc}, \mathrm{N}_{3}, \mathrm{CN}$, etc.; $\mathrm{Z}=\mathrm{H}, \mathrm{Ac}$, etc.

Scheme 1. Common classes of polyvalent iodine(III) compounds.

The heterocyclic iodanes 6 and 7 have a considerably higher stability than that of their acyclic analogues, which makes possible the isolation and practical use of several otherwise unstable iodine(III) derivatives. A comprehensive review on the chemistry of hypervalent iodine heterocycles 6 and 7 was published in Current Organic Synthesis in 2005. ${ }^{1 \mathrm{k}}$ Iodonium salts 8 in general do not possess any significant oxidizing properties, but have a diverse reactivity pattern mainly due to the exceptional leaving group ability of the -IAr fragment. Iodonium ylides 9 and imides $\mathbf{1 0}$ are excellent carbene and nitrene precursors, respectively. In a widely accepted 
terminology, structural types 1-7 are commonly referred to as "hypervalent iodine reagents", while iodonium salts $\mathbf{8}$, ylides $\mathbf{9}$ and imides $\mathbf{1 0}$ usually are classified separately. In the present review, the preparation and chemistry of structural classes 1-5 will be discussed.

General aspects of structure and bonding in hypervalent iodine(III) organic compounds, or $\lambda^{3}$-iodanes according to the IUPAC nomenclature, have been summarized by Ochiai in a chapter in the volume on Hypervalent Iodine Chemistry in Topics in Current Chemistry. ${ }^{1 \mathrm{~b}}$ A brief summary of the key structural features of hypervalent iodine(III) compounds is provided below. The iodine atom in $\lambda^{3}$-iodanes, RIX $_{2}$, has a total 10 electrons and the overall geometry of a distorted trigonal bipyramid with two heteroatom ligands $\mathrm{X}$ occupying the axial positions, and the least electronegative carbon ligand $\mathrm{R}$ and both electron pairs residing in equatorial positions. In the hypervalent model, bonding in $\mathrm{RIX}_{2}$ uses the non-hybridized $5 \mathrm{p}$ orbital of iodine in the linear $\mathrm{X}-\mathrm{I}-\mathrm{X}$ bond. Such a linear three-center, four-electron (3c-4e) bond is highly polarized and is longer and weaker compared to a regular covalent bond. This bond is termed "hypervalent" and the presence of this bond in $\lambda^{3}$-iodanes is responsible for their high electrophilic reactivity. Structural aspects of hypervalent iodine compounds have been investigated by numerous research groups, ${ }^{1 \mathrm{c}, 3,4}$ most notably by Katritzky and coauthors in a series of papers published in 1989-1990. ${ }^{3}$ Several areas of structural research on hypervalent organoiodine have recently attracted especially active interest. These areas include the preparation and structural study of complexes of hypervalent iodine compounds with crown ethers ${ }^{4 a}$ or nitrogen ligands, ${ }^{4 b, c}$ selfassembly of hypervalent iodine compounds into various supramolecular structures, ${ }^{4 \mathrm{~d}-\mathrm{f}}$ and the intramolecular secondary bonding in hypervalent iodine derivatives. ${ }^{4 \mathrm{~g}-\mathrm{i}}$

Typical coordination patterns in various organic derivatives of iodine(III) in the solid state with consideration of primary and secondary bonding have been summarized by Sawyer and coauthors $^{5 \mathrm{a}}$ in 1986 and updated in recent publications. ${ }^{5 \mathrm{~b}-\mathrm{e}}$

Several important spectroscopic structural studies of polyvalent iodine compounds in the solution have been published. ${ }^{6}$ Hiller and coauthors reported NMR and LC-MS study on the structure and stability of 1-iodosyl-4-methoxybenzene and 1-iodosyl-4-nitrobenzene in methanol solution. ${ }^{6 a}$ Interestingly, LC-MS analyses provided evidence that unlike the parent iodosylbenzene, which has a polymeric structure, the 4-substituted iodosylarenes exist in the monomeric form. Both iodosylarenes are soluble in methanol and provide acceptable ${ }^{1} \mathrm{H}$ and ${ }^{13} \mathrm{C}$ NMR spectra; however, gradual oxidation of the solvent was observed after several hours. ${ }^{6 a}$ Cerioni, Mocci and coauthors investigated the structure of bis(acyloxy)iodoarenes and benzoiodoxolones in chloroform solution by ${ }^{17} \mathrm{O}$ NMR spectroscopy and also by DFT calculations. ${ }^{6 b}$ This investigation provided substantial evidence that the T-shaped structure of iodine(III) compounds observed in the solid state is also adopted in solution. Furthermore, the "free" carboxylic groups of bis(acyloxy)iodoarenes show a dynamic behavior, observable only in the ${ }^{17} \mathrm{O}$ NMR. This behavior is ascribed to a $[1,3]$ sigmatropic shift of the iodine atom between the two oxygen atoms of the carboxylic groups, and the energy involved in this process varies significantly between bis(acyloxy)iodoarenes and benzoiodoxolones. ${ }^{6 \mathrm{~b}}$ Silva and coauthors analyzed solutions of bis(acyloxy)iodobenzenes in acetonitrile, acetic acid, aqueous methanol 
and anhydrous methanol by electrospray ionization mass spectrometry (ESI-MS) and tandem mass spectrometry (ESI-MS/MS). ${ }^{6}$ The major species found in the solutions of $\mathrm{PhI}(\mathrm{OAc})_{2}$ in acetonitrile, acetic acid, and aqueous methanol are $\left[\mathrm{PhI}(\mathrm{OAc})_{2} \mathrm{Na}\right]^{+},\left[\mathrm{PhI}(\mathrm{OAc})_{2} \mathrm{~K}\right]^{+},[\mathrm{PhI}]^{+}$, $[\mathrm{PhIOAc}]^{+},[\mathrm{PhIOH}]^{+},\left[\mathrm{PhIO}_{2} \mathrm{Ac}\right]^{+},\left[\mathrm{PhIO}_{2} \mathrm{H}\right]^{+}$and the dimer $\left[\mathrm{Ph}_{2} \mathrm{I}_{2} \mathrm{O}_{2} \mathrm{Ac}\right]^{+}{ }^{6 c}$

Several theoretical computational studies concerning the structure and reactivity of hypervalent iodine compounds have appeared in the last 10 years. ${ }^{7,8}$ In particular, Kiprof has analyzed the iodine oxygen bonds of hypervalent 10-I-3 iodine(III) compounds with T-shaped geometry using the Cambridge Crystallographic Database and ab initio MO calculations. The statistical analysis of the $\mathrm{I}-\mathrm{O}$ bond lengths in $\mathrm{PhI}(\mathrm{OR})_{2}$ revealed an average of $2.14 \AA$ and a strong correlation between the two bond lengths. ${ }^{7 \mathrm{a}}$ Further theoretical investigation of the mutual ligand interaction in the hypervalent $\mathrm{L}-\mathrm{I}-\mathrm{L}$ ' system has demonstrated that ligands' trans influences play an important role in the stability of hypervalent molecules. ${ }^{7 \mathrm{~b}}$ In particular, combinations of ligands with large and small trans influences, as in $\mathrm{PhI}(\mathrm{OH}) \mathrm{OTs}$, or of two moderately trans influencing ligands, as in $\mathrm{PhI}(\mathrm{OAc})_{2}$, are favored and lead to higher stability of the molecule. trans Influences also seem to explain why iodosylbenzene, $(\mathrm{PhIO})_{\mathrm{n}}$, adopts an oxobridged zigzag polymer structure in contrast to $\mathrm{PhI}(\mathrm{OH})_{2}$, which is monomeric. ${ }^{7 \mathrm{~b}}$

The structure and reactivity of several specific classes of hypervalent iodine compounds were theoretically investigated. ${ }^{8}$ Goddard and $\mathrm{Su}$ have theoretically investigated the mechanism of alcohol oxidation with 2-iodoxybenzoic acid (IBX) on the basis of density functional quantum mechanics calculations. ${ }^{8 a}$ It has been found that the rearrangement of hypervalent bonds, so called hypervalent twisting, is the rate-determining step in this reaction. Based on this mechanism, the authors explain why IBX oxidizes large alcohols faster than small ones and propose a modification to the reagent predicted to make it more active. ${ }^{8 \mathrm{a}}$

Very recently, Quideau and coauthors reported DFT calculations of spiroheterocylic iodine(III) intermediates to validate their participation in the $\mathrm{PhI}(\mathrm{OAc})_{2}$-mediated spiroketalization of phenolic alcohols. $^{8 \mathrm{~b}}$

\section{Preparation of Iodine(III) Compounds}

\section{1. (Difluoroiodo)arenes}

Various (difluoroiodo)arenes can be prepared by the fluorination of iodoarenes with powerful fluorinating reagents, such as $\mathrm{F}_{2}, \mathrm{ClF}, \mathrm{CF}_{3} \mathrm{OCl}, \mathrm{BrF}_{5}, \mathrm{C}_{6} \mathrm{~F}_{5} \mathrm{BrF}_{2}, \mathrm{C}_{6} \mathrm{~F}_{5} \mathrm{BrF}_{4}, \mathrm{XeF}_{2}, \mathrm{XeF}_{2} / \mathrm{BF}_{3}$, etc. ${ }^{1 \mathrm{~d}}$ A convenient procedure for the preparation of (difluoroiodo)benzene and 4-(difluoroiodo)toluene consists of direct fluorination of the respective iodoarenes with the commercially available fluorinating reagent Selectfluor in acetonitrile solution. ${ }^{9 a}$

An older general procedure for the preparation of (difluoroiodo)arenes involves a one-step reaction of mercuric oxide and aqueous hydrofluoric acid with the (dichloroiodo)arenes in dichloromethane. ${ }^{9 b}$ A drawback of this method is the use of a large quantity of harmful $\mathrm{HgO}$ in 
order to remove the chloride ion from the reaction mixture. A convenient modified procedure without the use of $\mathrm{HgO}$ consists of the treatment of iodosylarenes with $40-46 \%$ aqueous hydrofluoric acid (Scheme 2) followed by crystallization of resulting (dichloroiodo)arenes from hexane. ${ }^{9 \mathrm{~d}, \mathrm{~d}}$ It is important that the freshly prepared iodosylarenes are used in this procedure.

$$
\begin{aligned}
& \text { ArlO } \underset{46 \% \mathrm{HF} / \mathrm{H}_{2} \mathrm{O}, \mathrm{CH}_{2} \mathrm{Cl}_{2}, \mathrm{rt}}{79-86 \%} \mathrm{ArIF}_{2} \\
& \mathrm{Ar}=\mathrm{Ph}, 4-\mathrm{Tol}, 4-\mathrm{ClC}_{6} \mathrm{H}_{4}, 4-\mathrm{NO}_{2} \mathrm{C}_{6} \mathrm{H}_{4} \text {, etc. }
\end{aligned}
$$

\section{Scheme 2}

(Difluoroiodo)arenes are extremely sensitive to moisture and are commonly used as a freshly prepared solution, without isolation. Very recently, DiMagno and coauthors reported a convenient procedure for almost quantitative generation of $\mathrm{PhIF}_{2}$ in acetonitrile solution by the reaction of $\left(\mathrm{PhI}(\mathrm{OAc})_{2}\right.$ with anhydrous tetrabutylammonium fluoride under absolutely dry conditions. $9 \mathrm{e}$

\section{2. (Dichloroiodo)arenes}

The most general approach to (dichloroiodo)arenes involves the direct chlorination of iodoarenes with chlorine in a suitable solvent, such as chloroform or dichloromethane. ${ }^{10}$ This method can be applied to a large scale $(20-25 \mathrm{~kg})$ preparation of $\mathrm{PhICl}_{2}$ by the reaction of iodobenzene with chlorine at -3 to $+4{ }^{\circ} \mathrm{C}$ in dichloromethane. ${ }^{10 \mathrm{c}}$ The direct chlorination of the appropriate iodoarenes has recently been used for the preparation of 4,4'-bis(dichloroiodo)biphenyl and 3(dichloroiodo)benzoic acid, which are convenient recyclable hypervalent iodine reagents. ${ }^{10 \mathrm{~d}}$

In order to avoid the use of elemental chlorine, the chlorination of iodoarenes can be effected in situ in aqueous hydrochloric acid in the presence of an appropriate oxidant, such as $\mathrm{KMnO}_{4}$, activated $\mathrm{MnO}_{2}, \mathrm{KClO}_{3}, \mathrm{NaIO}_{3}$, concentrated $\mathrm{HNO}_{3}, \mathrm{NaBO}_{3}, \mathrm{Na}_{2} \mathrm{CO}_{3} \cdot \mathrm{H}_{2} \mathrm{O}_{2}, \mathrm{Na}_{2} \mathrm{~S}_{2} \mathrm{O}_{8}, \mathrm{CrO}_{3}$, and the urea- $\mathrm{H}_{2} \mathrm{O}_{2}$ complex. ${ }^{11 \mathrm{a}}$ A recently reported convenient and mild approach to (dichloroiodo)arenes consists of the chlorination of iodoarenes using concentrated hydrochloric acid and aqueous sodium hypochlorite (Scheme 3). ${ }^{11 \mathrm{~b}}$ Sodium chlorite, $\mathrm{NaClO}_{2}$, can also be used in this procedure; however, in this case the chlorination takes longer time ( 3 hours at room temperature) and the yields of products are generally lower. ${ }^{11 \mathrm{~b}}$

$$
\begin{gathered}
\text { Arl } \underset{\mathrm{NaClO}(5.84 \%), \mathrm{HCl}, \mathrm{H}_{2} \mathrm{O}, 15^{\circ} \mathrm{C}, 5 \mathrm{~min}}{94-100 \%} \mathrm{ArICl}_{2} \\
\mathrm{Ar}=\mathrm{Ph}, 4-\mathrm{MeC}_{6} \mathrm{H}_{4}, 2-\mathrm{FC}_{6} \mathrm{H}_{4}, 2-\mathrm{BrC}_{6} \mathrm{H}_{4}, 3-\mathrm{BrC}_{6} \mathrm{H}_{4}, 4-\mathrm{BrC}_{6} \mathrm{H}_{4}, \\
\text { 4-ClC } \mathrm{C}_{6} \mathrm{H}_{4}, 3-\mathrm{NO}_{2} \mathrm{C}_{6} \mathrm{H}_{4}, 4-\mathrm{NO}_{2} \mathrm{C}_{6} \mathrm{H}_{4}, 4-\mathrm{PhC}_{6} \mathrm{H}_{4} \text {, etc. }
\end{gathered}
$$

\section{Scheme 3}


(Dichloroiodo)arenes are generally isolated as light and heat sensitive yellow crystalline solids, which are insufficiently stable for extended storage even at low temperatures.

\subsection{Iodosylarenes}

The most important representative of iodosylarenes, iodosylbenzene, is best prepared by alkaline hydrolysis of (diacetoxyiodo)benzene. ${ }^{12 a}$ The same procedure can be used for the preparation of a variety of ortho-, meta-, and para-substituted iodosylbenzenes from the respective (diacetoxyiodo)arenes (Scheme 4). ${ }^{6 \mathrm{a}, 12}$ This procedure, for example, was recently used for the preparation of 4-methoxyiodosylbenzene, ${ }^{6 a}$ 4-nitroiodosylbenzene ${ }^{6 a}$ and pseudocyclic iodosylarenes bearing tert-butylsulfonyl ${ }^{12 \mathrm{a}}$ or diphenylphosphoryl ${ }^{12 \mathrm{~b}}$ groups in the orthoposition.

$$
\begin{aligned}
& \operatorname{Arl}(\mathrm{OAc})_{2} \underset{64-95 \%}{\stackrel{3 \mathrm{~N} \mathrm{NaOH}, \mathrm{H}_{2} \mathrm{O}, 0^{\circ} \mathrm{C} \text { to rt }}{\longrightarrow}} \text { ArlO } \\
& \mathrm{Ar}=4-\mathrm{MeOC}_{6} \mathrm{H}_{4}, 4-\mathrm{NO}_{2} \mathrm{C}_{6} \mathrm{H}_{4}, 4-\mathrm{MeC}_{6} \mathrm{H}_{4}, 2-\mathrm{Bu}^{\mathrm{t} S \mathrm{SO}_{2}} \mathrm{C}_{6} \mathrm{H}_{4} \text {, } \\
& \text { 2- } \mathrm{Ph}_{2} \mathrm{P}(\mathrm{O}) \mathrm{C}_{6} \mathrm{H}_{4}, 4-\mathrm{CF}_{3}\left(2-\mathrm{Bu}^{\mathrm{t} S \mathrm{~S}_{2}}\right) \mathrm{C}_{6} \mathrm{H}_{3} \text {, etc. }
\end{aligned}
$$

\section{Scheme 4}

An alternative general procedure for the preparation of iodosylarenes employs the alkaline hydrolysis of (dichloroiodo)arenes under conditions similar to the hydrolysis of (diacetoxyiodo)arenes. ${ }^{13 a}$ In a modified procedure aqueous tetrahydrofuran is used as the solvent for the hydrolysis of para-substituted (dichloroiodo)arenes (Scheme 5). ${ }^{13 \mathrm{~b}}$

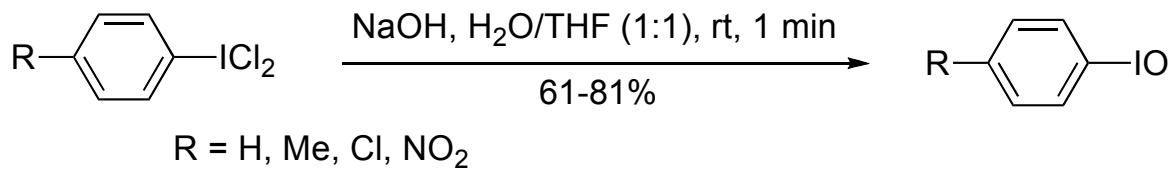

\section{Scheme 5}

Iodosylbenzene is a yellowish amorphous powder, which cannot be recrystallized due to its polymeric nature; it dissolves in methanol with depolymerization affording $\mathrm{PhI}(\mathrm{OMe})_{2}$. Heating or extended storage at room temperature results in disproportionation of iodosylbenzene to $\mathrm{PhI}$ and a colorless, explosive iodylbenzene, $\mathrm{PhIO}_{2}$. A violent explosion of a sample of iodosylbenzene upon drying at $110{ }^{\circ} \mathrm{C}$ in vacuum has been reported. ${ }^{13 \mathrm{c}}$ 


\section{4. [Bis(acyloxy)iodo]arenes}

Two general approaches are used for the preparation of [bis(acyloxy)iodo]arenes: (1) the oxidation of iodoarenes in the presence of a carboxylic acid, and (2) a ligand exchange reaction of the readily available (diacetoxyiodo)benzene (DIB) with an appropriate carboxylic acid. DIB is usually prepared by the oxidation of iodobenzene with peracetic acid in acetic acid. ${ }^{14 a} \mathrm{~A}$ similar peracid oxidation of substituted iodobenzenes can be used for the preparation of other [bis(acyloxy)iodo]arenes. In particular, the polymer-supported analogs of DIB have been prepared by treatment of poly(iodostyrene) or aminomethylated poly(iodostyrene) with peracetic acid, ${ }^{1 \mathrm{~g}, 14 \mathrm{~b}, \mathrm{c}}$ and the ion-supported [bis(acyloxy)iodo]arenes, imidazolium derivatives $\mathbf{1 1}$ and $\mathbf{1 2}$, have been prepared by the peracetic oxidation of the appropriate aryliodides. ${ }^{14 \mathrm{~d}, \mathrm{e}}$ Likewise, various [bis(trifluoroacetoxy)iodo]arenes can be synthesized in high yield by the oxidation of the respective iodoarenes with peroxytrifluoroacetic acid in trifluoroacetic acid. ${ }^{14 f, g}$

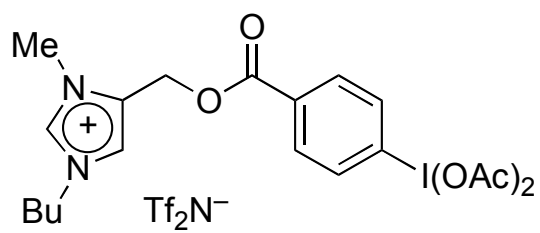

11

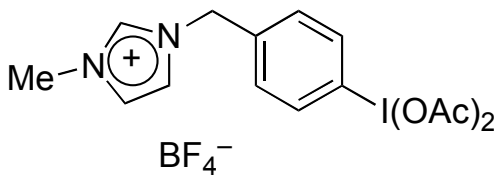

12

A modification of this method consists of the oxidative diacetoxylation of iodoarenes in acetic or trifluoroacetic acid using appropriate oxidants, such as periodates, ${ }^{15 a, b} \mathrm{~m}$ chloroperoxybenzoic acid, ${ }^{15 \mathrm{c}, \mathrm{d}}$ potassium peroxodisulfate, ${ }^{15 \mathrm{e}} \mathrm{H}_{2} \mathrm{O}_{2}$-urea, ${ }^{15 \mathrm{f}}$ Selectfluor, ${ }^{9 \mathrm{a}}$ and sodium perborate. ${ }^{15 \mathrm{~d}, \mathrm{~g}, \mathrm{~h}}$ The oxidation of iodoarenes with sodium perborate in acetic acid at $40{ }^{\circ} \mathrm{C}$ is the most simple and general procedure that has been used for a small scale preparation of numerous (diacetoxyiodo)-substituted arenes and hetarenes. ${ }^{15 \mathrm{~d}, \mathrm{~g}, \mathrm{~h}}$ This method has been improved by performing the perborate oxidation in the presence of trifluoromethanesulfonic acid. ${ }^{15 \mathrm{i}}$ A further convenient modification of this approach employs the interaction of arenes with iodine and potassium peroxodisulfate in acetic acid (Scheme 6). ${ }^{15 \mathrm{j}}$

$$
\begin{aligned}
& \mathrm{ArH}+\mathrm{I}_{2} \frac{\mathrm{K}_{2} \mathrm{~S}_{2} \mathrm{O}_{8}, \mathrm{AcOH}, \mathrm{H}_{2} \mathrm{SO}_{4}, \mathrm{ClCH}_{2} \mathrm{CH}_{2} \mathrm{Cl}, 40{ }^{\circ} \mathrm{C}, 12-30 \mathrm{~h}}{69-73 \%} \mathrm{Arl}(\mathrm{OAc})_{2} \\
& \mathrm{Ar}=\mathrm{Ph}, 4-\mathrm{MeC}_{6} \mathrm{H}_{4}, 4-\mathrm{ClC}_{6} \mathrm{H}_{4}, 4-\mathrm{BrC}_{6} \mathrm{H}_{4}, 4-\mathrm{FC}_{6} \mathrm{H}_{4}
\end{aligned}
$$

\section{Scheme 6}

The second general approach to [bis(acyloxy)iodo]arenes is based on the ligand exchange reaction of a (diacetoxyiodo)arene (usually DIB) with the appropriate carboxylic acid. A typical procedure consists of heating DIB with a non-volatile carboxylic acid in the presence of a high boiling solvent, such as chlorobenzene (Scheme 7). ${ }^{16}$ The equilibrium in this reversible reaction 
can be shifted towards the synthesis of the product by distillation under reduced pressure of the relatively volatile acetic acid formed during the reaction. This procedure, in particular, has recently been used for the preparation of the protected amino acid derivatives 13 , ${ }^{16 a}$ glutamatederived (diacyloxyiodo)benzenes $\mathbf{1 4},{ }^{16 \mathrm{~b}}$ the cinnamate derivative $\mathbf{1 5},{ }^{16 \mathrm{c}}$ and 3 -methylfurazan-4carboxylic acid derivative $16 .{ }^{16 \mathrm{~d}}$

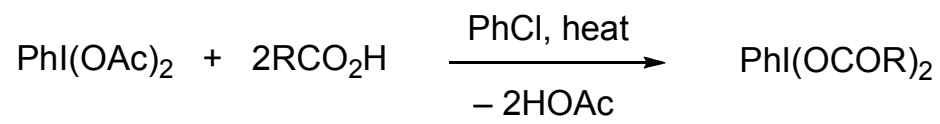<smiles>[R]CCCCC(N)C([R])C(=O)OI(C)c1ccccc1</smiles>

13

$\mathrm{R}=\mathrm{Me}, \mathrm{CH}_{2} \mathrm{Ph}, \mathrm{CH}\left(\mathrm{CH}_{3}\right)_{2}$, $\mathrm{CH}_{2} \mathrm{CH}\left(\mathrm{CH}_{3}\right)_{2}, \mathrm{CH}\left(\mathrm{CH}_{3}\right) \mathrm{CH}_{2} \mathrm{CH}_{3}$<smiles>CC=CC(=O)OI(C)c1ccccc1</smiles>

15

$$
\mathrm{Ar}=4-\mathrm{MeOC}_{6} \mathrm{H}_{4}
$$<smiles>CCCC(=O)[C@H](N)CCC(=O)O[I](C)(C)c1ccccc1</smiles>

14

$\mathrm{P}=\mathrm{Cbz}$ or $\mathrm{Boc}$

16

\section{Scheme 7}

The reactions of DIB with stronger carboxylic acids usually proceed under milder conditions at room temperature. A convenient procedure for the preparation of [bis(trifluoroacetoxy)iodo]benzene (BTI) consists of simply dissolving DIB in trifluoroacetic acid and evaporating to a small volume. ${ }^{16 \mathrm{e}}$

[Bis(acyloxy)iodo] arenes are generally colorless, stable microcrystalline solids, which can be easily recrystallized and stored for extended periods of time without significant decomposition.

\subsection{Aryliodine(III) organosulfonates}

[Hydroxy(tosyloxy)iodo]arenes are usually prepared by a ligand exchange reaction of (diacetoxyiodo)arenes with $p$-toluenesulfonic acid monohydrate in acetonitrile (Scheme 8). ${ }^{5 \mathrm{~d}, 15 \mathrm{~d}, 17 \mathrm{a}-\mathrm{f}}$ This method has recently been applied to the synthesis of [hydroxy(tosyloxy)iodo]heteroaromatic derivatives (e.g., 17 and 18), ${ }^{17 \mathrm{c}}$ the derivatives with various substituted aromatic groups (e.g. 19 and 20), ${ }^{5 \mathrm{~d}, 17 \mathrm{~b}, \mathrm{c}}$ and the recyclable hypervalent iodine 
reagents 21 and 22. ${ }^{17 e, f}$ A convenient modified procedure for the preparation of various [hydroxy(sulfonyloxy)iodo] arenes consists of the one-pot reaction of iodoarenes and $m$ CPBA in the presence of sulfonic acids in a small amount of chloroform at room temperature. ${ }^{17 \mathrm{~d}}$ This modified procedure was recently used for the preparation of new biphenyl- and terphenyl-based recyclable organic trivalent iodine reagents $\mathbf{2 3}$ and $24 .{ }^{15 \mathrm{~d}}$

$$
\operatorname{Arl}(\mathrm{OAc})_{2}+\mathrm{TsOH} \bullet \mathrm{H}_{2} \mathrm{O} \underset{90-100 \%}{\stackrel{\mathrm{MeCN}, \mathrm{rt}}{\longrightarrow}} \operatorname{Arl}(\mathrm{OH}) \mathrm{OTs}
$$

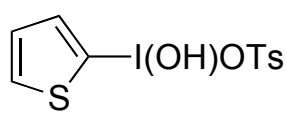

17<smiles>[AsH2-]n1cc([AlH2]O[TeH-])cn1</smiles>

18<smiles></smiles>

19<smiles>O=C(O)c1cccc(C(O)O[Na])c1</smiles>

20

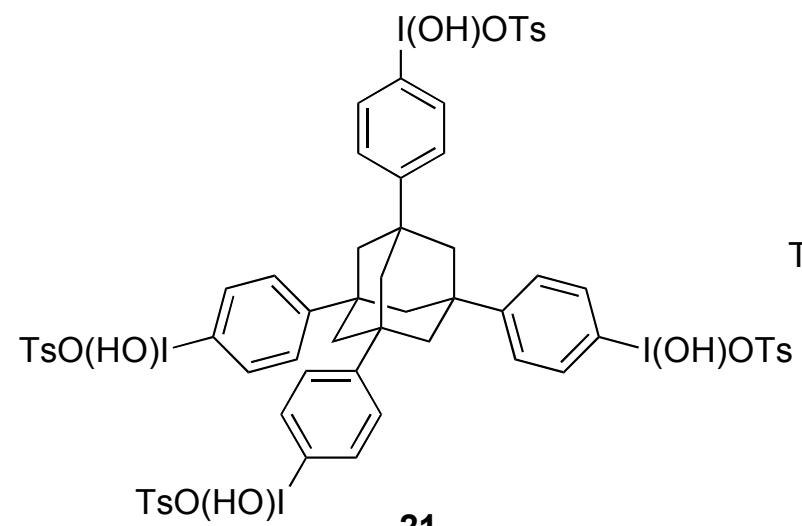

21

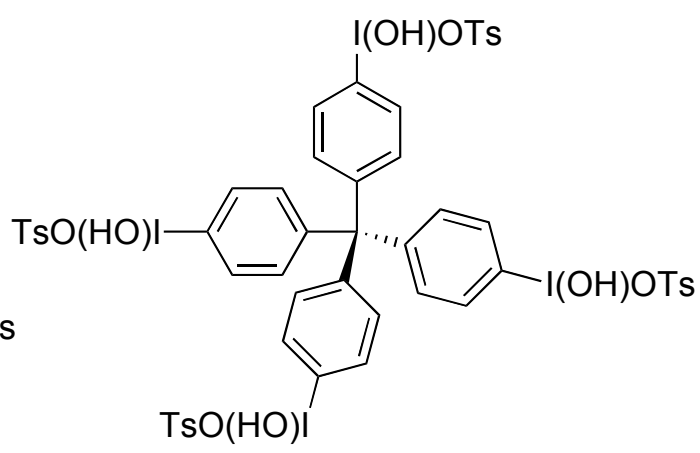

22

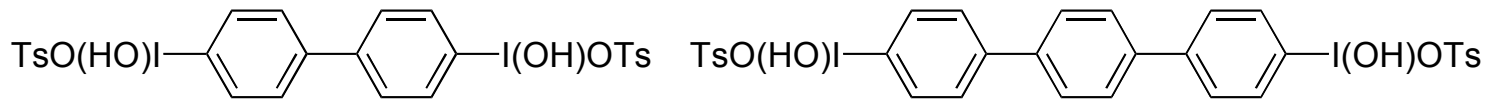

23

24

\section{Scheme 8}

A solvent-free, solid-state version of this reaction is carried out by simple grinding of $\operatorname{ArI}(\mathrm{OAc})_{2}$ with the appropriate sulfonic acid in a mortar followed by washing the solid residue with diethyl ether. ${ }^{17 \mathrm{~g}}$ This solid-state procedure has been used for the preparation of HTIB and several other [hydroxy(organosulfonyloxy)iodo]arenes in 77-98\% yields. A recyclable, polymersupported [hydroxy(tosyloxy)iodo]benzene can be prepared similarly by treatment of poly[(diacetoxy)iodo]styrene with $p$-toluenesulfonic acid monohydrate in chloroform at room temperature. $^{17 \mathrm{~h}}$ 
The highly electrophilic phenyliodine(III) trifluoromethanesulfonate $(\mathrm{PhIO})_{2} \bullet \mathrm{Tf}_{2} \mathrm{O}$, which is also known as Zefirov's reagent, may be prepared either by the exchange reaction of (diacetoxyiodo)benzene with trifluoromethanesulfonic acid, ${ }^{18 a}$ or by the combination of two equivalents of iodosobenzene with one equivalent of triflic anhydride. ${ }^{18 \mathrm{~b}}$ This triflate has an oxobridged structure and is isolated as a relatively stable yellow microcrystalline solid that can be handled for brief periods in air and stored under a nitrogen atmosphere. It can be conveniently generated in situ from iodosylbenzene and triflic anhydride or trimethylsilyl triflate and immediately used in the subsequent reactions; ${ }^{18 \mathrm{c}}$ the extended storage of this reagent in the presence of trifluoromethanesulfonic acid results in self-condensation with the formation of oligomeric products. ${ }^{18 \mathrm{~d}}$

\section{Halogenations using Hypervalent Iodine(III) Reagents}

\subsection{Fluorination}

(Difluoroiodo)arenes are powerful and selective fluorinating reagents towards organic substrates. Various $\beta$-dicarbonyl compounds can be selectively fluorinated at the $\alpha$-position by 4(difluoroiodo)toluene. In a specific example, the monofluorinated products $\mathbf{2 6}$ can be prepared from $\beta$-ketoesters, $\beta$-ketoamides and $\beta$-diketones 25 in good yields under mild conditions (Scheme 9). ${ }^{19 a}$ Ketones cannot be directly fluorinated by (difluoroiodo)arenes; however, $\alpha$ fluoroketones can be prepared by the reaction of silyl enol ethers with 4-(difluoroiodo)toluene in the presence of $\mathrm{BF}_{3} \cdot \mathrm{OEt}_{2}$ and the $\mathrm{Et}_{3} \mathrm{~N}-\mathrm{HF}$ complex. ${ }^{19 \mathrm{~b}}$

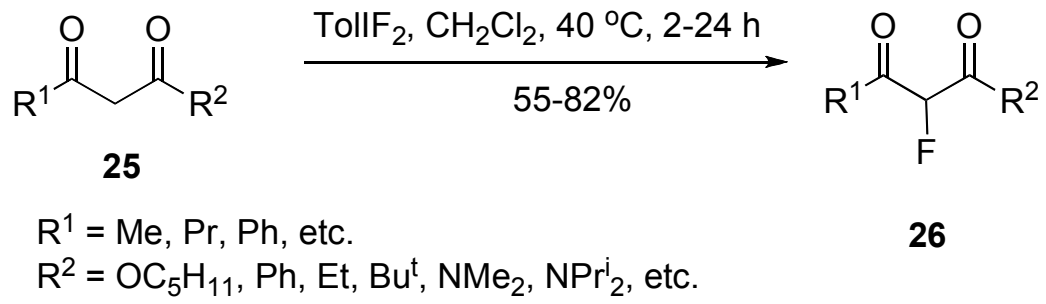

\section{Scheme 9}

Treatment of $\alpha$-phenylthio esters 27 with one equivalent of 4-(difluoroiodo)toluene affords the $\alpha$-fluoro sulfides $\mathbf{2 8}$ in good overall yield through a fluoro-Pummerer reaction (Scheme 15). ${ }^{19 \mathrm{c}}$ The $\alpha$-monofluorination of sulfanyl amides can be achieved by treatment of $\alpha$ phenylsulfanylacetamides with one equivalent of 4-(difluoroiodo)toluene under similar conditions. $^{19 \mathrm{~d}}$ 
<smiles>[R]OC(=O)C[SbH2]</smiles>

27

$\mathrm{R}=\mathrm{Ph}, \mathrm{CH}_{2} \mathrm{CH}=\mathrm{CHPh}, \mathrm{CH}_{2} \mathrm{CH}=\mathrm{CMe}_{2}$, etc. $\underset{\text { TollF }}{2 \text { (1 equiv), } \mathrm{CH}_{2} \mathrm{Cl}_{2}, 0^{\circ} \mathrm{C}, 12 \mathrm{~h}}$<smiles>[R]OC(=O)C(F)Sc1ccccc1</smiles>

28

\section{Scheme 10}

Arrica and Wirth have reported the monofluorination of a series of $\alpha$-acceptor-substituted selenides 29 using (difluoroiodo)toluene (Scheme 11). ${ }^{\text {d }}$ Although the yields of products 30 are only moderate, the reactions are usually very clean and, under the reaction conditions used, no further oxidized products are observed.

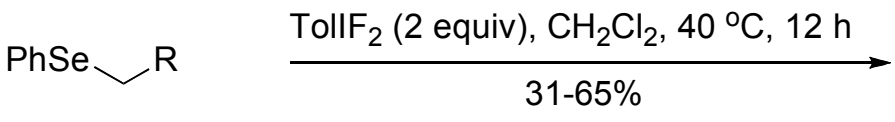

29

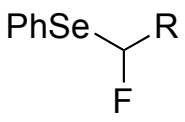

30

$$
\mathrm{R}=\mathrm{CO}_{2} \mathrm{Et}, \mathrm{CO}_{2} \mathrm{Ph}, \mathrm{CO}_{2} \mathrm{CH}_{2} \mathrm{CH}=\mathrm{CH}_{2}, \mathrm{CONHMe}, \mathrm{CONMe}_{2}, \mathrm{CN} \text {, etc. }
$$

\section{Scheme 11}

Fluorinated five- to seven-membered cyclic ethers were stereoselectively synthesized from iodoalkyl substituted four- to six-membered cyclic ethers by fluorinative ring-expansion reaction using (difluoroiodo)toluene. ${ }^{19} \mathrm{~A}$ A specific example of a fluorinative ring-expansion reaction leading to five-membered cyclic ethers $\mathbf{3 1}$ is shown in Scheme 12. ${ }^{19 \mathrm{e}}$
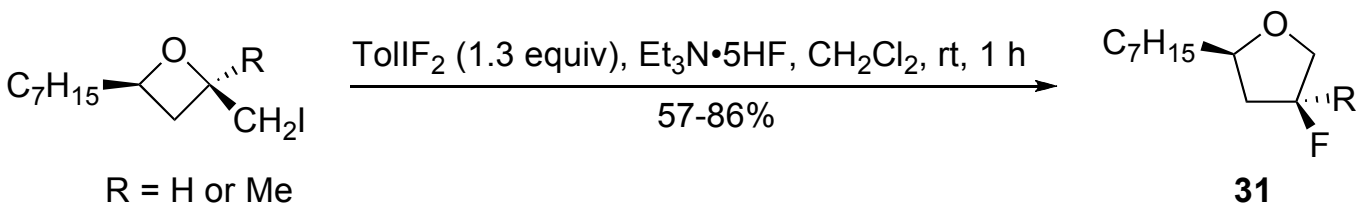

31

\section{Scheme 12}

The fluorination of alkenes 32 and alkynes 34 with 4-(difluoroiodo)toluene in the presence of iodine affords vic-fluoroiodoalkanes 33 and fluoroiodoalkenes 35 in moderate to good yields (Scheme 13). ${ }^{19 f}$ This reaction proceeds in a Markovnikov fashion and with prevalent antistereoselectivity via the initial addition of the electrophilic iodine species followed by nucleophilic attack of fluorine anion. The analogous reaction of alkenes and alkynes with 4(difluoroiodo)toluene in the presence of diphenyl diselenides affords the respective products of phenylselenofluorination in good yields. ${ }^{19 g}$ 


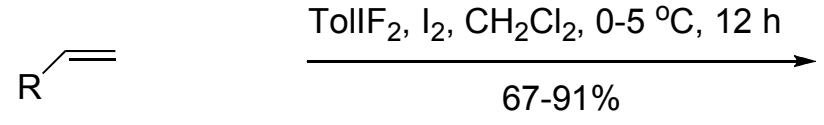

32

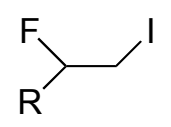

33

$\mathrm{R}=n-\mathrm{C}_{6} \mathrm{H}_{13}, \mathrm{Ph}, 4-\mathrm{Bu}^{\mathrm{t}} \mathrm{C}_{6} \mathrm{H}_{4}, \mathrm{PhCH}_{2}$, etc.

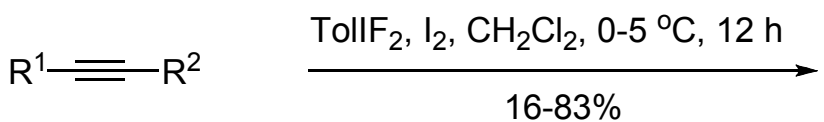

34

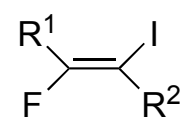

35

$\mathrm{R}^{1}=\mathrm{R}^{2}=\mathrm{Pr} ; \mathrm{R}^{1}=\mathrm{R}^{2}=\mathrm{Ph} ; \mathrm{R}^{1}=\mathrm{Ph}, \mathrm{R}^{2}=\mathrm{Me} ; \mathrm{R}^{1}=\mathrm{Ph}, \mathrm{R}^{2}=\mathrm{H}$

\section{Scheme 13}

The reaction of 4-(difluoroiodo)toluene with a four-, five-, or six-membered carbocycle 36 afforded the ring-expanded $(E)$ - $\delta$-fluoro- $\beta$-halovinyl iodonium tetrafluoroborates 37 stereoselectively in high yields (Scheme 14). ${ }^{19 f}$ This reaction proceeds via a sequence of $\lambda^{3}$ iodanation-1,4-halogen shift-ring enlargement-fluorination steps.

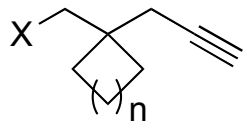

36

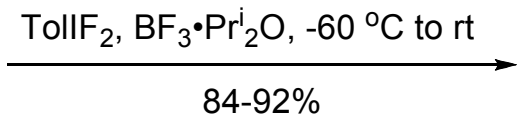

$\mathrm{X}=\mathrm{Cl}, \mathrm{Br} ; \mathrm{n}=1-3$

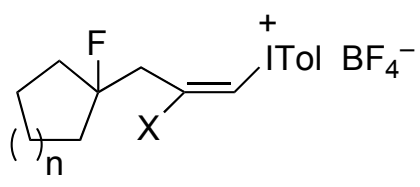

37

\section{Scheme 14}

\subsection{Chlorinations}

(Dichloroiodo)arenes have found practical application as reagents for chlorination of various organic substrates. Chlorinations of alkanes with (dichloroiodo)arenes proceed via a radical mechanism and generally require photochemical conditions or the presence of radical initiators in solvents of low polarity, such as chloroform or carbon tetrachloride. ${ }^{\text {lc }}$ The chlorination of alkenes usually has an ionic mechanism. ${ }^{20 \mathrm{a}}$ For example, reactions of (dichloroiodo)benzene with various monoterpenes in methanol proceed via the ionic mechanism and afford the respective products of chloromethoxylation of the double bond with high regio- and stereoselectivity. ${ }^{20 a}$ Likewise, the reaction of the recyclable chlorinating reagent, 4,4'-bis(dichloroiodo)biphenyl 39 with styrene derivatives $\mathbf{3 8}$ in methanol affords exclusively the products of electrophilic chloromethoxylation $\mathbf{4 0}$ (Scheme 15). ${ }^{10 \mathrm{~d}}$ 
<smiles>[R]/C=C(/[R])P</smiles>

38<smiles>Clc1ccc(-c2ccc(Cl)cc2)cc1</smiles>

39

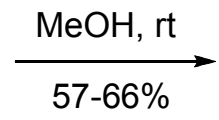

$R^{1}=H, R^{2}=H ; R^{1}=P h, R^{2}=H ; R^{1}=H, R^{2}=P h$

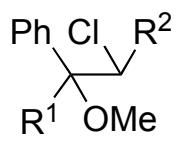

40

\section{Scheme 15}

(Dichloroiodo)arenes can also be used for the chlorination of electron-rich aromatic compounds. Aminoacetophenone $\mathbf{4 1}$ is selectively chlorinated with (dichloroiodo)benzene to give product 42 in good yield (Scheme 16). This process can be scaled up to afford $24.8 \mathrm{~kg}$ of product $\mathbf{4 2}$ with $94 \%$ purity. ${ }^{10 c}$

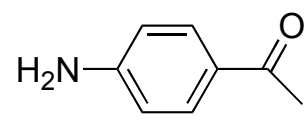

41

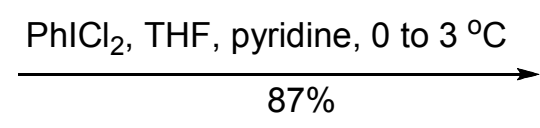

$87 \%$

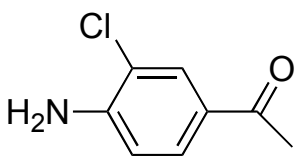

42

\section{Scheme 16}

(Dichloroiodo)toluene was found to be an efficient chlorinating reagent in the catalytic asymmetric chlorination of $\beta$-keto esters 43 , catalyzed by the titanium complex 44 , leading to the respective $\alpha$-chlorinated products $\mathbf{4 5}$ in generally good yields and enantioselectivities (Scheme 17). The enantioselectivity of this reaction showed a remarkable temperature dependence, and the maximum selectivity was obtained at $50{ }^{\circ} \mathrm{C} .{ }^{20 \mathrm{~b}}$

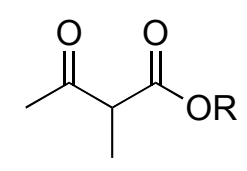

43

$\mathrm{R}=\mathrm{Et}, \mathrm{Bn}, \mathrm{Ph}, \mathrm{or}$ 9-(anthracenyl) $\mathrm{CH}_{2}$
$\mathrm{TollCl}_{2}, 44$ (5 mol\%), pyridine (1.2 equiv), toluene, $50^{\circ} \mathrm{C}, 20 \mathrm{~h}$

\section{$37-82 \%$}

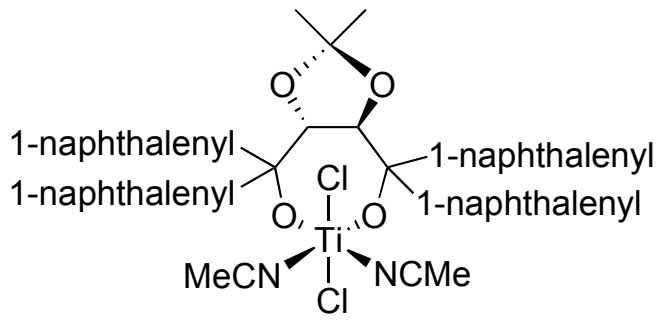

44<smiles>[R]OC(=O)C(C)(Cl)C(C)=O</smiles>

45, $60-71 \%$ ee

\section{Scheme 17}


Treatment of 5,10,15-trisubstituted porphyrins 46 with (dichloroiodo)benzene affords the corresponding meso-chlorinated porphyrins 47 (Scheme 18). ${ }^{20 \mathrm{c}}$ The chlorination of 5,10,15,20tetraarylporphyrins, in which all meso-positions are substituted, under similar conditions affords $\beta$-monochlorinated products in high yields. ${ }^{20 c}$

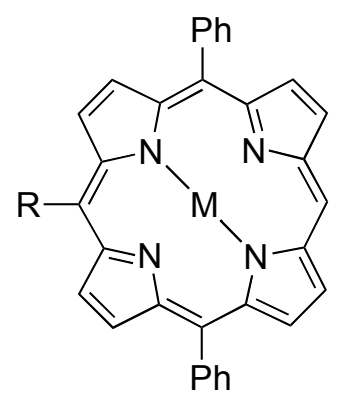

46

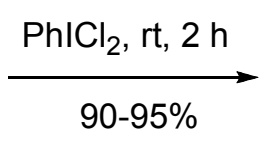

$\mathrm{M}=2 \mathrm{H}, \mathrm{Cu}, \mathrm{Ni}$

$\mathrm{R}=\mathrm{Ph}$ or $4-\mathrm{CF}_{3} \mathrm{C}_{6} \mathrm{H}_{4}$

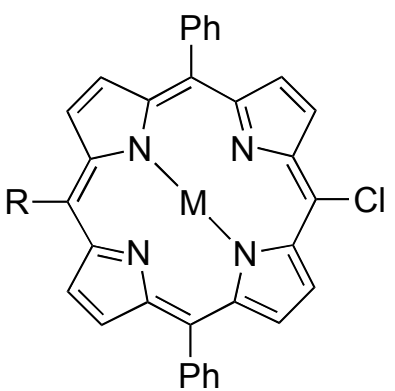

47

\section{Scheme 18}

A simple and mild system using bis(dichloroiodo)biphenyl $\mathbf{3 9}$ in combination with tetraethylammonium bromide at room temperature has been developed for selective debenzylation of sugars. Acetates, benzoate, and sensitive glycosidic linkages are unaffected under the reaction conditions. A specific example of the debenzylation of benzyl 4-O-benzoyl 2,3-O-isopropylidene- $\alpha$-L-arabinopyranoside $\mathbf{4 8}$ is shown in Scheme $19 .^{231}$

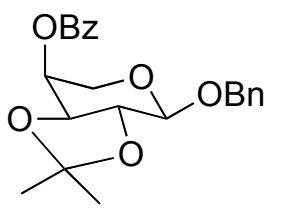

48
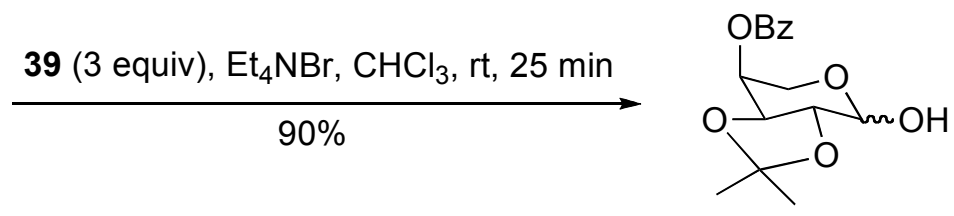

\section{Scheme 19}

(Dichloroiodo)benzene is commonly used as a reagent for the oxidation or chlorination of various transition metal complexes. Recent examples include the oxidation of $\mathrm{d} 8 \bullet \bullet \mathrm{d} 10$ heterobimetallic $\mathrm{Pt}(\mathrm{II})-\mathrm{Au}(\mathrm{I})$ complex to give the d7-d9 Pt(III)-Au(II) complex containing a $\mathrm{Pt}(\mathrm{III})-\mathrm{Au}(\mathrm{II})$ bond, $^{20 \mathrm{e}}$ and oxidations or chlorinations of palladium, ${ }^{20 \mathrm{f}}$ cobalt,${ }^{20 \mathrm{~g}}$ vanadium, ${ }^{20 \mathrm{~h}}$ and molybdenum ${ }^{20 \mathrm{i}}$ complexes.

\subsection{Brominations and iodinations}

Kirschning and coauthors have developed several experimental procedures for the stereoselective bromoacetoxylation or iodoacetoxylation of alkenes based on the interaction of DIB with iodide 
or bromide anions. ${ }^{21 \mathrm{a}}$ The actual reacting electrophilic species in these reactions are the diacetylhalogen(I) anions, $(\mathrm{AcO})_{2} \mathrm{I}^{-}$and $(\mathrm{AcO})_{2} \mathrm{Br}^{-}$, which can also be prepared as the polymersupported variant. $^{21 \mathrm{~b}}$ A similar iodocarboxylation of alkenes using amino acid-derived iodobenzene dicarboxylates 13 selectively affords the respective amino acid esters 49 in moderate yields (Scheme 20). ${ }^{16 a}$

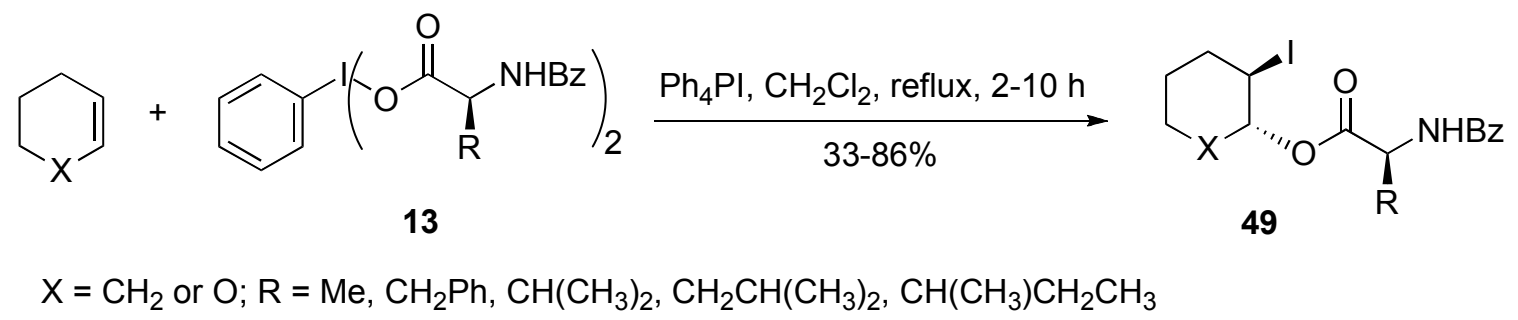

\section{Scheme 20}

A new and convenient procedure for the aminobromination of electron-deficient olefins $\mathbf{5 0}$ using Bromamine-T as nitrogen and bromine source promoted by (diacetoxyiodo)benzene was developed by Xia, Wu, and Wang. ${ }^{21 \mathrm{c}}$ This metal-free protocol is highly efficient and affords the vicinal bromamines $\mathbf{5 1}$ with excellent stereoselectivities (Scheme 21).

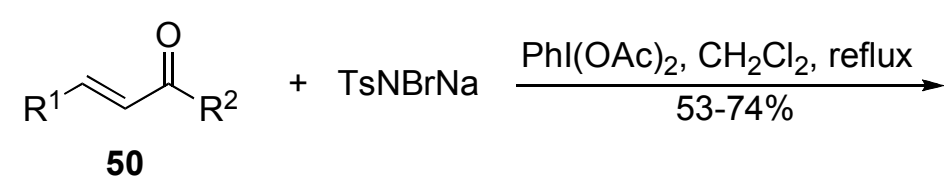

$\mathrm{R}^{1}=3,4-\mathrm{Cl}_{2} \mathrm{C}_{6} \mathrm{H}_{3}, 4-\mathrm{ClC}_{6} \mathrm{H}_{4}, 4-\mathrm{NO}_{2} \mathrm{C}_{6} \mathrm{H}_{4}$, Ph, etc. $\mathrm{R}^{1}=\mathrm{Ph}, 4-\mathrm{ClC}_{6} \mathrm{H}_{4}, \mathrm{OMe}, \mathrm{NEt}_{2}$, etc.<smiles>[R]C(=O)C([NH-])C([R])Br</smiles>

51

anti/syn $>99 / 1$

\section{Scheme 21}

Iodine in combination with [bis(acyloxy)iodo]arenes can be used for the oxidative iodination of aromatic and heteroaromatic compounds. ${ }^{1 \mathrm{c}} \mathrm{A}$ mixture of iodine and BTI in acetonitrile or methanol iodinates the aromatic ring of methoxy substituted alkyl aryl ketones to afford the products of electrophilic monoiodination in $68-86 \%$ yield. ${ }^{21 \mathrm{~d}}$ 1-Iodoalkynes can be prepared in good to excellent yields by the oxidative iodination of terminal alkynes with DIB, potassium iodide, and copper(I) iodide. ${ }^{21 \mathrm{e}}$ A solvent-free, solid state oxidative halogenation of arenes using DIB as the oxidant has recently been reported. ${ }^{21 \mathrm{f}}$

Substituted pyrazoles can be iodinated to the corresponding 4-iodopyrazole derivatives by treatment with iodine and DIB or polymer-supported DIB at room temperature (Scheme 22). ${ }^{21 \mathrm{~g}}$ 

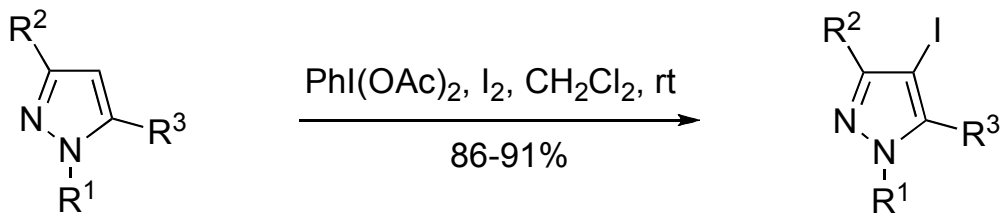

$$
\begin{aligned}
& \mathrm{R}^{1}=\mathrm{H}, \mathrm{Ph}, 2,4-\left(\mathrm{NO}_{2}\right)_{2} \mathrm{C}_{6} \mathrm{H}_{3}, 4-\mathrm{ClC}_{6} \mathrm{H}_{4} \\
& \mathrm{R}^{2}=\mathrm{Me} \text { or } \mathrm{Ph} ; \mathrm{R}^{3}=\text { Me or } \mathrm{Ph}
\end{aligned}
$$

\section{Scheme 22}

Various dihydropyridone derivatives can be efficiently iodinated by the treatment with $N$ iodosuccinimide (NIS) in the presence of [hydroxy(tosyloxy)iodo]benzene. ${ }^{21 \mathrm{~h}}$

The $\mathrm{DIB} / \mathrm{I}_{2}$ system can be used for the oxidative decarboxylation/iodination of carboxylic acids. Juaristi, Iglesias-Arteaga, and coauthors have utilized this reaction in the efficient syntheses of enantiopure 1-benzoyl-2(S)-tert-butyl-3-methylperhydropyrimidin-4-one ${ }^{21 i}$ and 2substituted-5-halo-2,3-dihydro-4(H)-pyrimidin-4-ones. ${ }^{21 \mathrm{j}}$

\section{Oxidative Transformations of Organic Substrates}

\subsection{Oxidation of alcohols}

An efficient procedure for the oxidation of alcohols with DIB in the presence of catalytic amounts of TEMPO (2,2,6,6-tetramethylpiperidin-1-oxyl) has been developed and frequently used in recent years. ${ }^{22}$ An optimized protocol, published in Organic Synthesis for the oxidation of nerol 52 to nepal 53 (Scheme 23), consists of the treatment of the alcohol 52 solution in buffered $(\mathrm{pH} 7)$ aqueous acetonitrile with DIB and TEMPO $\left(0.1\right.$ equivalent) at $0{ }^{\circ} \mathrm{C}$ for 20 minutes. $^{22 \mathrm{a}}$
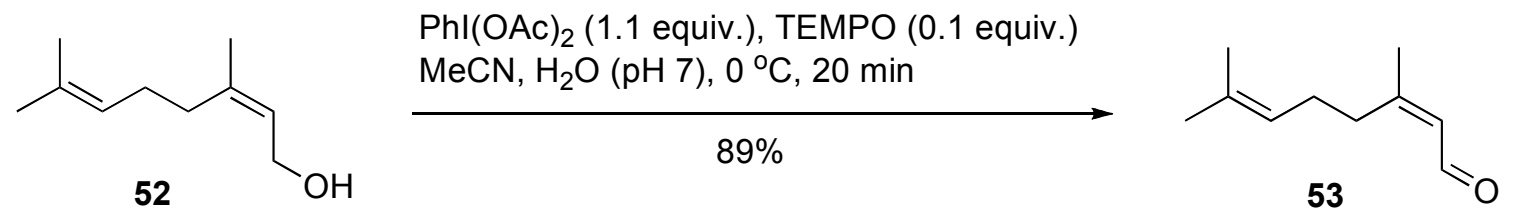

\section{Scheme 23}

This procedure exhibits a very high degree of selectivity for the oxidation of primary alcohols to aldehydes, without any noticeable overoxidation to carboxylic acids, and a high chemoselectivity in the presence of either secondary alcohols or of other oxidizable moieties. ${ }^{22}$ This procedure has been used for the oxidation of (fluoroalkyl)alkanols, $\mathrm{R}_{\mathrm{F}}\left(\mathrm{CH}_{2}\right)_{\mathrm{n}} \mathrm{CH}_{2} \mathrm{OH}$, to the respective aldehydes, ${ }^{22 c}$ in the one-pot selective oxidation/olefination of primary alcohols using 
DIB-TEMPO system and stabilized phosphorus ylides, ${ }^{22 \mathrm{~d}}$ and in the chemo-enzymatic oxidationhydrocyanation of $\gamma, \delta$-unsaturated alcohols. ${ }^{22 \mathrm{e}}$ (Dichloroiodo)benzene in the presence of pyridine can also be used as a stoichiometric oxidant insread of DIB in the TEMPO-catalyzed oxidations. $^{22 \mathrm{f}}$

Based on the ability of the DIB-TEMPO system to selectively oxidize primary alcohols to the corresponding aldehydes in the presence of secondary alcohols, Forsyth and coauthors have developed selective oxidative conversion of a variety of highly functionalized $1^{\circ}, 2^{\circ}-1,5$-diols into the corresponding $\delta$-lactones. ${ }^{22 g}$ A representative example of converting substrate $\mathbf{5 4}$ to the $\delta$-lactone 55 is shown in Scheme 24. A similar DIB-TEMPO promoted $\gamma$-lactonization has recently been utilized in the asymmetric total synthesis of the antitumor $(+)$-eremantholide $A .^{22 \mathrm{~h}}$

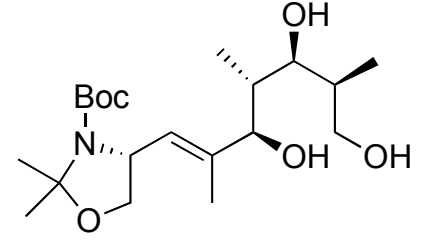

54

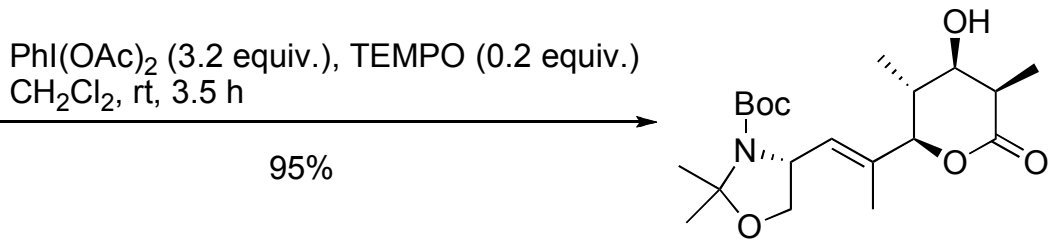

55

\section{Scheme 24}

Kita, Tohma, and coauthors found that iodosylbenzene or DIB in the presence of bromide salts can also be used as an efficient reagent for selective oxidation of alcohols. ${ }^{23}$ In particular, the $(\mathrm{PhIO})_{\mathrm{n}} / \mathrm{KBr}$ system is applicable to the oxidation of a variety of primary and secondary alcohols, even in the presence of sensitive functional groups such as ether, ester, sulfonamide, and azido groups. Primary alcohols under these conditions afford carboxylic acids, while the oxidation of various secondary alcohols under similar conditions results in the formation of the appropriate ketones in almost quantitative yield. ${ }^{23 a, b}$ Aldehydes can be converted to methyl esters by a similar procedure using DIB and $\mathrm{NaBr}$ in the acidic aqueous methanol solution. ${ }^{23 \mathrm{c}}$

Molecular iodine can serve as an efficient catalyst in the oxidation of secondary alcohols to ketones and primary alcohols to carboxylic acids using DIB as an oxidant in acetonitrile solution. $^{24 \mathrm{a}}$ The oxidation of primary alcohols or aldehydes with the $\mathrm{DIB} / \mathrm{I}_{2}$ system in methanol solution affords the respective methyl esters in excellent yields. ${ }^{24 b}$

Benzylic alcohols can be oxidized with [hydroxy(tosyloxy)iodo]benzene under solvent-free microwave irradiation conditions to afford the corresponding aldehydes or ketones in excellent yields. $^{24 \mathrm{c}}$

\subsection{Oxidative functionalization of carbonyl compounds, alkenes, and arenes}

In the 1980s Moriarty and coauthors have developed a particularly useful methodology for the oxidative $\alpha$-functionalization of enolizable carbonyl compounds or their enol ethers using DIB or 
other hypervalent iodine oxidants. ${ }^{25 a, b}$ The applications of this methodology in organic synthesis, especially in the chemistry of heterocyclic compounds, have been summarized in several reviews. $^{1 \mathrm{a}, 25 \mathrm{c}-\mathrm{e}}$

The functionalization of carbonyl compounds at an $\alpha$-carbon represents the most typical reaction of [hydroxy(organosulfonyloxy)iodo]arenes (Scheme 25). ${ }^{26 a}$ Recent examples of synthetic application of this procedure include the following: the preparation of $\alpha$ mesyloxyketones for the photochemical synthesis of highly functionalized cyclopropyl ketones, ${ }^{26 \mathrm{~b}}$ the one-pot conversion of ketones into $\beta$-keto sulfones using HTIB and sodium arene sulfinate under solvent-free conditions, ${ }^{26 c}$ the solvent-free synthesis of $\alpha$-tosyloxy $\beta$-keto sulfones using HTIB, ${ }^{26 \mathrm{~d}}$ the use of HTIB in the synthesis of 1,4-diaryl-2-(arylamino)-but-2-ene1,4-diones, ${ }^{26}$ the HTIB promoted synthesis of 6-arylimidazo[2,1- $\left.b\right]$ thiazoles, ${ }^{26 f}$ the HTIB promoted synthesis of 2-substituted 4,5-diphenyloxazoles under solvent-free microwave irradiation conditions, ${ }^{26 \mathrm{~g}}$ the one-pot preparation of 2,4,5-trisubstituted oxazoles from ketones, nitriles, and aryliodine(III) triflates generated in situ from iodoarene, $m$ CPBA and triflic acid, ${ }^{26 \mathrm{~h}}$ the preparation of flavones from flavanones using HTIB, ${ }^{26 \mathrm{i}}$ the preparation of 3tosyloxychromanones by the reaction of HTIB with chromanone and 2-methylchromanone, ${ }^{26 j}$ the HTIB promoted one-pot synthesis of 3-carbomethoxy-4-arylfuran-2-(5H)-ones from ketones, ${ }^{26 \mathrm{k}}$ and the HTIB mediated synthesis of thiazol-2(3H)-imine-linked glycoconjugates. ${ }^{261}$<smiles>[R]CC([R])=O</smiles>
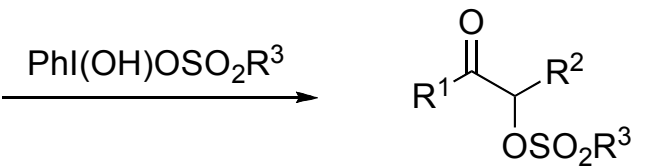

$\mathrm{R}^{1}, \mathrm{R}^{2}=$ alkyl, aryl; $\mathrm{R}^{3}=\mathrm{Me}, \mathrm{p}$-Tol, etc.

\section{Scheme 25}

HTIB is commonly used for the oxidative functionalization of arenes, alkenes and alkynes. ${ }^{26 a}$ Koser, Telu, and Laali investigated the oxidative substitution reactions of polycyclic aromatic hydrocarbons with iodine(III) sulfonate reagents. ${ }^{261}$ Various polycyclic arenes, such as pyrene, anthracene, phenanthrene, perylene and others, undergo regioselective oxidative substitution reactions with iodine(III) sulfonate reagents in dichloromethane at room temperature to give the corresponding aryl sulfonate esters in moderate to good yields. ${ }^{26 \mathrm{~m}}$

Numerous examples of oxidative transformations of alkenes using [bis(acyloxy)iodo]arenes have been reported. ${ }^{27}$ BTI reacts with alkenes in the absence of any additive or catalyst affording bis(trifluoroacetates), which can be converted into the corresponding diols or carbonyl compounds by hydrolysis. ${ }^{27 a, b}$ For example, cyclohexene reacts with BTI in dichloromethane under reflux conditions to give the corresponding cis-1,2-bis(trifluoroacetate) in almost quantitative yield (Scheme 26). ${ }^{27 a}$ Similar rearranged products are formed in the reactions of alkenes with DIB in the presence of strong acids. ${ }^{27 \mathrm{c}}$ 


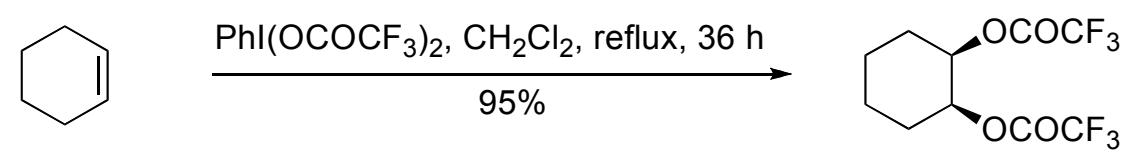

\section{Scheme 26}

[Bis(acyloxy)iodo]arenes can be utilized as the oxidants in organocatalytic, asymmetric epoxidation of $\alpha, \beta$-unsaturated aldehydes using imidazolidinone catalyst $57{ }^{27 \mathrm{~d}}$ In a specific example, the reaction of aldehyde 56 with DIB affords epoxide 58 with good enantioselectivity (Scheme 27).

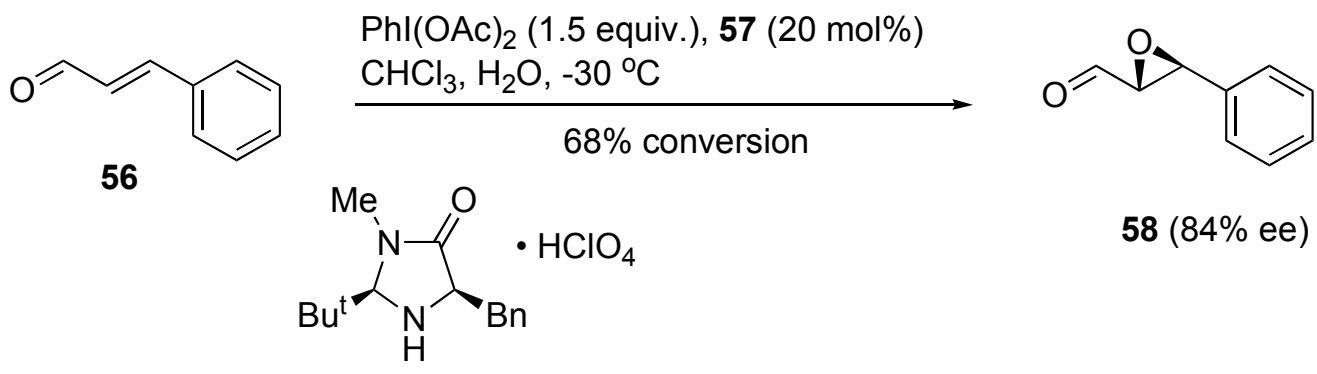

57

\section{Scheme 27}

A procedure for the preparation of aromatic aldehydes 60 from isopropenylbenzenes 59 and zeolite-supported DIB under microwave irradiation (Scheme 28) has been reported. This method was used for a clean and reproducible preparation of piperonal, vanillin and $p$-anisaldehyde in generally high yields and selectivities. ${ }^{27 \mathrm{e}}$

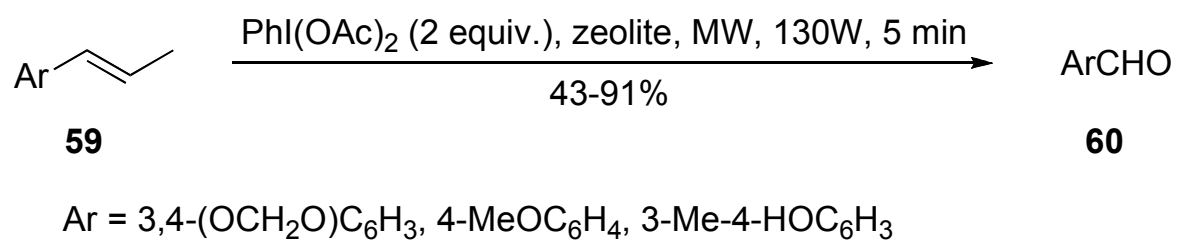

\section{Scheme 28}

Iodosobenzene in the presence of $\mathrm{KBr}$ and montmorillonite-K10 clay can be used as an efficient oxidant of the benzylic $\mathrm{C}-\mathrm{H}$ bonds to give the corresponding arylketones in good yields. ${ }^{27 \mathrm{f}}$ 


\subsection{Oxidative rearrangements and fragmentations}

[Bis(acyloxy)iodo]arenes and aryliodine(III) organosulfonates are commonly used as the reagents in various cationic rearrangements and fragmentations. DIB, BTI and HTIB can serve as excellent oxidants in Hofmann-type degradation of aliphatic or aromatic carboxamides to the respective amines. ${ }^{1 \mathrm{c}}$ Recent examples include the oxidative rearrangement of anthranilamides or salicylamides 61 to the respective heterocycles $62,{ }^{28 a}$ and the preparation of alkyl carbamates of 1-protected indole-3-methylamines 64 from the corresponding acetamides 63 (Scheme 29). ${ }^{28 \mathrm{~b}}$<smiles>[R]c1ccc([Y])c(C(N)=O)c1</smiles>

61

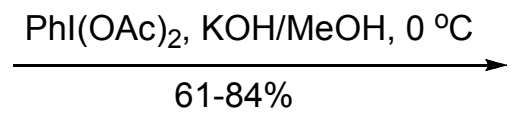

$61-84 \%$<smiles>[R]c1ccc2[nH]c(=O)[nH]c2c1</smiles>

62

$\mathrm{R}=\mathrm{H}$ or $\mathrm{Cl} ; \mathrm{X}=\mathrm{NH}, \mathrm{NMe}, \mathrm{NEt}, \mathrm{NPr}, \mathrm{NPr}^{\mathrm{i}}, \mathrm{NBu}, \mathrm{NBn}, \mathrm{O}$<smiles>[R]n1cc(CC(N)=O)c2ccccc21</smiles>

63

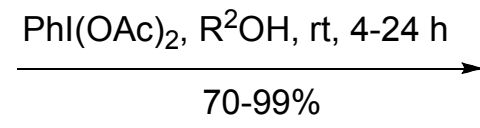

$\mathrm{R}^{1}=\mathrm{Boc}$ or Ts; $\mathrm{R}^{2}=\mathrm{Me}, \mathrm{Et}, \mathrm{Pr}^{\mathrm{i}}, \mathrm{Bu}^{\mathrm{t}}, \mathrm{Bn}$<smiles>[R]OC(=O)NCc1cn([R1])c2ccccc12</smiles>

64

\section{Scheme 29}

BTI has also been used as a reagent for the Hofmann rearrangement, as illustrated by the conversion of amide 65 to the respective amine 66 (Scheme 30). ${ }^{28 c}$ A similar BTI-induced Hofmann rearrangement has been used for the preparation of both enantiomers of trans-2aminocyclohexanecarboxylic acid from trans-cyclohexane-1,2-dicarboxylic acid. ${ }^{28 \mathrm{~d}}$

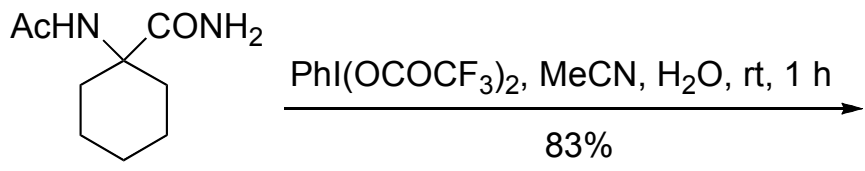

65<smiles>NC1(N)CCCCC1</smiles>

66

\section{Scheme 30}

BTI, DIB and HTIB are widely used in various cationic cyclizations, which are particularly useful in the synthesis of heterocycles. ${ }^{29,30}$ Tellitu and Domínguez have developed a series of 
BTI-promoted intramolecular amidation reactions, generalized in Scheme 31, leading to various five, six and seven-membered heterocycles 69. ${ }^{29}$ Experimental evidence supports the ionic mechanism of this reaction, involving $N$-acylnitrenium intermediates $\mathbf{6 8}$ generated in the initial reaction of the amide 67 with the hypervalent iodine reagent. ${ }^{29 a}$

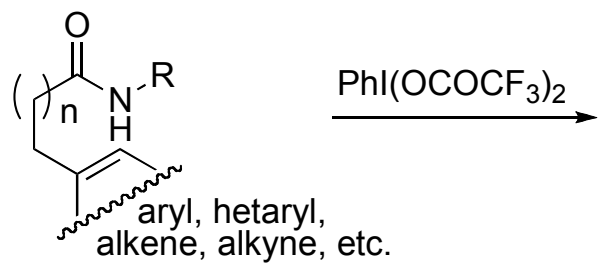

67

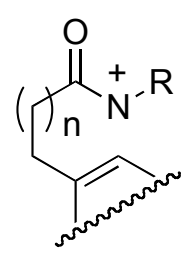

68

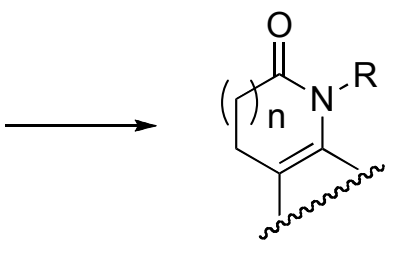

69

$\mathrm{R}=\mathrm{OMe}$, alkyl, Bn, Ph, Ts, Bz, etc.

$\mathrm{n}=0,1,2$

\section{Scheme 31}

This methodology with some variations (Scheme 48) has been utilized by Tellitu, Domínguez, and coauthors in the synthesis of numerous heterocyclic systems, for example, benzo-, naphtho-, and heterocycle-fused pyrrolo[2,1-c][1,4]diazepines, ${ }^{29 \mathrm{~b}}$ 2,3diarylbenzo[ $b]$ furans, ${ }^{29 \mathrm{c}} \quad$ quinolinone or ${ }^{2}$ pyrrolidinone derivatives, ${ }^{29 \mathrm{~d}}$ dibenzo $[a, c]$ phenanthridines, ${ }^{29 \mathrm{e}}$ thiazolo-fused quinolinones, ${ }^{29 \mathrm{f}}$ indoline derivatives, ${ }^{29 \mathrm{~g}}$ 5-aroylpyrrolidinones, ${ }^{29 \mathrm{~h}}$ and indazolone derivatives. ${ }^{29 \mathrm{i}}$ Recent representative examples include the preparation of indoline derivatives $\mathbf{7 1}$ from anilides $\mathbf{7 0}^{29 \mathrm{~g}}$ and indazol-3-ones $\mathbf{7 3}$ from anthranilamides 72 (Scheme 32). ${ }^{29 i}$<smiles>[R16]Nc1c([R2])cc([R])cc1CC=C</smiles>

$70 \mathrm{R}^{1}=\mathrm{OMe}, \mathrm{Et}, \mathrm{Br}$, or $\mathrm{H} ; \mathrm{R}^{2}=\mathrm{H}$ or $\mathrm{Et}$<smiles>[R]c1cc(N)c(C(=O)N[Al])cc1[R]([H])[H]</smiles>

72

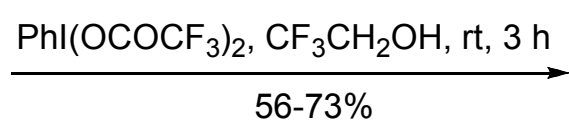

$56-73 \%$<smiles>[R]c1cc([R2])c2c(c1)CC(CO)N2C(=O)c1ccccc1</smiles>

71<smiles>[R]c1cc2c(=O)n([Al])n(-c3ccccc3)c2cc1[R]</smiles>

73

$$
\begin{aligned}
& \mathrm{R}^{1}=\mathrm{H} \text { or } \mathrm{F} ; \mathrm{R}^{2}=\mathrm{H} \text { or } \mathrm{Cl} \\
& \mathrm{Ar}=4-\mathrm{MeOC}_{6} \mathrm{H}_{4}
\end{aligned}
$$

\section{Scheme 32}


Similar DIB or BTI induced cyclizations of the appropriate amide or amine precursors have been used in various useful synthetic transformations, recent examples of which include: the synthesis of highly substituted pyrrolin-4-ones via BTI-mediated cyclization of enaminones, ${ }^{30 a}$ the synthesis of 2-substituted-4-bromopyrrolidines via DIB-induced intramolecular oxidative bromocyclization of homoallylic sulfonamides in the presence of $\mathrm{KBr},{ }^{30 \mathrm{~b}}$ the preparation of 2( $N$-acylaminal) substituted tetrahydropyrans by DIB-induced oxidative cyclization of hydroxysubstituted $N$-acyl enamines, ${ }^{30 c}$ the stereocontrolled preparation of highly substituted lactams and $N$-hydroxy lactams from appropriate hydroxamates and $\mathrm{BTI},{ }^{30 \mathrm{~d}}$ the synthesis of various substituted 1,2,4-triazolo[4,3-a]pyrimidines by the DIB-oxidation of the appropriate 2,4pyrimidinylhydrazones, ${ }^{30 \mathrm{e}}$ the synthesis of 1,3,4-oxadiazoles from acylhydrazones by BTI oxidation, ${ }^{30 \mathrm{f}}$ the synthesis of various $N$-substituted indole derivatives via BTI-mediated intramolecular cyclization of enamines, ${ }^{30 \mathrm{~g}}$ the synthesis of 2-substituted benzothiazoles via the oxidative cyclization of thiobenzamides, ${ }^{30 \mathrm{~h}}$ the preparation of 2 -substituted oxazolines from aldehydes and 2-amino alcohols using DIB as an oxidant, ${ }^{30 \mathrm{i}}$ the synthesis of 3,4-bis(1-phenyl-3arylpyrazolyl)-1,2,5-oxadiazole- $N$-oxides by the DIB oxidation of pyrazole-4-carboxaldehyde oximes, ${ }^{30 \mathrm{j}}$ the synthesis of 2-arylbenzimidazoles from phenylenediamines and aldehydes via a one-step process using DIB as an oxidant, ${ }^{30 \mathrm{k}}$ the preparation of dihydrooxazole derivatives by DIB-promoted 1,3-dipolar cycloaddition reactions of phthalhydrazide, ${ }^{301}$ the synthesis of secopsymberin/irciniastatin A via a DIB-mediated cascade cyclization reaction, ${ }^{30 \mathrm{~m}}$ the synthesis of quinolinone derivatives by hypervalent iodine-mediated oxidation of aromatic compounds carrying methoxyamide side chains, ${ }^{30 \mathrm{n}}$ the synthesis of functionalized isoxazolines by oxidative cyclization of aldoximes using iodosobenzene and surfactants in neutral aqueous media, ${ }^{30 o}$ and the oxidative cyclization of urea-tethered alkenes using iodosylbenzene and an acid promoter. ${ }^{30 \mathrm{p}}$ Similar to [bis(acyloxy)iodo]arenes, HTIB can be applied in the intramolecular cyclization reactions involving $N$-acylnitrenium intermediates 68 (Scheme 31). ${ }^{31}$ For example, spirodienones 75 bearing the 1-azaspiro[4.5]decane ring system were synthesized from $N$-methoxy-3-(4halophenyl)propanamides $\mathbf{7 4}$ via the intramolecular ipso-cyclization of a nitrenium ion generated with HTIB in trifluoroethanol (Scheme 33). ${ }^{31 \mathrm{~b}}$ The HTIB-promoted cyclizations of the appropriate amides were also utilized in the preparation of 2,1-benzothiazine derivatives from sulfonamides $^{31 \mathrm{c}}$ and in the synthesis of (-)-lapatin B via oxidative cyclization of $N, N$ diacetylglyantrypine. $^{31 \mathrm{~d}}$
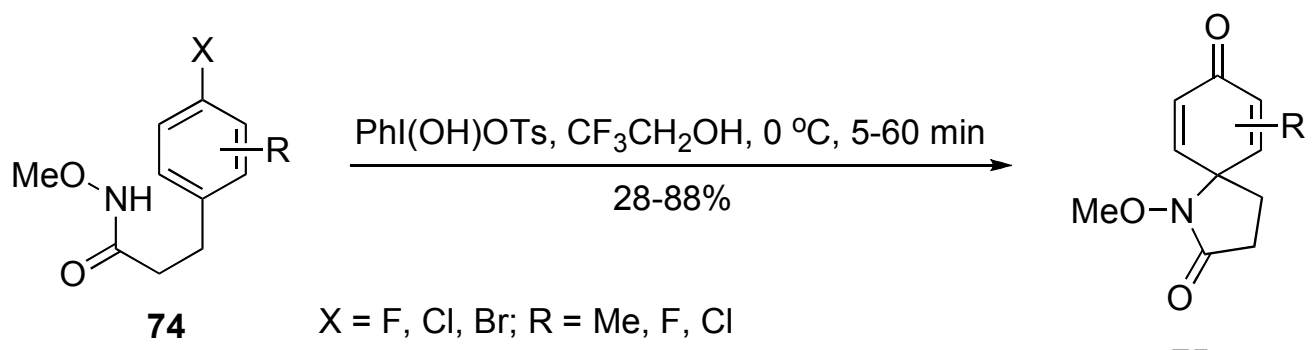

Scheme 33 
Several examples of the DIB or BTI-induced cyclizations of non-amine substrates have also been reported. Wirth and coauthors reported the oxidative cyclization of 4-phenyl-4-pentenoic acid 76 upon treatment with DIB leading to the rearranged lactone 77. (Scheme 34). ${ }^{32 \mathrm{a}}$ The same group reported a one-pot procedure for the conversion of alkenes into 1,1-dicyanocyclopropane derivatives by treatment with DIB and 1,1-dicyanopropane. ${ }^{32 \mathrm{~b}}$

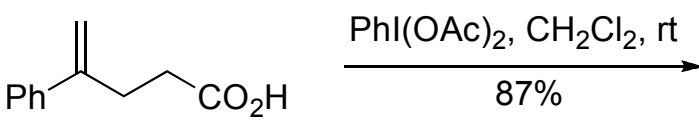

76

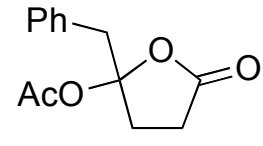

77

\section{Scheme 34}

Kita and coauthors developed an efficient synthesis of lactols 79 via an oxidative rearrangement reaction of 2,3-epoxy alcohols 78 with BTI (Scheme 35). ${ }^{32 \mathrm{c}}$ This BTI-induced oxidative transformation has been utilized in the synthesis of several lactones and in the asymmetric synthesis of the marine $\gamma$-lactone metabolite $(+)$-tanikolide.

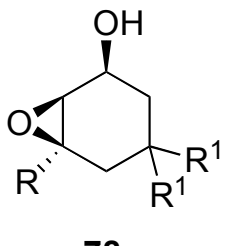

78

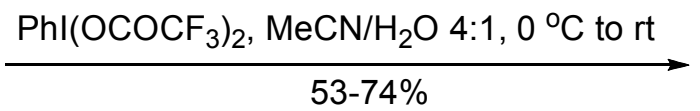

$\mathrm{R}=\mathrm{Me}, \mathrm{Et}, n-\mathrm{C}_{11} \mathrm{H}_{23}, \mathrm{CH}_{2} \mathrm{CH}\left(\mathrm{CH}_{3}\right)_{2}, \mathrm{CH}_{2} \mathrm{Ph} ; \mathrm{R}^{1}=\mathrm{H}$ or $\mathrm{Me}$<smiles>[R]C1CC2([R])CCC(OC2O)C1[R]</smiles>

79

\section{Scheme 35}

A DIB-induced domino reaction of the vicinal unsaturated diol $\mathbf{8 0}$ afforded cyclic ene-acetal 81 (Scheme 36), which was further utilized in the synthesis of a norsesquiterpene spirolactone/testosterone hybrid. ${ }^{32 \mathrm{~d}}$

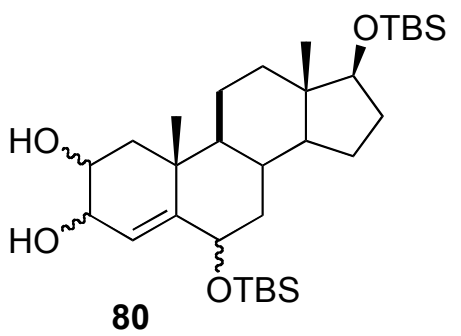

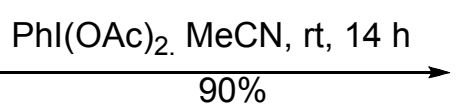

80

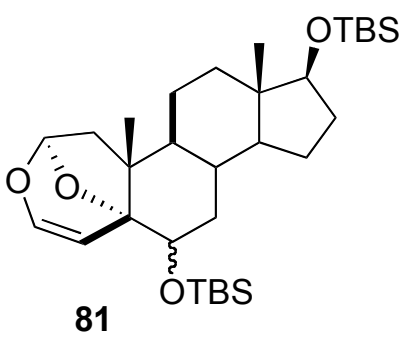

\section{Scheme 36}


Iglesias-Arteaga and coauthors reported several DIB-promoted oxidative transformations of steroidal substrates. ${ }^{33}$ In particular, the treatment of (25R)-3a-acetoxy-5b-spirostan-23-one 82 with DIB in basic methanol leads to F-ring contraction via Favorskii rearrangement to afford product 83 (Scheme 37). ${ }^{33 a}$

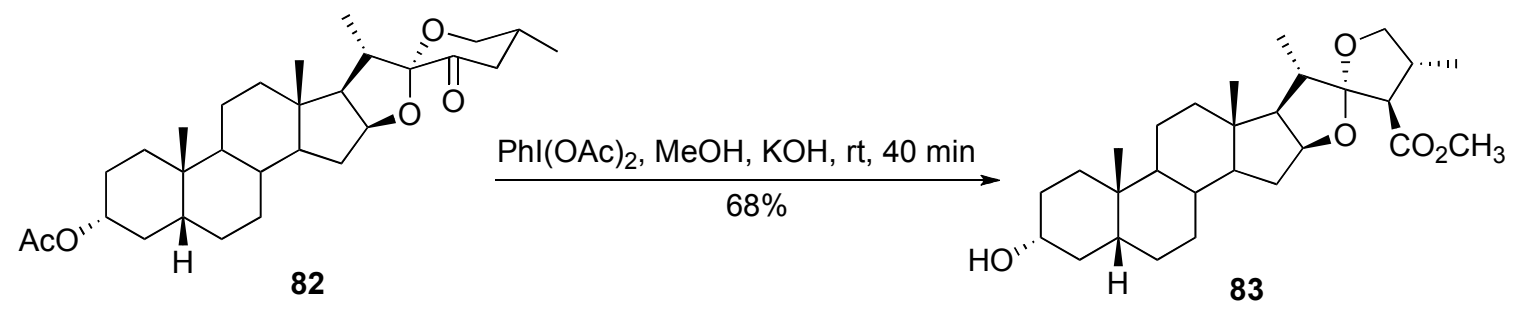

\section{Scheme 37}

Kita and coauthors reported a mild and efficient fragmentation reaction of $\beta$-amino alcohols 84 and $\alpha$-amino acids 85 upon treatment with [bis(trifluoroacetoxy)iodo]pentafluorobenzene leading to N,O-acetals 86 (Scheme 38). This method has been utilized in an improved synthesis of the key intermediate of discorhabdins. ${ }^{34}$

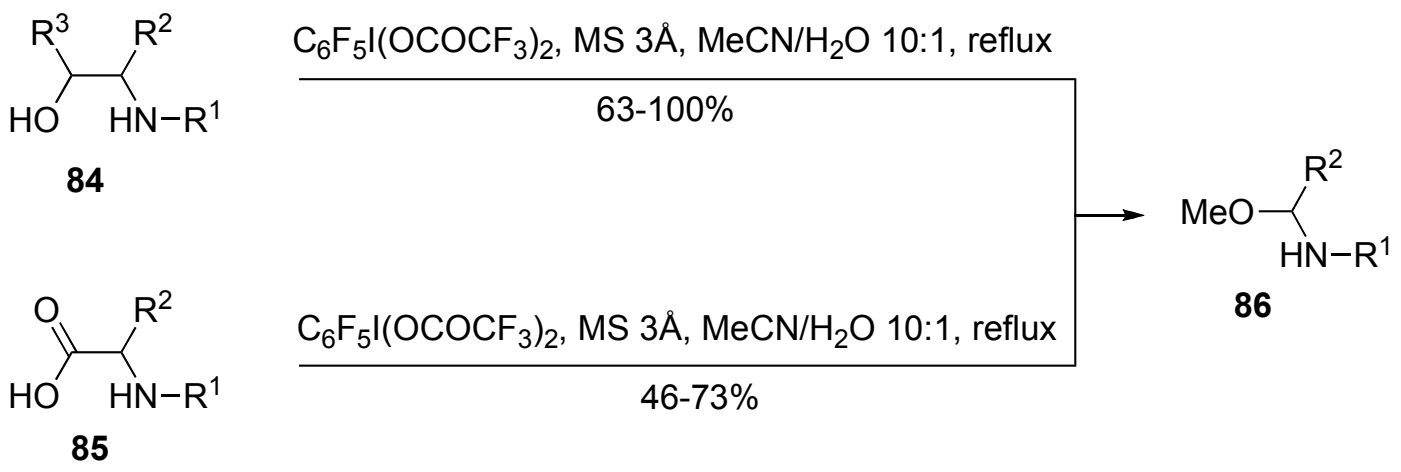

$$
\mathrm{R}^{1}=\mathrm{Cbz} \text { or Fmoc; } \mathrm{R}^{2}=\mathrm{H}, \mathrm{Me}, \mathrm{CO}_{2} \mathrm{Me} \text {, etc; } \mathrm{R}^{3}=\mathrm{H} \text { or } \mathrm{CH}_{3}
$$

\section{Scheme 38}

HTIB has also been used in various oxidative rearrangements and fragmentations. Justik and Koser have reported a study of an oxidative rearrangement that occurs upon the treatment of arylalkenes $\mathbf{8 7}$ with HTIB in $95 \%$ methanol affording the corresponding $\alpha$-aryl ketones $\mathbf{8 8}$ in generally high yields (Scheme 39). This oxidative rearrangement is general for acyclic and cyclic arylalkenes and permits the regioselective syntheses of isomeric $\alpha$-phenyl ketone pairs. ${ }^{35 a} \mathrm{~A}$ similar HTIB induced oxidative rearrangement has recently been utilized in the regioselective synthesis of 6-prenylpolyhydroxyisoflavone (wighteone) ${ }^{35 \mathrm{~b}}$ and in a diastereoselective total synthesis of $( \pm)$-indatraline. ${ }^{35 \mathrm{c}}$ 


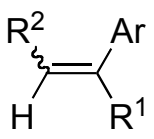

87

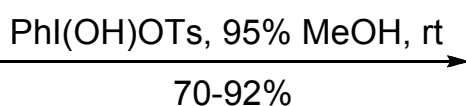

$\mathrm{R}^{1}, \mathrm{R}^{2}=$ alkyl, aryl<smiles>[R]C(=O)C([R])[Al-]</smiles>

88

\section{Scheme 39}

The HTIB induced oxidative rearrangement of alkenes can be effectively used in ring expansion reactions. Justik and Koser have investigated the oxidative ring expansions of alkylidenebenzocycloalkenes 89 to $\beta$-benzocycloalkenones 90 using HTIB in 95\% methanol (Scheme 40). ${ }^{35 \mathrm{~d}}$<smiles>[R]C=C1c2ccccc2NC1[R]</smiles>

89

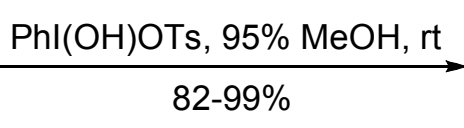

$\mathrm{R}^{1}, \mathrm{R}^{2}=\mathrm{H}$ or $\mathrm{Me} ; \mathrm{n}=1-3$<smiles>[R]C1Nc2ccccc2C([R])C1=O</smiles>

90

\section{Scheme 40}

Silva and coauthors reported a similar HTIB-promoted ring expansion of 1-vinylcycloalkanol derivatives leading to seven- or eight-membered rings. In a specific example, the reaction of the unsaturated TMS ether 91 with excess HTIB affords benzocycloheptanone derivative 92 in high yield (Scheme 41). ${ }^{35 \mathrm{e}}$

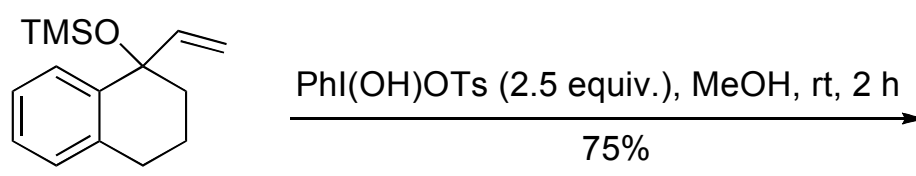

91

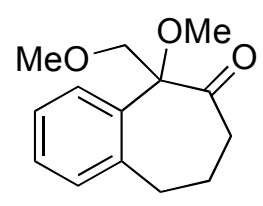

92

\section{Scheme 41}

Aryl ketones 93 can be converted to the corresponding substituted benzoic acids 94 by sequential treatment with [hydroxy(2,4-dinitrobenzenesulfonyloxy)iodo]benzene and ureahydrogen peroxide in $[\mathrm{bmim}] \mathrm{BF}_{4}$ ionic liquid (Scheme 42$){ }^{35 \mathrm{f}}$ 


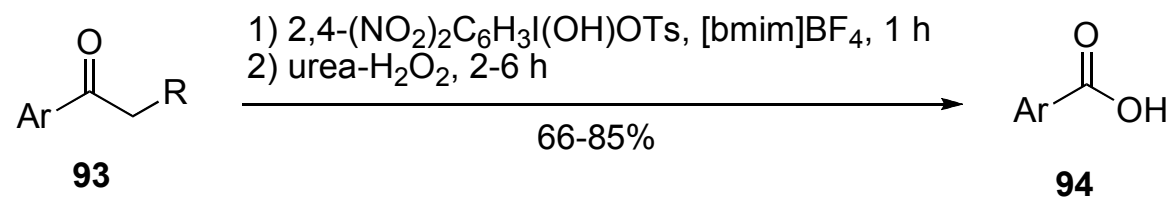

$$
\begin{aligned}
& \mathrm{Ar}=\mathrm{Ph}, 4-\mathrm{MeC}_{6} \mathrm{H}_{4}, 4-\mathrm{BrC}_{6} \mathrm{H}_{4}, 4-\mathrm{ClC}_{6} \mathrm{H}_{4}, 4-\mathrm{FC}_{6} \mathrm{H}_{4}, 4-\mathrm{NO}_{2} \mathrm{C}_{6} \mathrm{H}_{4} \\
& \mathrm{R}=\mathrm{Me}, \mathrm{Pr}, \mathrm{Bu}
\end{aligned}
$$

\section{Scheme 42}

Vatele has described a mild and environmentally friendly method for Lewis acid catalyzed oxidative rearrangement of tertiary allylic alcohols 95 to $\beta$-disubstituted enones 96 (Scheme 43). ${ }^{35 \mathrm{~g}}$ Bismuth triflate was found to be the most efficient catalyst for the majority of substrates 95 tested except for tertiary vinyl carbinols which could be transformed to enals in fair yields only when $\mathrm{Re}_{2} \mathrm{O}_{7}$ was used as catalyst.

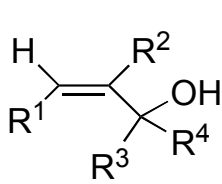

95

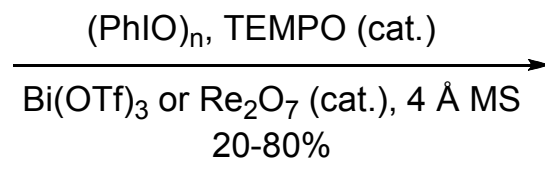

$$
\begin{aligned}
& R^{1}, R^{2}=H, R^{3}=n-C_{5} H_{11}, R^{4}=C_{3} \\
& R^{1}+R^{3}=\left(C_{2}\right)_{3}, R^{2}=H, R^{4}=B u \text { or } P h \\
& R^{1}+R^{3}=\left(C_{2}\right)_{2}, R^{2}=H, R^{4}=B u, \text { etc }
\end{aligned}
$$<smiles>[R]C(=O)C([R])=C([R])[R]</smiles>

96

\section{Scheme 43}

Several synthetically useful transformations are based on the oxidation of hydrazones by DIB or BTI. Specific examples include the BTI oxidations of phenylhydrazones leading to regeneration of the carbonyl function, ${ }^{35 \mathrm{~h}}$ the low temperature generation of diazo compounds by the reaction of BTI with hydrazones and application of this reaction to the preparation of highly sterically hindered alkenes, ${ }^{35 i}$ the preparation of $N$-aroyl- $N$ '-arylsulfonylhydrazines by oxidation of aromatic aldehyde $N$-arylsulfonylhydrazones with BTI, ${ }^{35 \mathrm{j}}$ and the preparation of fused 1,2,3triazolo heterocycles by DIB oxidation of hydrazones of $N$-heterocyclic ketones and aldehydes. $^{35 \mathrm{k}}$

\subsection{Oxidative dearomatization of phenolic substrates}

[Bis(acyloxy)iodo]arenes are commonly used as the reagents for various synthetically useful oxidative transformations of phenolic compounds. ${ }^{\text {a-d }}$ Particularly useful is the oxidative dearomatization of 4- or 2-substituted phenols (e.g. 97 and 100) with DIB or BTI in the presence of an appropriate external or internal nucleophile $(\mathrm{Nu})$ leading to the respective cyclohexadienones 99 or $\mathbf{1 0 1}$ according to Scheme 44. The mechanism of this reaction most 
likely involves the initial formation of the phenoxyiodine(III) species $\mathbf{9 8}$ followed by elimination of $\mathrm{PhI}$ and the generation of cationic phenoxenium intermediates which finally combine with the nucleophile. $^{1 \mathrm{c}}$

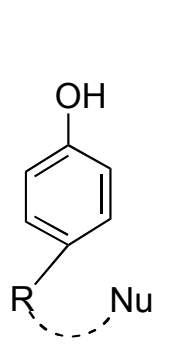

97

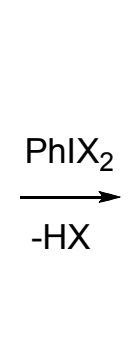

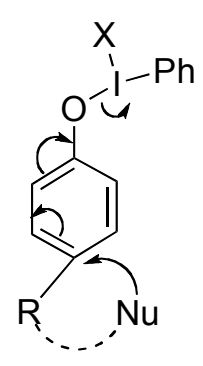

98<smiles>[R]C12C=CCCC1C(=O)C=C2</smiles>

99<smiles>[R]c1ccccc1O</smiles>

100

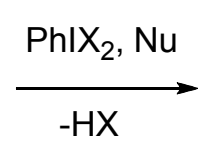

101

$$
\begin{aligned}
& R=\text { alkyl, aryl, Oalkyl, halogen, etc. } \\
& X=O A c \text { or OCOCF }
\end{aligned}
$$

\section{Scheme 44}

Various nucleophiles, such as water, alcohols, fluoride ion, carboxylic acids, amides, oximes, allylsilanes and electron-rich aromatic rings, have been used successfully in this reaction (Scheme 44) in either an inter- or intra-molecular mode. ${ }^{\text {a-d }}$ Recent examples of this reaction in the inter-molecular mode are represented by the oxidative allylation of phenols $\mathbf{1 0 2}^{36 \mathrm{a}}$ and the ipso-fluorination of $p$-substituted phenols 103 using pyridinium polyhydrogen fluoride, $\mathrm{Py} \cdot(\mathrm{HF})_{\mathrm{x}}$, in combination with DIB or BTI (Scheme 45$) .{ }^{36 \mathrm{~b}} \mathrm{~A}$ similar ipso-fluorination of $p$ substituted anilines leading to 4-fluorocyclohexa-2,5-dienimines was recently reported by Jouannetaud and coauthors. ${ }^{36 \mathrm{c}}$ 

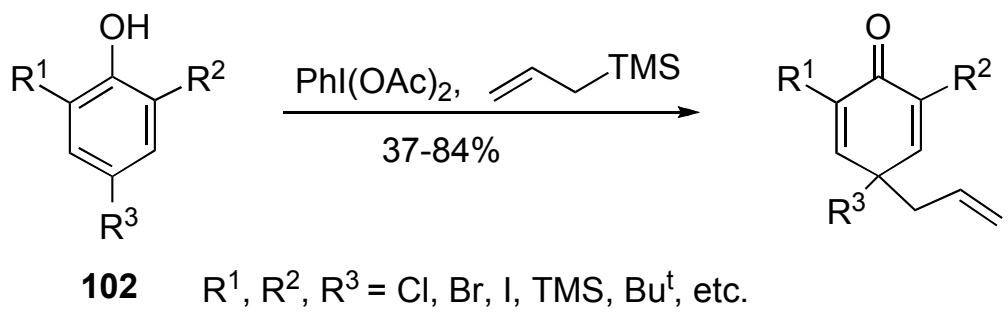

$102 \mathrm{R}^{1}, \mathrm{R}^{2}, \mathrm{R}^{3}=\mathrm{Cl}, \mathrm{Br}, \mathrm{I}, \mathrm{TMS}, \mathrm{Bu}^{\mathrm{t}}$, etc.<smiles>[R]c1ccc(O)cc1</smiles>

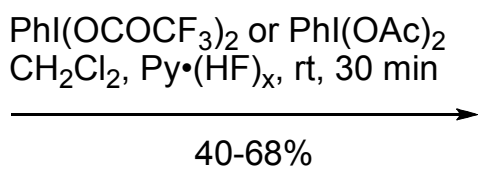<smiles>[R]C1(F)C=CC(=O)C=C1</smiles>

$103 \mathrm{R}=\mathrm{Me}, \mathrm{Et}, \mathrm{CH}_{2} \mathrm{CH}_{2} \mathrm{Br}, \mathrm{F}, \mathrm{Cl}$, etc.

\section{Scheme 45}

Felpin has recently demonstrated that the phenolic oxidation can be further improved by using phenol trimethylsilyl ethers instead of phenols as the substrates. ${ }^{36 \mathrm{~d}}$ In particular, it was shown that the oxidation of trimethylsilyl ethers 104 affords $p$-quinols 105 in greatly improved yields due to the minimization of oligomer side products formation compared to the oxidation of free phenol (Scheme 46). ${ }^{36 \mathrm{c}}$

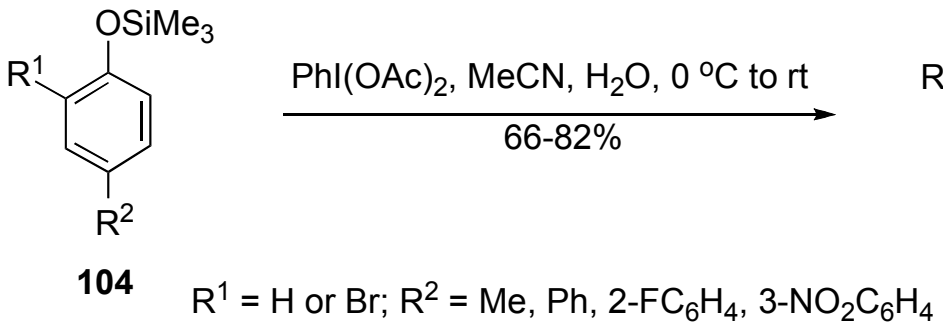<smiles>[R]C1=CC([R])(O)C=CC1=O</smiles>

105

\section{Scheme 46}

Very recently, Quideau and coauthors have reported the preparation of versatile chiral substrates $\mathbf{1 0 7}$ for asymmetric synthesis through the DIB induced spiroketalization of phenols 106 with a chiral substituted ethanol unit $O$-tethered to the ortho position (Scheme 47). ${ }^{8 \mathrm{~b}}$ This reaction has been successfully utilized in the asymmetric total synthesis of the natural product $(+)$-biscarvacrol. 


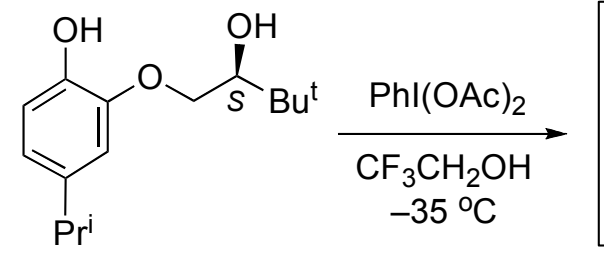

106

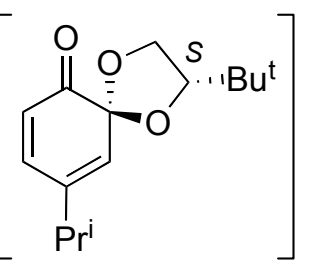

$\underset{-78^{\circ} \mathrm{C}}{\stackrel{\mathrm{MeMgBr}}{\mathrm{THF}}}$

$54 \%$

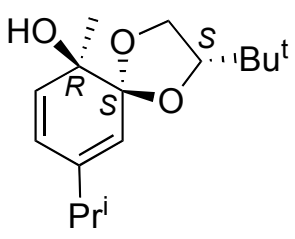

107

\section{Scheme 47}

Quideau and coauthors have developed a BTI-mediated regioselective protocol for the oxidative dearomatization of 2-alkoxyarenols in the presence of external carbon-based nucleophiles. ${ }^{37}$ This is a synthetically valuable process, as illustrated by the BTI-mediated oxidative nucleophilic substitution of the 2-alkoxynaphthol 108 with the silyl enol ether 109 leading to the highly functionalized naphthoid cyclohexa-2,4-dienone $\mathbf{1 1 0}$ (Scheme 48), which is an important intermediate product in the synthesis of aquayamycin-type angucyclinones. ${ }^{37 a, b}$<smiles>COc1ccc2ccccc2c1O</smiles>

108

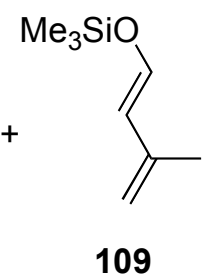<smiles>COC1(C/C(C)=C/C=O)C=Cc2ccccc2C1=O</smiles>

$110(E / Z$ 1.3:1)

\section{Scheme 48}

The DIB or BTI-induced phenolic oxidation in the intra-molecular mode provides an efficient approach to synthetically valuable polycyclic products. Representative examples of oxidative phenolic cyclizations promoted by [bis(acyloxy)iodo]arenes are shown in Scheme 49. In particular, the oxidative cyclization of phenolic oxazolines 111 affords synthetically useful spirolactams $\mathbf{1 1 2},{ }^{38 a}$ the oxidation of enamide $\mathbf{1 1 3}$ leads to the spiroenamide 114, which is a key intermediate product in the total synthesis of annosqualine, ${ }^{38 \mathrm{~b}}$ and the spirocyclic product $\mathbf{1 1 6}$ has been prepared by a BTI-induced oxidation of catechol 115 in a key step of the total synthesis of the marine sesquiterpene quinone (+)-puupehenone. ${ }^{38 c}$ 


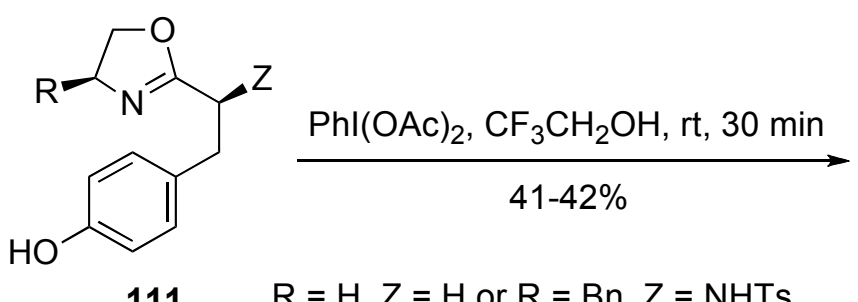<smiles>[R]C(COC(C)C)N1C(=O)[C@H]([Z])CC12C=CC(=O)C=C2</smiles>

111
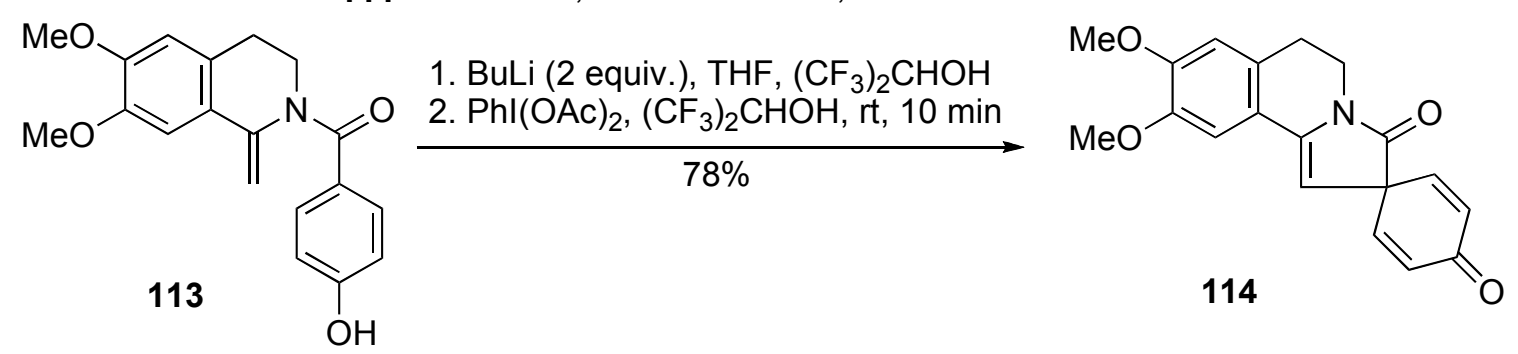<smiles>C[C@]1(O)CCC[C@@](C)(O)[C@@H]1Cc1ccc(O)c(O)c1</smiles>

115

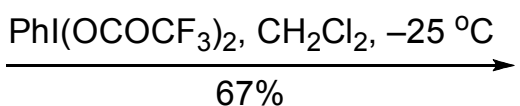

116

\section{Scheme 49}

Additional examples of the DIB or BTI-induced oxidative phenolic cyclizations include the following studies: the preparation of different heterocyclic rings such as dihydrofuranobenzofurans, tetrahydrofuranobenzofurans, tetrahydropyranofurans, and dihydrobenzofurans by the treatment of various substituted phenols with DIB in the presence of furan, allylsilanes or cyclic enol ethers, ${ }^{39 a}$ the asymmetric total syntheses of the pentacyclic Stemona alkaloids tuberostemonine and didehydrotuberostemonine, ${ }^{39 b}$ the fully stereocontrolled total syntheses of (-)-cylindricine $\mathrm{C}$ and (-)-2-epicylindricine $\mathrm{C},{ }^{39 c}$ the asymmetric total syntheses of platensimycin, ${ }^{39 \mathrm{~d}}$ the total synthesis of a potent antitumor alkaloid, discorhabdin $\mathrm{A},{ }^{39 \mathrm{e}}$ the total synthesis of the amaryllidaceae alkaloid $(+)$-plicamine using solid-supported reagents, ${ }^{39 f}$ the development of enantioselective organocatalytic oxidative dearomatization methodology, ${ }^{39 \mathrm{~g}}$ the development of a flow process for the multi-step synthesis of the alkaloid natural product oxomaritidine, ${ }^{39 \mathrm{~h}}$ the synthesis of carpanone using solid-supported reagents and scavengers, ${ }^{39 \mathrm{i}}$ and the studies on ring expansions of a spirocyclohexadienone system. ${ }^{39 j}$

Very recently, Kita and coauthors reported the first enantioselective spirocyclization reaction of the ortho-substituted phenolic substrates 117 using chiral aryliodine(III) diacetate 118 having a rigid spirobiindane backbone (Scheme 50). ${ }^{39 \mathrm{k}}$ 


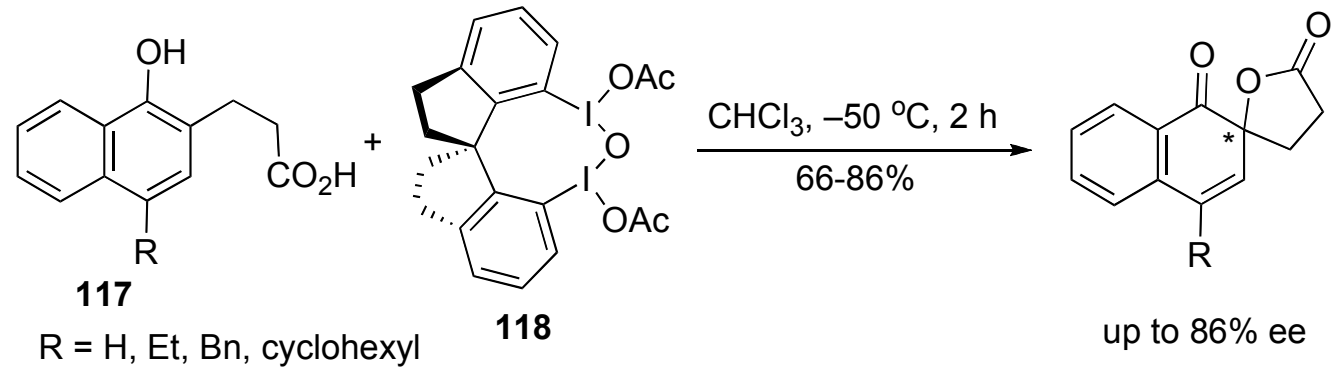

\section{Scheme 50}

The oxidative dearomatization of ortho-substituted phenols 100 leads to 6,6-disubstituted cyclohexa-2,4-dienones 101 (see Scheme 44), which can be conveniently utilized in situ as dienes in Diels-Alder reactions. ${ }^{40}$ When the oxidation of phenols is performed in the absence of an external dienophile, a dimerization via [4+2] cycloaddition often occurs spontaneously at ambient temperature to afford the corresponding dimers with an extraordinary level of regio-, site-, and stereoselectivity. A detailed experimental and theoretical investigation of such hypervalent iodine induced Diels-Alder cyclodimerizations has recently been published by Quideau and coauthors. ${ }^{40 \mathrm{~b}}$ A representative example of an oxidative Diels-Alder cyclodimerization of a phenolic substrate $\mathbf{1 1 9}$ to the dimer $\mathbf{1 2 0}$ is shown in Scheme 51.<smiles>[R]c1ccc(OC)c(O)c1</smiles>

119

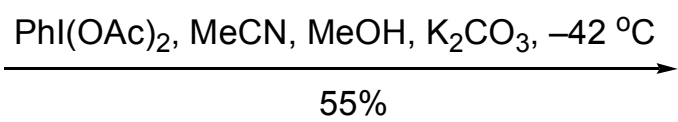

$\mathrm{R}=\mathrm{CO}_{2} \mathrm{Me}$

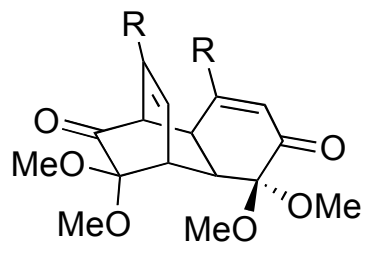

120

\section{Scheme 51}

When the oxidation is performed in the presence of an external dienophile, the respective products of [4+2] cycloaddition are formed. ${ }^{41}$ Typical examples are illustrated by a one-pot synthesis of several silyl bicyclic alkenes $\mathbf{1 2 3}$ by intermolecular Diels-Alder reactions of 4trimethylsilyl substituted masked o-benzoquinones 122 derived from the corresponding 2methoxyphenols 121, ${ }^{41 \mathrm{a}}$ and by the hypervalent iodine-mediated oxidative dearomatization/Diels-Alder cascade reaction of phenols 124 with allyl alcohol affording polycyclic acetals 125 (Scheme 52). ${ }^{41 \mathrm{~b}}$ The BTI-promoted tandem phenolic oxidation/DielsAlder reaction has been utilized in the stereoselective synthesis of the bacchopetiolone carbocyclic core. $^{41 \mathrm{c}}$ 
<smiles>[R]c1c(S(C)(=O)=O)cc(OC)c(O)c1[R]</smiles>

121

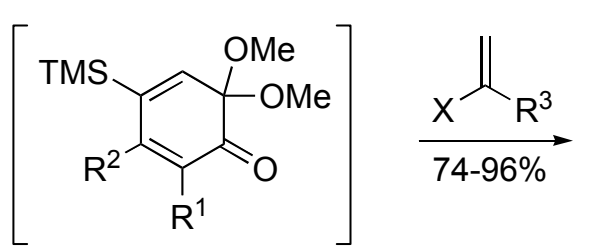

122

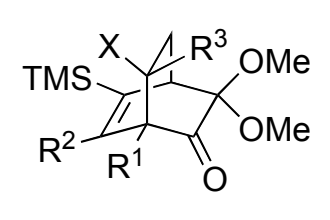

123

$\mathrm{R}^{1}, \mathrm{R}^{2}, \mathrm{R}^{3}=\mathrm{H}$ or $\mathrm{Me} ; \mathrm{X}=\mathrm{CO}_{2} \mathrm{Me}$

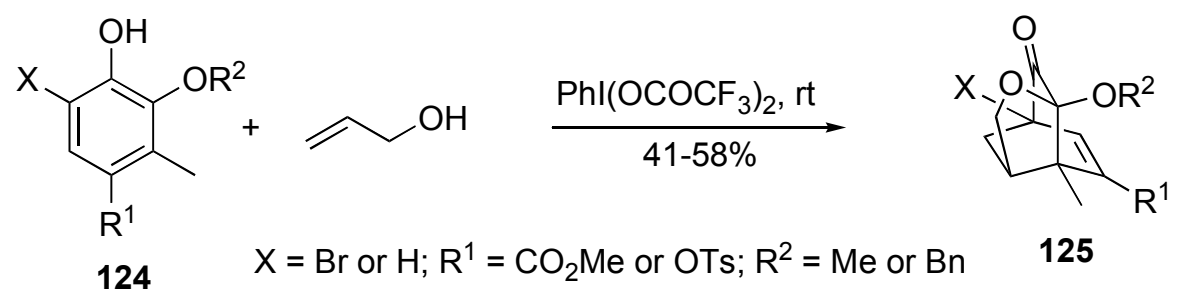

\section{Scheme 52}

A mechanistic investigation of the oxidation of 2,6-dimethylphenol using different oxidizing systems has shown that DIB is the most efficient reagents for the oxidative coupling leading to 3,5,3',5'-tetramethyl-biphenyl-4,4'-diol. A reaction mechanism was proposed which involved an initial formation of a [bis(phenoxy)iodo]benzene intermediate followed by its radical fragmentation and then radical coupling and comproportionation/redox reaction steps. ${ }^{42}$

\subsection{Oxidative coupling of aromatic substrates}

The interaction of phenol ethers $\mathbf{1 2 6}$ or other electron-rich aromatic substrates with BTI leads to the generation of cation radical intermediates $\mathbf{1 2 7}$, which can combine with external or internal nucleophiles affording the products of dearomatization 128 or coupling 129 according to Scheme 53. Kita and coauthors have recently published a detailed mechanistic study of this process (Scheme 53) for a specific reaction of oxidative cyclization of electron-rich aromatics with the intramolecular hydroxyl group. ${ }^{43 a}$ In this study, the formation of the cation radical intermediates $126\left(\mathrm{R}-\mathrm{Nu}=-\mathrm{CH}_{2} \mathrm{CH}_{2} \mathrm{CH}_{2} \mathrm{OH}\right)$ was experimentally confirmed by ESR spectroscopy, and the factors determining the ratio of products $\mathbf{1 2 8}$ and $\mathbf{1 2 9}$ and their consequent transformations were clarified. 
<smiles>[R]c1cc([R])c(OC)c([R])c1[R]</smiles>

126

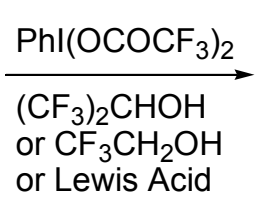

or Lewis Acid

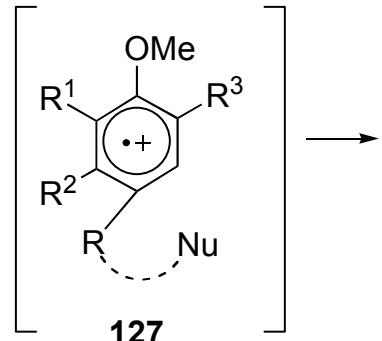

127<smiles>[R]C1=CC([R])([N])C([R])=C([R])C1=O</smiles>

128<smiles>[R]Cc1c([R])c(OC)c([R])c([R])c1NCC</smiles>

129

$\mathrm{R}=$ alkyl, alkoxy, halogen, etc.

$\mathrm{Nu}=$ external or internal nucleophilic group, including electron-rich aromatics

\section{Scheme 53}

The direct nucleophilic substitution of electron-rich phenol ethers using BTI and Lewis acid and involving aromatic cation radical intermediates was originally developed by Kita and coauthors in 1994 . $^{43 \mathrm{~b}}$ Since then this procedure with some variations has been extensively applied for various oxidative transformations, such as the synthesis of biaryls, ${ }^{43 c-e}$ spirodienones, ${ }^{43, g}$ and chromans. ${ }^{43 \mathrm{~h}}$ Specific recent examples of the oxidative coupling of phenolic ethers include the oxidative biaryl coupling of various $N$-substituted 1benzyltetrahydroisoquinolines 130 to the corresponding aporphines $131^{43 \mathrm{~d}}$ and the oxidative cyclization of 3,4-dimethoxyphenyl 3,4-dimethoxyphenylacetate 132 leading the sevenmembered lactone $\mathbf{1 3 3}$ (Scheme 54). ${ }^{43 \mathrm{e}} \mathrm{A}$ similar oxidative coupling reaction of benzyltetrahydroisoquinolines (laudanosine derivatives) using BTI and heteropoly acid has been used in an efficient synthesis of morphinandienone alkaloids. ${ }^{43 g}$

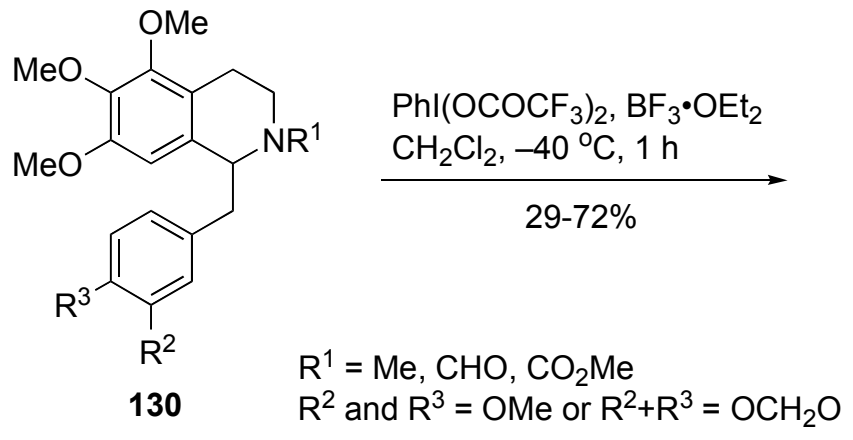<smiles>[R]c1cc2c(cc1[R])-c1c(OC)c(OC)c(OC)c3c1C(CCN3[Z17])C2</smiles>

131<smiles>COc1ccc(CC(=O)Oc2ccc(OC)c(OC)c2)cc1OC</smiles>

$\mathrm{Phl}\left(\mathrm{OCOCF}_{3}\right)_{2}, \mathrm{BF}_{3} \cdot \mathrm{OEt}_{2}$ $\mathrm{MeCN}, \mathrm{rt}, 10 \mathrm{~min}$

$85 \%$<smiles>COc1cc2c(cc1OC)-c1cc(OC)c(OC)cc1OC(=O)C2</smiles>

\section{Scheme 54}


The non-phenolic electron-rich aromatic substrates can also be oxidatively coupled using [bis(acyloxy)iodo]arenes. Kita and coauthors reported facile and efficient oxidative coupling reaction of alkylarenes 134 leading to alkylbiaryls 135 using a combination of BTI and $\mathrm{BF}_{3} \bullet \mathrm{OEt}_{2}$ (Scheme 55). ${ }^{44 a}$ Similarly, multiply iodinated biaryls can be prepared in good yields by the BTIinduced direct oxidative coupling reaction of the iodinated arenes. ${ }^{44 \mathrm{~b}}$

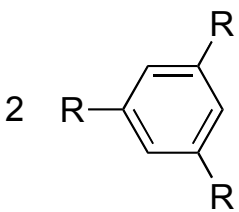

134

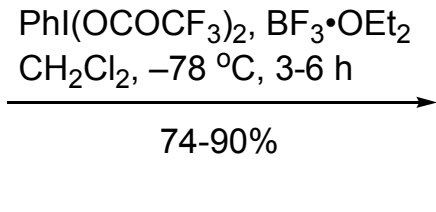

$\mathrm{R}=\mathrm{Me}, \mathrm{Et}$ or I

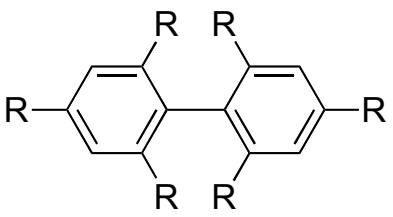

135

\section{Scheme 55}

Oxidation of $N$-aromatic methanesulfonamides 136 with DIB in the presence of thiophene $\mathbf{1 3 7}$ in trifluoroethanol or hexafluoroisopropanol affords the respective coupling products $\mathbf{1 3 8}$ in good yield. ${ }^{45}$ Likewise, the dimers of 3 -substituted thiophenes ${ }^{45 \mathrm{~b}, \mathrm{c}}$ and pyrroles ${ }^{45 \mathrm{~d}}$ can be regioselectively synthesized by the oxidative coupling of appropriate heterocycles using BTI in the presence of Lewis acids in dichloromethane at $-78{ }^{\circ} \mathrm{C}$.
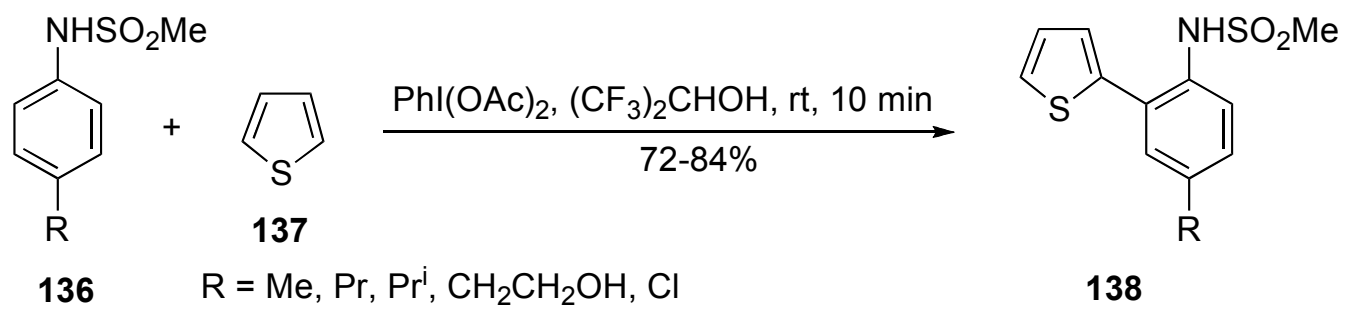

138

\section{Scheme 56}

Very recently, Yoshimura, Takahata and coauthors reported a direct coupling reaction of cycloalkenylsilanes with a silylated nucleobase promoted by DIB or BTI in the presence of trimethylsilyl triflate in dichloromethane at room temperature. ${ }^{45 e}$ This procedure was applied in the synthesis of a novel carbocyclic cytidine derivative having bis(hydroxymethyl)cyclohexene as a pseudosugar moiety, designed as a potential anti-HIV agent. ${ }^{45} \mathrm{e}$

\subsection{Radical rearrangements}

Useful synthetic methodologies are based on the cyclization, rearrangement or fragmentation of the alkoxyl radicals generated in the reaction of alcohols with [bis(acyloxy)iodo]arenes or iodosylbenzene in the presence of iodine under photochemical conditions or in the absence of 
irradiation. $^{1 \mathrm{c}}$ Suàrez and coauthors have applied this methodology in various useful transformations of carbohydrate derivatives. ${ }^{46}$ The intramolecular hydrogen abstraction reactions promoted by alkoxy radicals in carbohydrates are particularly useful for the stereoselective synthesis of various polycyclic oxygen-containing ring systems. ${ }^{46-j}$ This reaction can be illustrated by the intramolecular 1,8-hydrogen abstraction between glucopyranose units in disaccharide 139 promoted by alkoxyl radicals and leading to the 1,3,5-trioxocane derivative 140 (Scheme 57). ${ }^{46 \mathrm{~g}}$

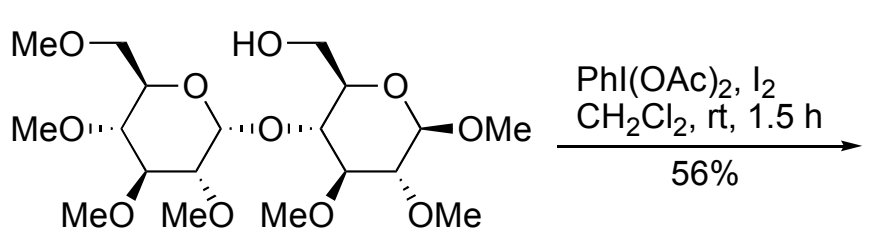

139

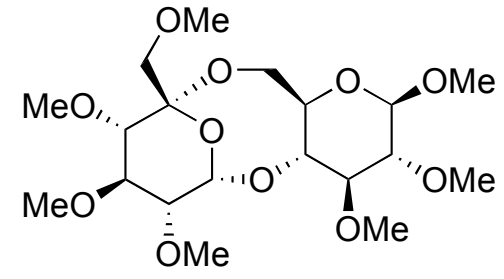

140

\section{Scheme 57}

Boto and Hernandez have reported a short and efficient synthesis of chiral furyl carbinols from carbohydrates, such as $\mathbf{1 4 1}$, based on the alkoxyl radicals fragmentation reaction leading to the intermediate product 142 (Scheme 58). ${ }^{4 \mathrm{a}}$ The same authors have developed an efficient procedure for the selective removal from carbohydrate substrates of methoxy protecting groups next to hydroxy groups by treatment with the DIB-I system. $^{47 \mathrm{~b}}$

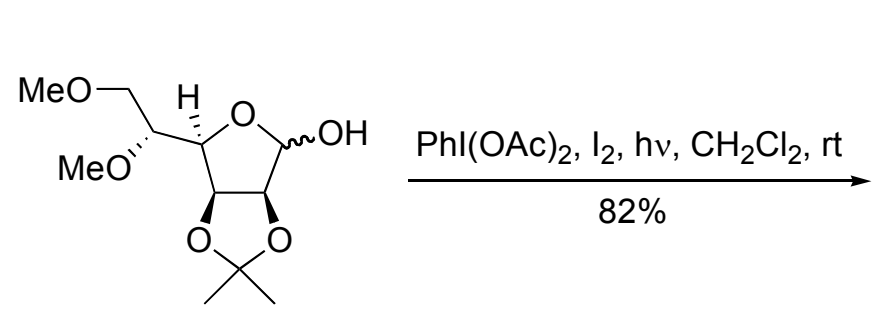

141

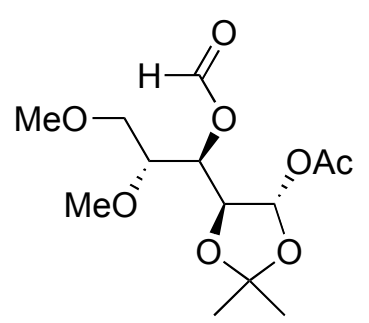

142

\section{Scheme 58}

The one-pot radical fragmentation-phosphorylation reaction of $\alpha$-amino acids or $\beta$-amino alcohols (e.g. 143) affords $\alpha$-amino phosphonates 144 in good yields (Scheme 59). This reaction was applied to the synthesis of potentially bioactive phosphonates. ${ }^{47 \mathrm{c}}$ 

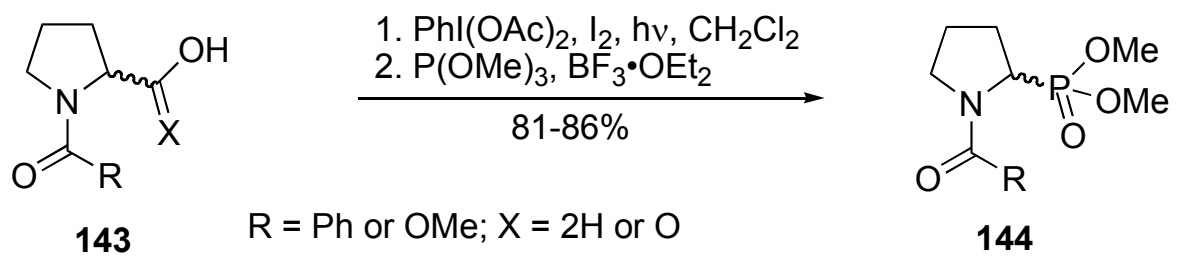

\section{Scheme 59}

Kita and coauthors developed a simple and reliable method for the direct construction of biologically important aryl lactones 146 from carboxylic acids 145 using a combination of DIB with $\mathrm{KBr}$ (Scheme 60). The mechanism of this reaction includes the initial generation of the carbonyloxy radical followed by the intramolecular benzylic hydrogen abstraction and cyclization. $^{48 \mathrm{a}}$
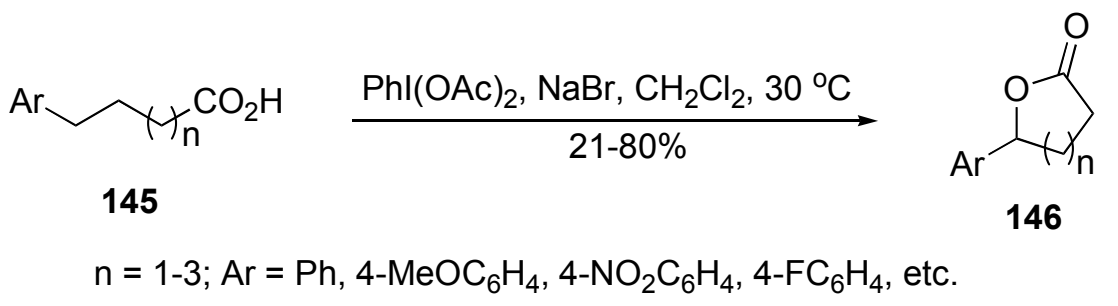

\section{Scheme 60}

The alkoxy radical fragmentation with DIB in the presence of iodine was also used in a facile synthesis of $(n+3)$ and $(n+4)$ ring-enlarged lactones as well as of spiroketolactones from $n$ membered cycloalkanones. ${ }^{48 \mathrm{~b}}$

Useful synthetic methodologies are based on the cyclization or rearrangement of the nitrogen-centered radicals generated in the reaction of the appropriate amides with DIB in the presence of iodine. ${ }^{1 c, 49}$ Specific examples are illustrated by the synthesis of bicyclic spirolactams 148 from amides $147,{ }^{49}$ and the preparation of the oxa-azabicyclic systems (e.g. 150) by the intramolecular hydrogen atom transfer reaction promoted by carbamoyl and phosphoramidyl radicals generated from the appropriately substituted carbohydrates 149 (Scheme 61). ${ }^{49 b}$ 

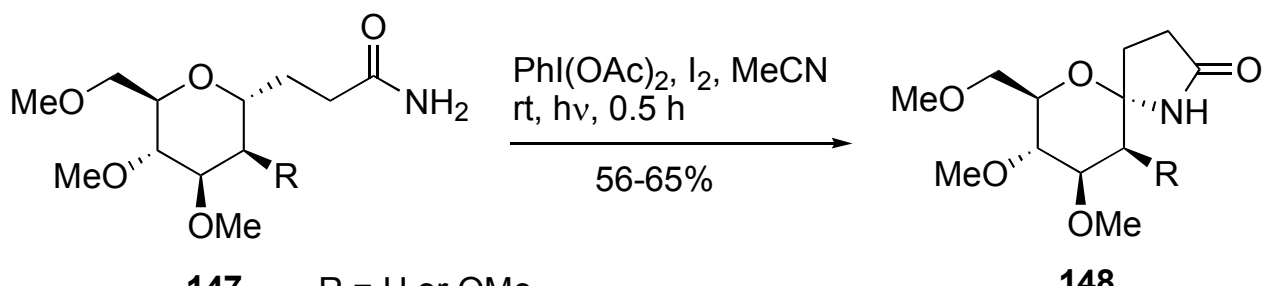

$147 \mathrm{R}=\mathrm{H}$ or $\mathrm{OMe}$

148
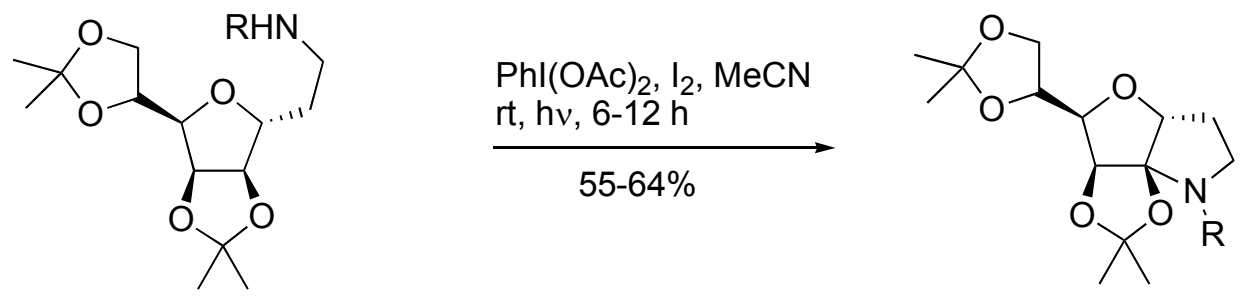

149

$\mathrm{R}=\mathrm{Boc}$ or $\mathrm{PO}(\mathrm{OPh})_{2}$

150

\section{Scheme 61}

\subsection{Thiocyanations, azidations, arylselenations, and aryltellurations}

Various organic substrates, such as enol silyl ethers, ketene silyl acetals, $\beta$-dicarbonyl compounds, alkynes, and para-unsubstituted phenols and naphthols, can be effectively thiocyanated with the combination reagent $\mathrm{PhICl}_{2} / \mathrm{Pb}(\mathrm{SCN})_{2} .{ }^{1 \mathrm{c}}$ Recently, Prakash and coauthors have reported an improved method for the thiocyanation of 2-arylindan-1,3-diones, phenols, and anilines using a reagent combination of (dichloroiodo)benzene and potassium thiocyanate in dry dichloromethane. ${ }^{50 a}$ For example, the para-unsubstituted phenols and anilines $\mathbf{1 5 1}$ are efficiently converted under these reaction conditions to the respective $p$-thiocyanato derivatives $\mathbf{1 5 2}$ in high yields (Scheme 62).<smiles>[R]c1cccc([X])c1[R]</smiles>

151

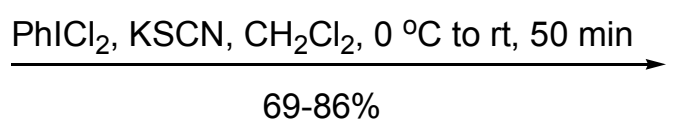

$$
\begin{aligned}
& \mathrm{X}=\mathrm{OH} \text { or } \mathrm{NH}_{2} \\
& \mathrm{R}^{1}=\mathrm{H}, \text { OH or } \mathrm{COOH} \\
& \mathrm{R}^{2}=\mathrm{H} \text { or } \mathrm{OH}
\end{aligned}
$$<smiles>[X]c1ccc([As])c([R])c1[R]</smiles>

152

\section{Scheme 62}


Koser, Telu, and Laali have found that the reaction of polycyclic aromatic hydrocarbons with HTIB in the presence of trimethylsilyl isothiocyanate leads to the regioselective thiocyanation of the PAH nucleus, as illustrated by the reaction of anthracene shown in Scheme $63 .{ }^{50 \mathrm{~b}}$
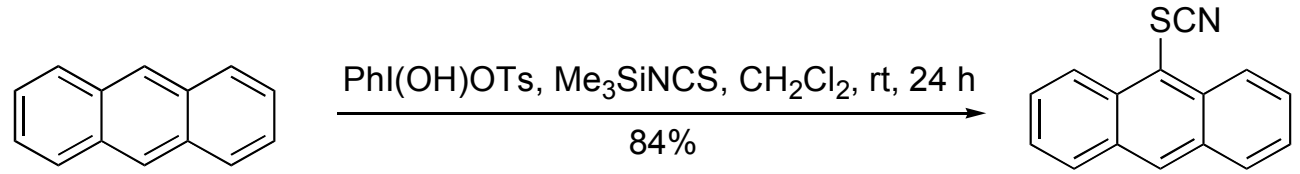

\section{Scheme 63}

The combination of iodosylbenzene or (diacetoxyiodo)benzene with trimethylsilyl azide or sodium azide is commonly used in various azidation reactions. ${ }^{1 \mathrm{c}}$ Recently, Bols and coauthors have found that the $\mathrm{PhI}(\mathrm{OAc})_{2} / \mathrm{TMSN}_{3}$ system is similar in reactivity to $\mathrm{IN}_{3}$ and can promote high-yield azidations of ethers, aldehydes and benzal acetals at $0{ }^{\circ} \mathrm{C}$ to room temperature in acetonitrile. ${ }^{51 \mathrm{a}}$ For example, the azidation of ethers $\mathbf{1 5 3}$ under these conditions leads to benzylic azides 154, while the aldehydes 155 initially afford the unstable acyl azides 156, which are converted to carbamoyl azides $\mathbf{1 5 7}$ via the Curtius rearrangement upon heating with an excess of $\mathrm{TMSN}_{3}$ (Scheme 64). ${ }^{51 \mathrm{a}}$ Very recently, Zhang and coauthors have reported the application of (dichloroiodo)benzene in combination with sodium azide for a similar synthesis of carbamoyl azides from aldehydes. ${ }^{51 \mathrm{~b}}$

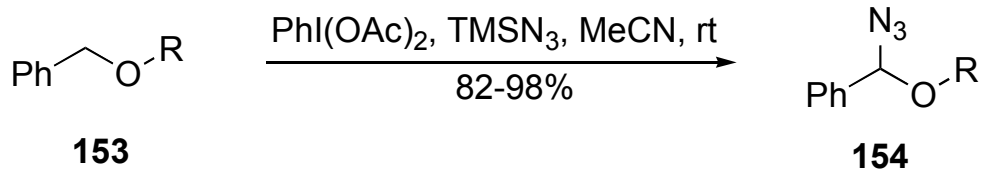

$\mathrm{R}=\mathrm{Me}, \mathrm{CH}_{2} \mathrm{Ph}, \mathrm{CH}_{2} \mathrm{CH}_{2} \mathrm{CH}_{2} \mathrm{OTMS}$, etc.

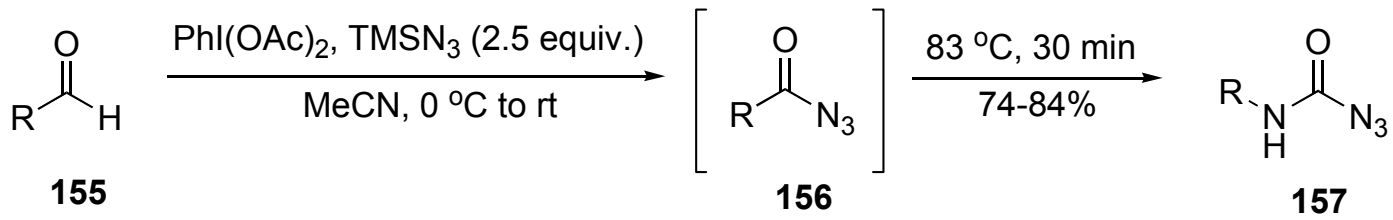

$\mathrm{R}=\mathrm{C}_{6} \mathrm{H}_{13}, \mathrm{PhCH}_{2} \mathrm{CH}_{2}, \mathrm{Ph}, 4-\mathrm{CH}_{3} \mathrm{C}_{6} \mathrm{H}_{4}, 4-\mathrm{MeOC}_{6} \mathrm{H}_{4}$, etc.

\section{Scheme 64}

Austin and coauthors utilized the $\operatorname{PhI}\left(\mathrm{N}_{3}\right)_{2}$ mediated vicinal diazidation of a double bond in the key step of the total synthesis of ( \pm )-dibromophakellstatin. The key syn-diazide 159 was prepared by the treatment of pyrazinone 158 with the $\mathrm{PhI}(\mathrm{OAc})_{2} / \mathrm{TMSN}_{3}$ system followed by the addition of tetraethylammonium iodide (Scheme 65$).{ }^{51 \mathrm{c}}$ 


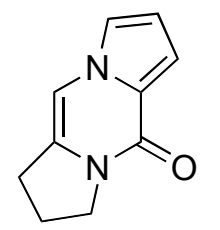

158
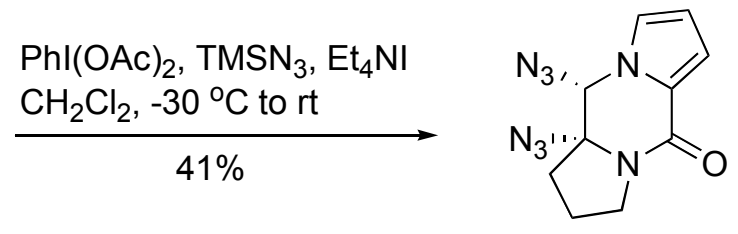

159

\section{Scheme 65}

Ketones can be conveniently converted into $\alpha$-azidoketones in one-step using HTIB and sodium azide. ${ }^{51 \mathrm{~d}, \mathrm{e}}$

In the 1990s, Tingoli and coauthors have found a general approach to various arylselenated products by the reaction of unsaturated compounds with diaryl diselenides and DIB. ${ }^{52 a, b}$ Several further modifications of this reaction have recently been reported. ${ }^{52 \mathrm{c}-\mathrm{g}}$ The reaction of gem-aryldisubstituted methylenecyclopropanes with diphenyl diselenide and DIB produced the corresponding bis-phenylselenated rearranged products in moderate yields under mild conditions. ${ }^{52 \mathrm{c}}$ A multicomponent reaction of allenes 160, diaryl diselenides, DIB, and alcohols or acids affords 3-functionalized-2-arylselenyl substituted allyl derivatives $\mathbf{1 6 1}$ in moderate yields (Scheme 66). ${ }^{52 \mathrm{~d}}$
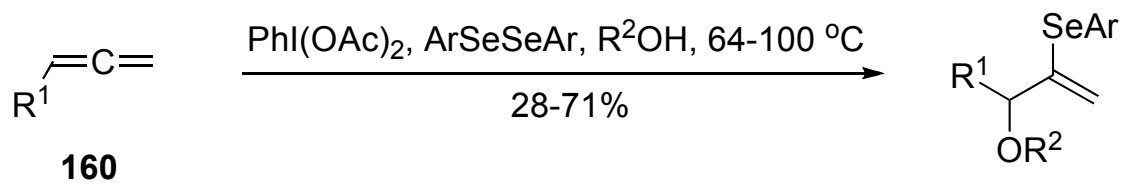

$$
\begin{aligned}
& \mathrm{R}^{1}=\mathrm{Ph}, 4-\mathrm{MeC}_{6} \mathrm{H}_{4}, 2-\mathrm{MeC}_{6} \mathrm{H}_{4}, 2,6-\mathrm{Me}_{2} \mathrm{C}_{6} \mathrm{H}_{3}, \alpha-\mathrm{C}_{10} \mathrm{H}_{7} \\
& \mathrm{Ar}=\mathrm{Ph} \text { or } 4-\mathrm{MeC}_{6} \mathrm{H}_{4} ; \mathrm{R}^{2}=\mathrm{Me}, \mathrm{Et}, \mathrm{Pr}^{\mathrm{i}}, \mathrm{Bu}^{\mathrm{t}}, \mathrm{Ac}, \mathrm{C}_{3} \mathrm{H}_{7} \mathrm{CO}
\end{aligned}
$$

\section{Scheme 66}

Nifantiev and coauthors reported an improved preparative method for homogeneous azidophenylselenylation (APS reaction) of glycals by the reaction with DIB, diphenyldiselenide, and trimethylsilyl azide. ${ }^{52 e, f}$ In a representative example, the reaction of tri- $O$-benzyl-galactal 162 with $\mathrm{DIB} / \mathrm{Ph}_{2} \mathrm{Se}_{2} / \mathrm{TMSN}_{3}$ in dichloromethane under mild conditions affords the corresponding selenoglycoside 163 in moderate yield (Scheme 67 ). ${ }^{52 \mathrm{e}}$ The noncarbohydrate alkenes, such as styrene and substituted cyclopentenes, can also be azidophenylselenated under these conditions. 


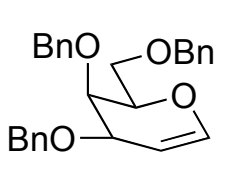

162

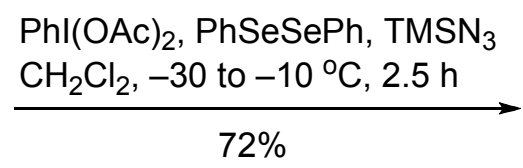

$72 \%$

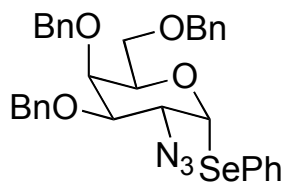

163

\section{Scheme 67}

The selenodecarboxylation of cinnamic acid derivatives 164 with diaryldiselenides promoted by DIB in acetonitrile affords vinyl selenides 165 in moderate yields (Scheme 68). ${ }^{52 \mathrm{~g}}$ A similar reaction of arylpropiolic acids gives respective alkynyl selenides in 60-90\% yields.<smiles>O=C(O)C=C[Br+]</smiles>

164

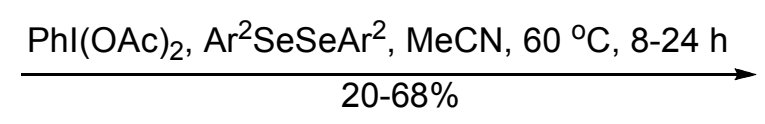

$\mathrm{Ar}^{1}=3,4-\left(\mathrm{OCH}_{2} \mathrm{O}\right) \mathrm{C}_{6} \mathrm{H}_{3}, 4-\mathrm{MeOC}_{6} \mathrm{H}_{4}, 3,4,5-(\mathrm{MeO})_{3} \mathrm{C}_{6} \mathrm{H}_{2}$

$\mathrm{Ar}^{2}=\mathrm{Ph}$ or $4-\mathrm{MeC}_{6} \mathrm{H}_{4}$

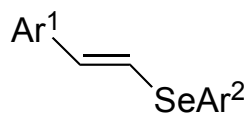

165

\section{Scheme 68}

The interaction of the $\mathrm{PhI}(\mathrm{OAc})_{2} / \mathrm{NaN}_{3}$ system with organic ditellurides can be used for the generation of the organotellurenyl radicals. This reaction has been utilized in the synthesis of organyltellurophosphates 168 by the treatment of diorganyl phosphites 167 and diorganyl ditellurides 166 with DIB and sodium azide in dichloromethane at room temperature (Scheme $102)^{52 \mathrm{~h}}$

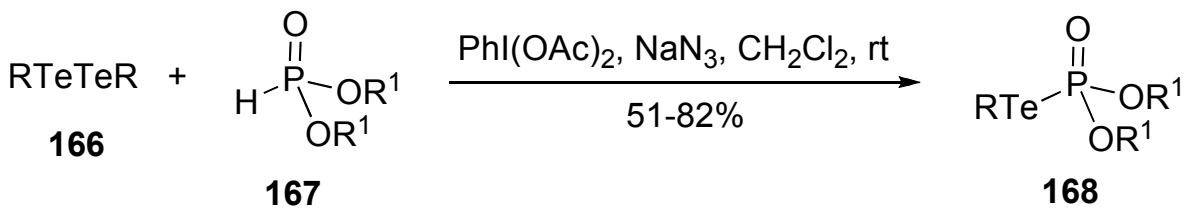

$$
\mathrm{R}=\mathrm{Ph}, \mathrm{Bu}, 4-\mathrm{ClC}_{6} \mathrm{H}_{4}, \alpha-\mathrm{C}_{10} \mathrm{H}_{7} ; \mathrm{R}^{1}=\mathrm{Me}, \mathrm{Et}, \mathrm{Pr}, \mathrm{Pr}^{\mathrm{i}}, \mathrm{Bu}, \mathrm{Ph}
$$

\section{Scheme 69}

\subsection{Transition metal catalyzed reactions}

Various oxidative transformations involving hypervalent iodine(III) reagents can be effectively catalyzed by transition metal salts and complexes. ${ }^{1 \mathrm{c}}$ Iodosylbenzene is widely used as the most efficient terminal oxidant - source of oxygen in biomimetic oxidations catalyzed by 
metalloporphyrins and other transition metal derivatives. Numerous older publications on the use of iodosylbenzene in transition metal catalyzed oxidations have been summarized in several books and reviews. ${ }^{53}$ Recent examples of transition metal catalyzed oxidations employing iodosylbenzene include the hydroxylation of hydrocarbons,${ }^{54}$ the transition metal-mediated epoxidation of alkenes, ${ }^{27,55}$ oxidation of alcohols to carbonyl compounds,${ }^{56} \delta$-sultone formation through Rh-catalyzed C-H insertion, ${ }^{57 \mathrm{a}}$ and oxidation of organic sulfides to sulfoxides. ${ }^{57 b, \mathrm{c}}$

[Bis(acyloxy)iodo]arenes are also commonly used as stoichiometric oxidants in the reactions catalyzed by transition metal salts and complexes. DIB is occasionally employed instead of iodosylbenzene as the terminal oxidant in biomimetic oxygenations catalyzed by metalloporphyrins and other transition metal complexes. ${ }^{58}$ Primary and secondary alcohols can be selectively oxidized to the corresponding carbonyl compounds by DIB in the presence of transition metal catalysts, such as $\mathrm{RuCl}_{3}{ }^{59}$ polymer-micelle incarcerated ruthenium catalysts, ${ }^{60 \mathrm{a}}$ chiral-Mn(salen)-complexes, ${ }^{60 b, c} \mathrm{Mn}(\mathrm{TPP}) \mathrm{CN} / \mathrm{Im}$ catalytic system, ${ }^{60 \mathrm{~d}}$ and (salen)Cr(III) complexes. ${ }^{60 \mathrm{e}}$ The epoxidation of alkenes, such as stilbenes, indene and 1-methylcyclohexene, using DIB in the presence of chiral binaphthyl ruthenium(III) catalysts (5 mol\%) has also been reported. The chemoselectivity and enantioselectivity of this reaction was found to be low (4\% ee). ${ }^{60 \mathrm{f}}$

The mechanisms and applications of palladium-catalyzed reactions of DIB and other hypervalent iodine reagents in synthetically useful organic transformations were recently reviewed by Deprez and Sanford. ${ }^{61 a}$ Particularly useful are the Pd-catalyzed oxidation reactions, including the oxidative functionalization of $\mathrm{C}-\mathrm{H}$ bonds and the 1,2-aminooxygenation of olefinic substrates. ${ }^{61}$ Representative examples of these catalytic oxidations are illustrated by the selective acetoxylation of $\mathrm{C}-\mathrm{H}$ bonds adjacent to coordinating functional groups (e.g., pyridine in substrate 169), ${ }^{6 \mathrm{~b}}$ and by the $\mathrm{Pd}(\mathrm{OAc})_{2}$-catalyzed intramolecular aminoacetoxylation in the reaction of $\gamma$ aminoolefins (e.g., cinnamyl alcohol derived tosyl carbamate 170) with DIB (Scheme 70). ${ }^{61 \mathrm{c}}$ The key mechanistic step in these catalytic transformations includes the DIB promoted oxidation of $\mathrm{Pd}(\mathrm{II})$ to the $\mathrm{Pd}(\mathrm{IV})$ species, as proved by the isolation and X-ray structural identification of stable $\mathrm{Pd}(\mathrm{IV})$ complexes prepared by the reaction of $\mathrm{PhI}\left(\mathrm{O}_{2} \mathrm{CPh}\right)_{2}$ with $\mathrm{Pd}(\mathrm{II})$ complexes containing chelating 2-phenylpyridine ligands. ${ }^{61 \mathrm{~m}}$ Several examples of Pd-catalyzed chlorinations of organic substrates using (dichloroiodo)benzene have also been reported. ${ }^{61 \mathrm{n}, \mathrm{o}}$ 
<smiles>c1ccc(-c2ccccn2)cc1</smiles>

169

$$
\begin{aligned}
& \mathrm{Phl}(\mathrm{OAc})_{2}(1.1-1.6 \text { equiv. }), \mathrm{Pd}(\mathrm{OAc})_{2}(1-6 \mathrm{~mol} \%) \\
& \mathrm{MeCN}, 75-100^{\circ} \mathrm{C}, 12-20 \mathrm{~h}
\end{aligned}
$$

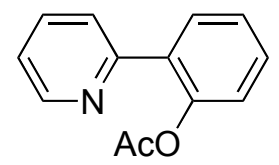<smiles>CC(=O)O[C@@H](c1ccccc1)[C@@H]1COC(=O)N1[Te]</smiles>

9.5:1 dr

\section{Scheme 70}

Yan and coauthors have developed an efficient procedure for synthesis of symmetrical conjugated diynes 172 from terminal alkynes 171 using DIB as oxidant under palladiumcatalyzed conditions (Scheme 71). ${ }^{62 a, b}$ A similar coupling of terminal alkynes can occur in the absence of palladium catalysts as well. ${ }^{62 \mathrm{c}}$

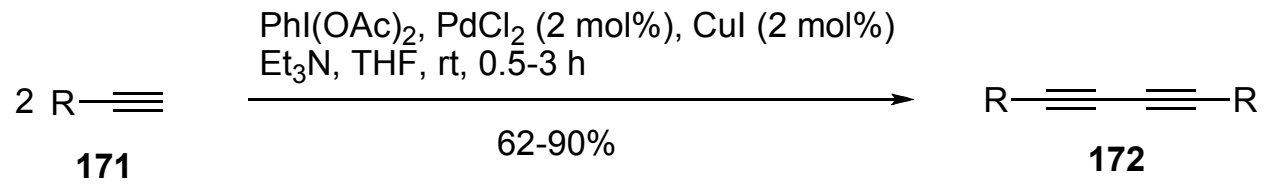

\section{Scheme 71}

\section{Hypervalent Iodine Compounds as Catalysts and Reusable Reagents}

\subsection{Catalytic utilization of hypervalent iodine reagents}

The catalytic utilization of hypervalent iodine reagents is one of the most impressive recent developments in the field of organoiodine chemistry. ${ }^{11,63}$ The first examples of a catalytic application of the iodine $(\mathrm{V})$ species in the oxidation of alcohols using oxone as a stoichiometric oxidant were independently reported by the groups of $\operatorname{Vinod}^{64 a}$ in 2005 and Giannis ${ }^{64 b}$ in 2006. Very recently, Ishihara and coauthors have optimized the procedure for the catalytic oxidation of alcohols by using 2-iodobenzenesulfonic acid as an extremely active catalyst and oxone as terminal oxidant. ${ }^{64 \mathrm{c}}$ 
Numerous examples of catalytic utilization of the iodine(III) species have been reported by several other groups in the last 2-3 years. The catalytic applications of hypervalent iodine have recently been overviewed by Richardson and Wirth ${ }^{63 \mathrm{a}}$ and by Ochiai. ${ }^{11,63 \mathrm{~b}}$

Ochiai and coauthors have reported a catalytic variant of $\alpha$-acetoxylation of ketones based on the in situ generation of DIB from iodobenzene using $m$-chloroperbenzoic acid ( $m$ CPBA) as a terminal oxidant. ${ }^{65}$ In a typical example, the oxidation of a ketone with $m$ CPBA ( 2 equiv.) in acetic acid in the presence of a catalytic amount of $\mathrm{PhI}\left(0.1\right.$ equiv.), $\mathrm{BF}_{3} \cdot \mathrm{OEt}_{2}$ ( 3 equiv.) and water ( 5 equiv.) at room temperature under argon affords the respective $\alpha$-acetoxy ketone in 63 $84 \%$ isolated yield (Scheme 72 ). $p$-Methyl- and $p$-chloroiodobenzene can also serve as efficient catalysts in the $\alpha$-acetoxylation of ketones using $m$ CPBA as a terminal oxidant. ${ }^{65 a}$

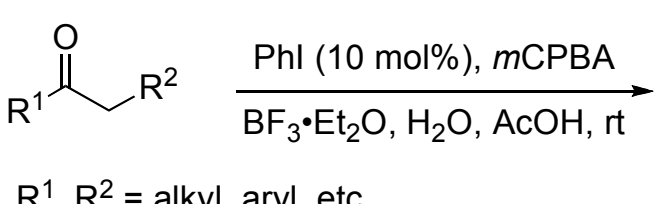<smiles>[R]C(=O)C([R])OC(C)=O</smiles>

$$
\mathrm{R}^{1}, \mathrm{R}^{2}=\text { alkyl, aryl, etc. }
$$

\section{Scheme 72}

A similar procedure for the catalytic $\alpha$-oxytosylation of ketones employs $m$ CPBA as stoichiometric oxidant and iodoarenes as catalysts in the presence of $p$-toluenesulfonic acid. ${ }^{65 \mathrm{~b}-\mathrm{e}}$ Kita and coauthors have reported a catalytic variant of the oxidative spirocyclization reaction based on the in situ regeneration of a [bis(trifluoroacetoxy)iodo]arene from iodoarene using $m$ CPBA as a terminal oxidant. ${ }^{66 a}$ In a typical example, the oxidation of the phenolic substrate 173 with $m$ CPBA in dichloromethane in the presence of a catalytic amount of $p$ [bis(trifluoroacetoxy)iodo]toluene (0.01 equiv.) and trifluoroacetic acid at room temperature affords the respective spirolactone 174 in good yield (Scheme 73). A variety of other [bis(trifluoroacetoxy)iodo]arenes can be used as catalysts in this reaction [e.g. BTI, 4$\mathrm{MeOC}_{6} \mathrm{H}_{4} \mathrm{I}\left(\mathrm{OCOCF}_{3}\right)_{2}$ and 2,4- $\left.\mathrm{F}_{2} \mathrm{C}_{6} \mathrm{H}_{3} \mathrm{I}\left(\mathrm{OCOCF}_{3}\right)_{2}\right]$ and different acidic additives (acetic acid, $\mathrm{BF}_{3} \bullet \mathrm{OEt}_{2}$, TMSOTf, molecular sieves), but the TolI $\left(\mathrm{OCOCF}_{3}\right)_{2} / \mathrm{CF}_{3} \mathrm{CO}_{2} \mathrm{H}$ system generally provides the best catalytic efficiency. Under these optimized conditions, a variety of phenolic substrates 175 was oxidized to spirolactones $\mathbf{1 7 6}$ in the presence of catalytic amounts of $p$ iodotoluene (Scheme 73). ${ }^{66 a}$ Likewise, the amide derivatives of phenolic substrates $\mathbf{1 7 5}$ can be catalytically oxidized to the respective $N$-fused spirolactams using catalytic amounts of $p$ iodotoluene and $m \mathrm{CPBA}$ as a terminal oxidant. ${ }^{66 \mathrm{~b}} \mathrm{~A}$ similar catalytic procedure has been reported for the oxidation of 4-alkoxyphenols to the corresponding 1,4-quinones using a catalytic amount of 4-iodophenoxyacetate in the presence of oxone as a co-oxidant in an aqueous acetonitrile solution. ${ }^{66 \mathrm{c}}$ 


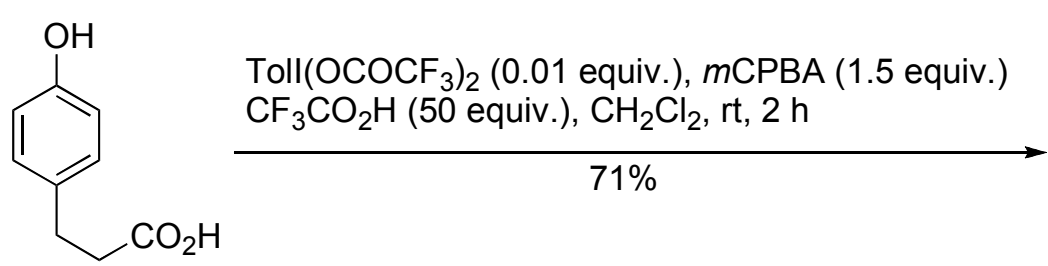<smiles>O=C1C=CC2(C=C1)CCC(=O)O2</smiles>

174<smiles>[R]C1=CC2(C=C([R])C1=O)OC(=O)C([R])C2[R]</smiles>

176

\section{Scheme 73}

A catalytic version of the intermolecular oxidative coupling of phenolic ethers using BTI ( 0.125 equivalents) as a catalyst and $m \mathrm{CPBA}$ as the stoichiometric oxidant has also been reported. ${ }^{66}$ Very recently, Kita and coauthors have developed a new $\mathrm{H}_{2} \mathrm{O}_{2}$ /acid anhydride system for the iodoarene-catalyzed intramolecular C-C cyclization of phenolic derivatives; a representative example of this catalytic cyclization is shown in Scheme $74 .^{66 \mathrm{~d}}$
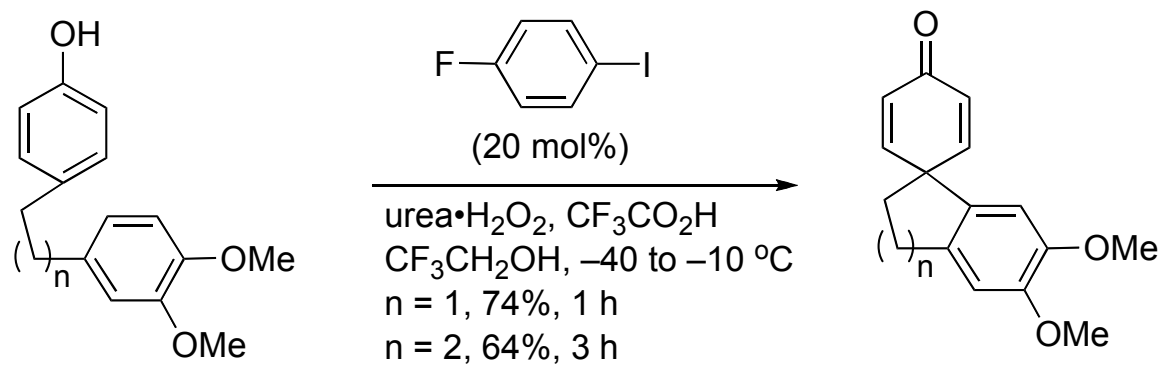

\section{Scheme 74}

Liu and Tan have developed a catalytic procedure for the DIB-promoted oxidative iodolactonization of pentenoic, pentynoic, and hexynoic acids in the presence of tetrabutylammonium iodide. $^{66 \mathrm{e}}$ In this procedure, DIB is generated in situ using a catalytic amount of iodobenzene with sodium perborate monohydrate as the stoichiometric oxidant. A variety of unsaturated acids including $\delta$-pentenoic acids 177, $\delta$-pentynoic acids and $\delta$-hexynoic acid gave high yields of the respective lactones (e.g. 178) using this organocatalytic methodology (Scheme 75). ${ }^{66 \mathrm{e}}$ 

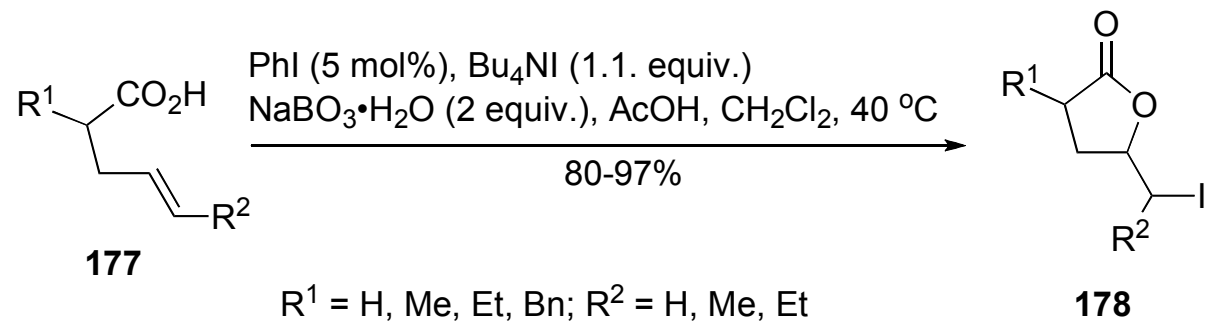

178

\section{Scheme 75}

Togo and Moroda have reported a DIB-mediated cyclization reaction of 2-aryl- $\mathrm{N}$ methoxyethanesulfonamides using iodobenzene as a catalyst $(5-10 \mathrm{~mol} \%)$ and $\mathrm{m}$ chloroperoxybenzoic acid as the stoichiometric oxidant. ${ }^{66 \mathrm{f}}$ Very recently, Ochiai and coauthors have reported an efficient iodomesitylene-catalyzed oxidative cleavage of alkenes and alkynes using $m$ CPBA as a terminal oxidant. ${ }^{66 g}$

\subsection{Polymer-supported and recyclable hypervalent iodine reagents}

The preparation and applications of polymer-supported hypervalent iodine reagents, bearing (diacetoxy)iodo, (dihalo)iodo, [hydroxy(tosyloxy)iodo], [hydroxy(phosphoryloxy)iodo], aryliodonium, 1,2-benziodoxol-3-one, and hypervalent iodine groups as counter anions, was reviewed by Togo and Sakuratani in 2002. ${ }^{1 \mathrm{~g}}$ More recently, in 2008, the polymer-supported and reusable monomeric hypervalent iodine reagents were overviewed by Ochiai and Miyamoto. ${ }^{11}$ These efficient and environmentally benign reagents can be used for various oxidative functional group conversions of substrates and can be recovered quantitatively by simple filtration, and then regenerated and reused. Recent representative examples of synthetic applications of the polystyrene-supported DIB and BTI are discussed in this section.

Polymer-supported [bis(acyloxy)iodo]arenes have been used for the oxidation of alcohols catalyzed by TEMPO ${ }^{67 a, b}$ or in the presence of $\mathrm{KBr}^{67 \mathrm{c}}$ In a specific example, primary alcohols $\mathbf{1 7 9}$ are readily oxidized to methyl esters $\mathbf{1 8 0}$ upon treatment with polystyrene-supported DIB in the presence of $\mathrm{KBr}$ in the acidic aqueous methanol solution (Scheme 76). ${ }^{67 \mathrm{c}}$ Likewise, organic sulfides are selectively oxidized to the respective sulfoxides by DIB or the polymer-supported DIB in water in the presence of $\mathrm{KBr}^{67 \mathrm{~d}}$

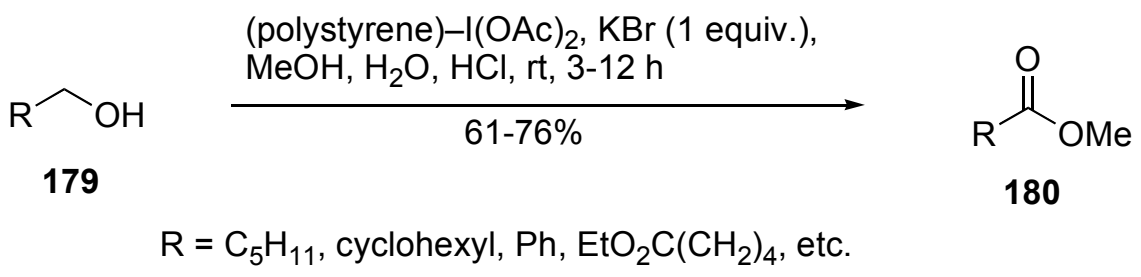

\section{Scheme 76}


Various vicinal diols 181 (13 examples) can be oxidized to aldehydes 182 using polymersupported DIB (Scheme 77). ${ }^{14 \mathrm{~b}}$ Protecting groups such as OAc, OR, OBn, OBz, and isopropylidene in the substrates are stable under these reaction conditions. cis-1,2Cyclohexandiol is converted to 1,6 -hexandial in this reaction. ${ }^{14 \mathrm{~b}}$

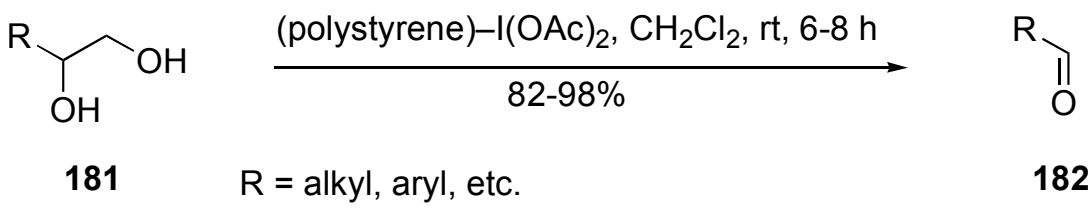

\section{Scheme 77}

The treatment of 1-alkynylcycloalkanols 183 with poly[styrene(iodosodiacetate)] and iodine affords (Z)-2-(1-iodo-1-organyl)methylenecycloalkanones 184 resulting, probably, from the alkoxyl radical promoted ring expansion reaction (Scheme 78$).{ }^{67 \mathrm{e}}$

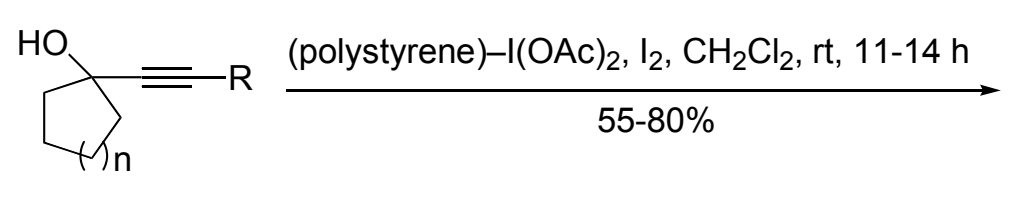

183

$\mathrm{n}=1 ; \mathrm{R}=\mathrm{Ph}, \mathrm{Bu}, \mathrm{TolOCH}_{2}$

$\mathrm{n}=2 ; \mathrm{R}=\mathrm{Ph}, \mathrm{PhCH}_{2} \mathrm{OCH}_{2}, \mathrm{TolOCH}_{2}$

$\mathrm{n}=3 ; \mathrm{R}=\mathrm{Ph}, \mathrm{Bu}, \mathrm{TolOCH}_{2}, \mathrm{PhCH}_{2} \mathrm{OCH}_{2}$<smiles>[R]C(I)=C1CCCCC1=O</smiles>

184

\section{Scheme 78}

Polymer-supported [bis(acyloxy)iodo]arenes have also been utilized in the synthesis of heterocycles. Representative examples include the preparation of thiazolo[2,3-c]-s-triazoles by the reaction of arenecarbaldehyde-4-arylthiazol-2-ylhydrazones with poly[(4diacetoxyiodo)styrene], ${ }^{67 f}$ the synthesis of 1-benzoyltetrahydroisoquinoline derivatives using polymer-supported BTI. ${ }^{67 \mathrm{~g}}$

The polymer-supported HTIB can be used in the same oxidative transformations as the monomeric HTIB. ${ }^{68}$ In particular, it can serve as excellent oxidant in the Hofmann-type degradation of carboxamides to the respective amines. In a recent example, primary alkyl- and benzylcarboxamides were converted to the corresponding alkylammonium tosylates with poly[4hydroxy(tosyloxy)iodo]styrene in acetonitrile at reflux in yields ranging from $60 \%$ to $90 \%{ }^{68 \text { a }}$ The polymer-supported HTIB has been employed in direct $\alpha$-hydroxylation of ketones ${ }^{68 \mathrm{~b}, \mathrm{c}}$ and in the synthesis of isoflavones from 2'-benzoyloxychalcones. ${ }^{68 \mathrm{~d}}$

Poly[4-(hydroxy)(tosyloxy)iodo]styrene can be used in the halotosyloxylation reaction of alkynes with iodine or $N$-bromosuccinimide (NBS) or $N$-chlorosuccinimide (NCS) (Scheme 79). ${ }^{68 \mathrm{e}}$ The polymeric reagent can be regenerated and reused. 


$$
\begin{aligned}
& \mathrm{R}^{1}=\mathrm{R}^{2} \frac{\text { (polystyrene)-I(OH)OTs, } \mathrm{I}_{2} \text { or NBS or NCS, } \mathrm{CH}_{2} \mathrm{Cl}_{2}, \mathrm{rt}}{60-97 \%} \\
& \mathrm{R}^{1}=\mathrm{Ph}, \mathrm{Bu}, \mathrm{Bu}^{\mathrm{t}}, \mathrm{CH}_{3} \mathrm{OCH}_{2}, \mathrm{H} \\
& \mathrm{R}^{2}=\mathrm{H}, \mathrm{Ph}, 4-\mathrm{MeC}_{6} \mathrm{H}_{4} \mathrm{C}(\mathrm{O}), 4-\mathrm{ClC}_{6} \mathrm{H}_{4} \mathrm{C}(\mathrm{O}), \mathrm{Ts}, \mathrm{P}(\mathrm{O}) \mathrm{Ph}_{2}, \mathrm{CO}_{2} \mathrm{Me}, \mathrm{TMS} \\
& \mathrm{X}=\mathrm{I}, \mathrm{Br}, \mathrm{Cl}
\end{aligned}
$$

\section{Scheme 79}

The polymer-supported hypervalent reagents are very useful for oxidative transformations of various functionalities; however, they have some serious disadvantages compared to the monomeric reagents. In particular, the polymeric reagents often have lower reactivities than the corresponding monomeric analogues and, moreover, the repeated use of these polymers leads to significant degradation due to the benzylic oxidation of the polystyrene chain. ${ }^{11}$ The alternative monomeric reusable reagents, that have been developed in the last 4-5 years, are free of these limitations. Several examples of these reagents are discussed below.

The ionic liquid-supported (diacetoxyiodo)arenes 11, 12 (see Section 3.5) ${ }^{14 \mathrm{~d}}$ and the similar [hydroxy(tosyloxy)iodo]arenes $\mathbf{1 8 5}^{14 \mathrm{e}}$ are thermally stable hypervalent iodine(III) reagents that allow easy recovery and recycling of the reduced aryl iodides either by extraction into an ionic liquid phase or by simple filtration, with subsequent reoxidation. Various primary and secondary alcohols can be oxidized to aldehydes and ketones with the ion-supported [bis(acyloxy)iodo]arene 12 (1.4 equivalents) in the ionic liquid [emim] $]^{+}\left[\mathrm{BF}_{4}\right]^{-}$(1-ethyl-3methylimidazolium tetrafluoroborate) in the presence of bromide anion without overoxidation to carboxylic acids. ${ }^{14 \mathrm{~d}}$ Likewise, the $\alpha$-tosyloxylation of ketones with the ion-supported Koser's reagent 185 proceeds smoothly in $\mathrm{MeCN}$ even at $0{ }^{\circ} \mathrm{C}$ (Scheme 80). ${ }^{14 \mathrm{e}}$ The reactions are faster than those with Koser's reagent itself, probably due to the presence of the electron-withdrawing ester group on the benzene ring.

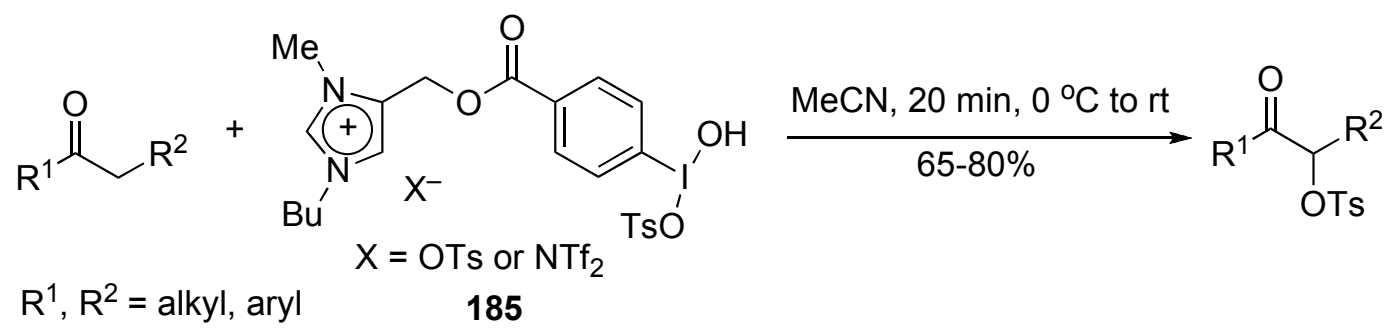

\section{Scheme 80}

Recently, Tesevic and Gladysz have demonstrated the utility of [bis(trifluoroacetoxy)iodo]perfluoroalkanes 187 with a long fluorous alkyl chain $(\mathrm{n}=7-12)$ as convenient recyclable oxidants. ${ }^{69 a, b}$ Similarly to BTI [bis(trifluoroacetoxy)iodo]perfluoroalkanes 
187 can serve as excellent reagents for the oxidation of phenolic substrates. The reduced form of the reagent, the respective iodoperfluoroalkane, can be efficiently separated from the reaction mixture using fluorous techniques and reused. In a specific example, reagents $\mathbf{1 8 7}(\mathrm{n}=8,10,12)$ can rapidly oxidize 1,4-hydroquinones 186 to the respective quinones 188 in methanol at room temperature (Scheme 81). Subsequent addition of a fluorous solvent, such as perfluoro(methylcyclohexane), results in a liquid/liquid biphase system. The product quinones 188 are generally isolated in about $95 \%$ yields from the methanol phase, and iodoperfluoroalkanes 189 are isolated in $98-99 \%$ yields from the fluorous phase. The recovered iodoperfluoroalkanes 189 may be reoxidized to the initial reagents 187 in $97 \%$ yield and reused. ${ }^{69}$
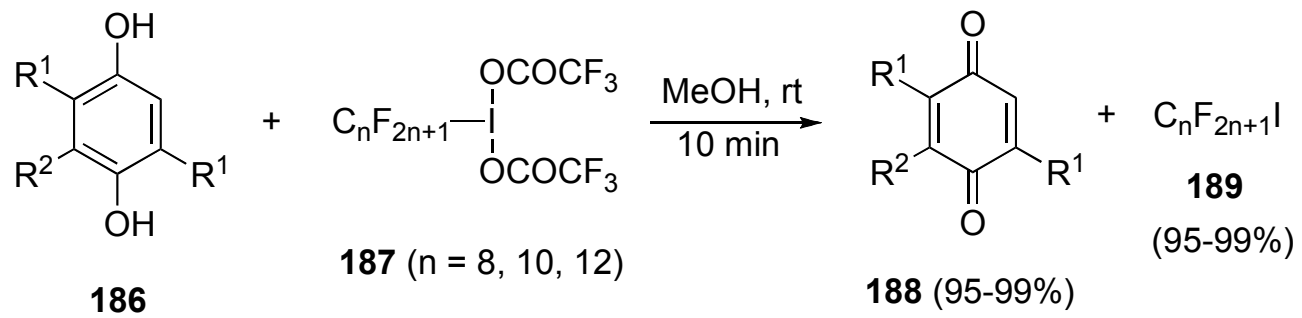

$\mathrm{R}^{1} / \mathrm{R}^{2}=\mathrm{H} / \mathrm{H}, \mathrm{Me} / \mathrm{Me}, \mathrm{Bu}^{\mathrm{t}} / \mathrm{H}, \mathrm{Cl} / \mathrm{H}$

\section{Scheme 81}

[Bis(trifluoroacetoxy)iodo]perfluoroalkanes $187(\mathrm{n}=7,8,10,12)$ are effective and easily recyclable reagents for the oxidation of aliphatic and benzylic secondary alcohols 190 to ketones 191 in the presence of aqueous $\mathrm{KBr}$ and the absence of organic or fluorous solvents (Scheme 82). ${ }^{69 \mathrm{~b}}$ The reduced form of the reagent, the respective iodoperfluoroalkane 189, can be efficiently isolated from the reaction mixture in 96-98\% yield by adding 3-5 volumes of methanol and separating the resulting fluorous/methanolic liquid/liquid biphase system. The recovered iodoperfluoroalkane 189 can be reoxidized to reagent 187 and reused. ${ }^{6 \mathrm{~b}}$

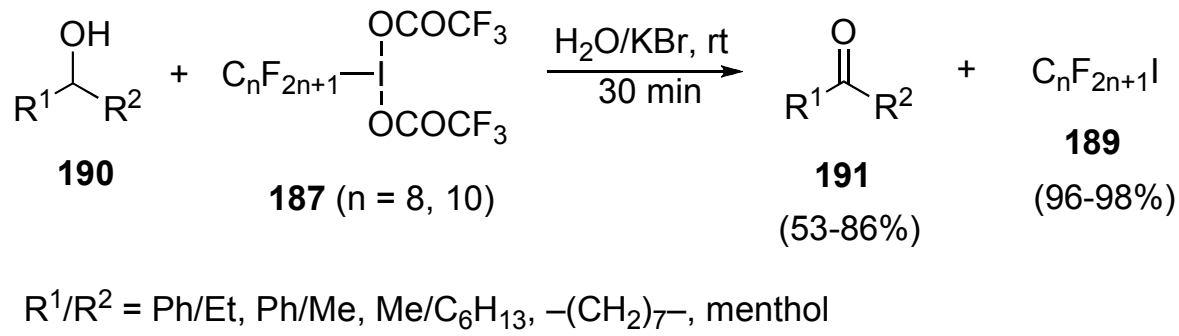

\section{Scheme 82}

It is noteworthy that the fluorous reagents 187 (Scheme 82) oxidize secondary alcohols in the presence of bromide ions much more rapidly than other iodine(III) compounds (e.g., 
iodosylbenzene or DIB) under similar conditions. The higher reactivity may in part be ascribed to the directly bound electron-withdrawing perfluoroalkyl substituent in compounds $\mathbf{1 8 7}$, which enhance its oxidizing strength. ${ }^{69 \mathrm{~b}}$

Westwell and coauthors investigated the oxidation of hydroxylated stilbenes 192 using [bis(trifluoroacetoxy)iodo]perfluorohexane (Scheme 83). ${ }^{69 \mathrm{c}}$ Instead of the expected products of the phenolic oxidation, diaryl-1,2-dimethoxyethanes 193 as mixtures of diastereoisomers were isolated in moderate yields from this reaction. The perfluorohexyl iodide by-product (bp $140{ }^{\circ} \mathrm{C}$ ) could be recovered simply by distillation of the reaction mixture under reduced pressure. ${ }^{69 \mathrm{c}}$

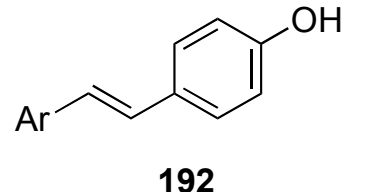

$\mathrm{Ar}=\mathrm{Ph}, 3-\mathrm{MeOC}_{6} \mathrm{H}_{4}, 3-\mathrm{FC}_{6} \mathrm{H}_{4}, 4-\mathrm{FC}_{6} \mathrm{H}_{4}$

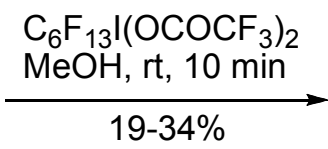<smiles>COC(Br)C(Br)c1ccc(O)cc1</smiles>

193

\section{Scheme 83}

Gladysz and Rocaboy have reported the application of fluorous (diacetoxyiodo)arenes in oxidations of hydroquinones to quinones; in this procedure the fluorous reagents can be conveniently recovered by simple liquid/liquid biphase workups. ${ }^{69 \mathrm{~d}}$

In the last few years, much effort has been devoted to the development of simple, nonpolymeric, recyclable iodanes, which show reactivities similar to those of the original hypervalent iodine(III) reagents. Examples of the recyclable analogs of the Koser's reagent are represented by structures 20-24 (see Section 3.5); recyclable $\mathrm{ArICl}_{2}$ are represented by 4,4'bis(dichloroiodo)biphenyl 39 and 3-(dichloroiodo)benzoic acid (see Sections 3.2 and 4.2), and the structures of recyclable [bis(acyloxy)iodo] arenes $\mathbf{1 9 4},{ }^{17 \mathrm{e}} \mathbf{1 9 5},{ }^{17 \mathrm{f}} \mathbf{1 9 6},{ }^{5 \mathrm{~d}} \mathbf{1 9 7},{ }^{59 \mathrm{a}}$ and $\mathbf{1 9 8} \mathbf{8}^{70}$ are shown in Scheme 84. 

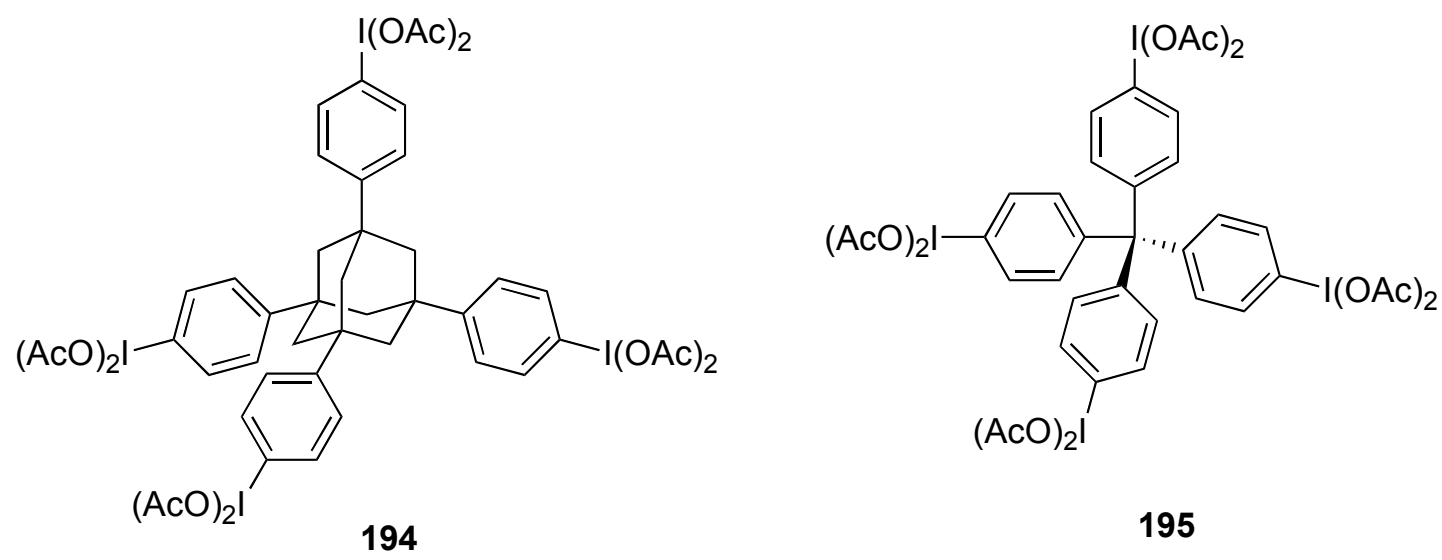

194

195<smiles>CC(C)(C)OC(=O)c1cccc(C(=O)O)c1</smiles>

196<smiles>O=C(O)c1cccc(O)c1</smiles>

197<smiles>CC(C)(C)COC(=O)c1ccc(OC(C)(C)C)cc1</smiles>

198

\section{Scheme 84}

A convenient recyclable reagent, $m$-iodosylbenzoic acid 197, selectively oxidizes primary and secondary alcohols to the respective carbonyl compounds in the presence of $\mathrm{RuCl}_{3}(0.5$ mol\%) at room temperature in aqueous acetonitrile. ${ }^{59 a}$ Separation of pure products in this case is achieved by simple extraction of the basic aqueous solution, and the reduced form of the reagent, $m$-iodobenzoic acid, can be easily recovered from the aqueous solution by simple acidification. Kirschning and coauthors have recently reported the use of the recyclable reagent 198, phenylsulfonate-tagged DIB, in a similar $\mathrm{RuCl}_{3}$-catalyzed oxidation of alcohols. ${ }^{70 a}$

The recyclable [bis(acyloxy)iodo]arenes 194 and 195 can be used instead of DIB in the $\mathrm{KBr}$ or TEMPO catalyzed oxidations of alcohols. ${ }^{17 e, f} 3$-[Bis(trifluoroacetoxy)iodo]benzoic acid 196, can oxidize organic sulfides to the respective sulfoxides at room temperature in aqueous acetonitrile. $^{5 \mathrm{~d}}$ [Bis(trifluoroacetoxy)iodo]benzoic acid 198, can be used as the oxidant in oxidative iodination reactions. ${ }^{5 \mathrm{~d}, 70 \mathrm{~b}}$

The recyclable analogs of the Koser's reagent $\mathbf{2 0}^{5 \mathrm{~d}}$ and $\mathbf{2 1}{ }^{17 \mathrm{e}}$ (see Section 3.5) can serve as excellent oxidants in Hofmann-type degradation of carboxamides to the respective amines (Scheme 85). ${ }^{5 \mathrm{~d}, 17 \mathrm{e}}$ 


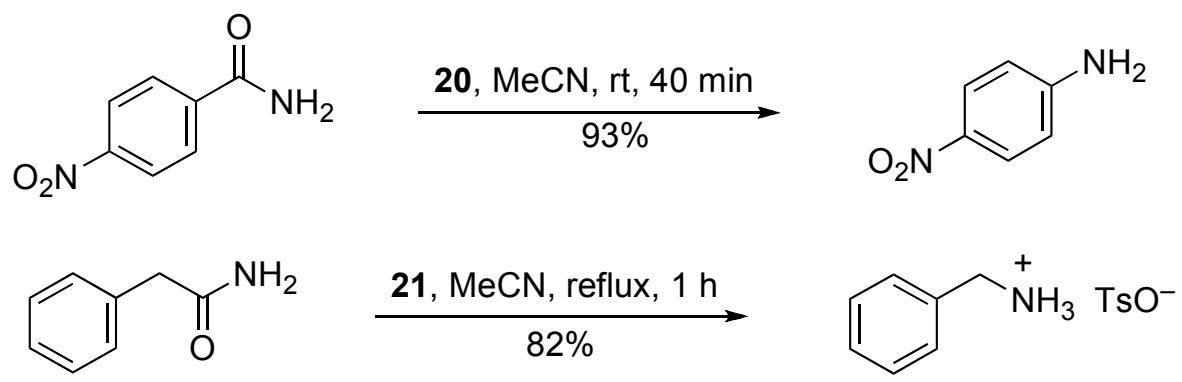

\section{Scheme 85}

\section{Conclusion and Outlook}

This review demonstrates an active current interest in synthetic applications of hypervalent iodine(III) reagents. This growing interest in iodine(III) compounds is mainly due to their very useful oxidizing properties, combined with benign environmental character and commercial availability. There has been a major surge of activity in several areas of the hypervalent iodine chemistry. These areas include the application of hypervalent iodine reagents in various oxidative transformations, the development and synthetic use of polymer-supported and recyclable hypervalent iodine reagents, and the catalytic applications of organoiodine compounds. We anticipate that these areas of hypervalent iodine chemistry will continue to attract significant research activity in the future.

\section{Acknowledgements}

Our own work described here was supported by a research grant from the National Science Foundation (NSF/CHE-0702734)

\section{References and Notes}

1. (a) Moriarty, R. M.; Prakash, O. Hypervalent Iodine in Organic Chemistry: Chemical Transformations; Wiley-Blackwell, 2008. (b) Wirth, T.; Ed. Hypervalent Iodine Chemistry: Modern Developments in Organic Synthesis. Top. Curr. Chem., 2003, 224. (c) Zhdankin, V. V.; Stang, P. J. Chem. Rev. 2008, 108, 5299. (d) Zhdankin, V. V. Science of Synthesis 2007, 31a, 161. (e) Ochiai, M. Coord. Chem. Rev. 2006, 250, 2771. (f) Tohma, H.; Kita, Y. Adv. Synth. Catal. 2004, 346, 111. (g) Togo, H.; Sakuratani, K. Synlett 2002, 1966. (h) Koser, G. F. Adv. Heterocycl. Chem. 2004, 86, 225. (i) Quideau, S.; Pouysegu, L.; Deffieux, D. Synlett 2008, 467. (j) Frohn, H.-J.; Hirschberg, M. E.; Wenda, A.; Bardin, V. V. J. Fluorine Chem. 
2008, 129, 459. (k) Zhdankin, V. V. Curr. Org. Synth. 2005, 2, 121. (1) Ochiai, M.; Miyamoto, K. Eur. J. Org. Chem. 2008, 4229. (m) Kieltsch, I.; Eisenberger, P.; Stanek, K.; Togni, A. Chimia 2008, 62, 260.

2. (a) Begtrup, M.; Ed. Commemorative Issue in Honor of Prof. Anastasios Varvoglis on the occasion of his 65th anniversary, ARKIVOC 2003, vi, 1-236. (b) Ladziata, U.; Zhdankin, V. V. ARKIVOC 2006, (ix), 26.

3. 3. (a) Katritzky, A. R.; Savage, G. P.; Gallos, J. K.; Durst, H. D. J. Chem. Soc., Perkin Trans. 2 1990, 1515. (b) Katritzky, A. R.; Savage, G. P.; Palenik, G. J.; Qian, K.; Zhang, Z.; Durst, H. D. J. Chem. Soc., Perkin Trans. 2 1990, 1657. (c) Katritzky, A. R.; Duell, B. L.; Gallos, J. K.; Durst, H. D. Magn. Res. Chem. 1989, 27, 1007. (d) Katritzky, A. R.; Gallos, J. K.; Durst, H. D. Magn. Res. Chem. 1989, 27, 815.4.

4. (a) Ochiai, M.; Miyamoto, K.; Yokota, Y.; Suefuji, T.; Shiro, M. Angew. Chem., Int. Ed. 2004, 44, 75. (b) Suefuji, T.; Shiro, M.; Yamaguchi, K.; Ochiai, M. Heterocycles 2006, 67, 391. (c) Zhdankin, V. V.; Koposov, A. Y.; Yashin, N. V. Tetrahedron Lett. 2002, 43, 5735. (d) Zhdankin, V. V.; Koposov, A. E.; Smart, J. T.; Tykwinski, R. R.; McDonald, R.; Morales-Izquierdo, A. J. Am. Chem. Soc. 2001, 123, 4095. (e) Richter, H. W.; Koser, G. F.; Incarvito, C. D.; Rheingold, A. L. Inorg. Chem. 2007, 46, 5555. (f) Koposov, A. Y.; Netzel, B. C.; Yusubov, M. S.; Nemykin, V. N.; Nazarenko, A. Y.; Zhdankin, V. V. Eur. J. Org. Chem. 2007, 4475. (g) Meprathu, B. V.; Protasiewicz, J. D. ARKIVOC 2003, (vi), 83. (h) Koposov, A. Y.; Nemykin, V. N.; Zhdankin, V. V. New J. Chem. 2005, 29, 998. (i) Nikiforov, V. A.; Karavan, V. S.; Miltsov, S. A.; Selivanov, S. I.; Kolehmainen, E.; Wegelius, E.; Nissine, M. ARKIVOC 2003, (vi), 191.

5. (a) Batchelor, R. J.; Birchall, T.; Sawyer, J. F. Inorg. Chem. 1986, 25, 1415. (b) Zhdankin, V. V.; Maydanovych, O.; Herschbach, J.; McDonald, R.; Tykwinski, R. R. J. Am. Chem. Soc. 2002, 124, 11614. (c) Zhdankin, V. V.; Koposov, A. Y.; Su, L. S.; Boyarskikh, V. V.; Netzel, B. C.; Young, V. G. Org. Lett. 2003, 5, 1583. (d) Yusubov, M. S.; Funk, T. V.; Chi, K.-W.; Cha, E.-H.; Kim, G. H.; Kirschning, A.; Zhdankin, V. V. J. Org. Chem. 2008, 73, 295. (e) Koposov, A. Y.; Litvinov, D. N.; Zhdankin, V. V.; Ferguson, M. J.; McDonald, R.; Tykwinski, R. R. Eur. J. Org. Chem. 2006, 4791.

6. (a) Hiller, A.; Patt, J. T.; Steinbach, J. Magn. Reson. Chem. 2006, 44, 955. (b) Mocci, F.; Uccheddu, G.; Frongia, A.; Cerioni, G. J. Org. Chem. 2007, 72, 4163. (c) Silva, L. F., Jr.; Vasconcelos, R. S.; Lopes, N. P. Int. J. Mass Spectrom. 2008, 276, 24.

7. (a) Kiprof, P. ARKIVOC 2005, (iv), 19. (b) Ochiai, M.; Sueda, T.; Miyamoto, K.; Kiprof, P.; Zhdankin, V. V. Angew. Chem., Int. Ed. 2006, 45, 8203.

8. (a) Su, J. T.; Goddard, W. A., III J. Am. Chem. Soc. 2005, 127, 14146. (b) Pouysegu, L.; Chassaing, S.; Dejugnac, D.; Lamidey, A.-M.; Miqueu, K.; Sotiropoulos, J.-M.; Quideau, S. Angew. Chem., Int. Ed. 2008, 47, 3552.

9. (a) Ye, C.; Twamley, B.; Shreeve, J. M. Org. Lett. 2005, 7, 3961. (b) Carpenter, W. R. J. Org. Chem. 1966, 31, 2688. (c) Sawaguchi, M.; Ayuba, S.; Hara, S. Synthesis 2002, 1802. 
(d) Arrica, M. A.; Wirth, T. Eur. J. Org. Chem. 2005, 395. (e) Sun, H.; Wang, B.; DiMagno, S. G. Org. Lett. 2008, 10, 4413.

10. (a) Willgerodt, C. J. Prakt. Chem. 1886, 33, 154. (b) Lucas, H. J.; Kennedy, E. R. Org. Synth. Coll. Vol. III 1955, 482. (c) Zanka, A.; Takeuchi, H.; Kubota, A. Org. Process Res. Dev. 1998, 2, 270. (d) Yusubov, M. S.; Drygunova, L. A.; Zhdankin, V. V. Synthesis 2004, 2289.

11. (a) Zielinska, A.; Skulski, L. Tetrahedron Lett. 2004, 45, 1087. (b) Zhao, X.-F.; Zhang, C. Synthesis 2007, 551.

12. (a) Saltzman, H.; Sharefkin, J. G. Org. Synth. Coll. Vol. V 1973, 658. (b) Meprathu, B. V.; Protasiewicz, J. D. ARKIVOC 2003, (vi), 83. (c) Meprathu, B. V.; Justik, M. W.; Protasiewicz, J. D. Tetrahedron Lett. 2005, 46, 5187.

13. (a) Lucas, H. J.; Kennedy, E. R.; Formo, M. W. Org. Synth. Coll. Vol. III 1955, 483. (b) Sawaguchi, M.; Ayuba, S.; Hara, S. Synthesis 2002, 1802. (c) McQuaid, K. M.; Pettus, T. R. R. Synlett 2004, 2403.

14. (a) Sharefkin, J. G.; Saltzman, H. Org. Synth. Coll. Vol. V 1973, 660. (b) Chen, F.-E.; Xie, B.; Zhang, P.; Zhao, J.-F.; Wang, H.; Zhao, L. Synlett 2007, 619. (c) Shang, Y.; But, T. Y. S.; Togo, H.; Toy, P. H. Synlett 2007, 67. (d) Qian, W.; Jin, E.; Bao, W.; Zhang, Y. Angew. Chem., Int. Ed. 2005, 44, 952. (e) Handy, S. T.; Okello, M. J. Org. Chem. 2005, 70, 2874. (f) Zhdankin, V. V.; Scheuller, M. C.; Stang, P. J. Tetrahedron Lett. 1993, 34, 6853. (g) Stang, P. J.; Zhdankin, V. V. J.Am. Chem. Soc. 1993, 115, 9808.

15. (a) Kazmierczak, P.; Skulski, L.; Kraszkiewicz, L. Molecules 2001, 6, 881. (b) Ross, T. L.; Ermert, J.; Hocke, C.; Coenen, H. H. J. Am. Chem. Soc. 2007, 129, 8018. (c) Dohi, T.; Morimoto, K.; Takenaga, N.; Goto, A.; Maruyama, A.; Kiyono, Y.; Tohma, H.; Kita, Y. J. Org. Chem. 2007, 72, 109. (d) Moroda, A.; Togo, H. Tetrahedron 2006, 62, 12408. (e) Hossain, D.; Kitamura, T. Synthesis 2005, 1932. (f) Page, T. K.; Wirth, T. Synthesis 2006, 3153. (g) Rocaboy, C.; Gladysz, J. A. Chem. Eur. J. 2003, 9, 88. (h) Fujita, M.; Okuno, S.; Lee, H. J.; Sugimura, T.; Okuyama, T. Tetrahedron Lett. 2007, 48, 8691. (i) Hossain, M. D.; Kitamura, T. J. Org. Chem. 2005, 70, 6984. (j) Hossain, M. D.; Kitamura, T. Tetrahedron Lett. 2006, 47, 7889.

16. (a) Koposov, A. Y.; Boyarskikh, V. V.; Zhdankin, V. V. Org. Lett. 2004, 6, 3613. (b) Sutherland, A.; Vederas, J. C. Chem. Commun. 2002, 224. (c) Das, J. P.; Roy, U. K.; Roy, S. Organometallics 2005, 24, 6136. (d) Sheremetev, A. B.; Konkina, S. M. Mendeleev Commun. 2003, 277. (e) Spyroudis, S.; Varvoglis, A. Synthesis 1975, 445.

17. (a) Hirt, U. H.; Schuster, M. F. H.; French, A. N.; Wiest, O. G.; Wirth, T. Eur. J. Org. Chem. 2001, 1569. (b) Lee, B. C.; Lee, K. C.; Lee, H.; Mach, R. H.; Katzenellenbogen, J. A. Bioconjugate Chem. 2007, 18, 514. (c) Nabana, T.; Togo, H. J. Org. Chem. 2002, 67, 4362. (d) Yamamoto, Y.; Togo, H. Synlett 2005, 2486. (e) Tohma, H.; Maruyama, A.; Maeda, A.; Maegawa, T.; Dohi, T.; Shiro, M.; Morita, T.; Kita, Y. Angew. Chem., Int. Ed. 2004, 43, 3595. (f) Dohi, T.; Maruyama, A.; Yoshimura, M.; Morimoto, K.; Tohma, H.; Shiro, M.; 
Kita, Y. Chem. Commun. 2005, 2205. (g) Yusubov, M. S.; Wirth, T. Org. Lett. 2005, 7, 519. (h) Abe, S.; Sakuratani, K.; Togo, H. J. Org. Chem. 2001, 66, 6174.

18. (a) Zefirov, N. S.; Zhdankin, V. V.; Dan'kov, Y. V.; Sorokin, V. D.; Semerikov, V. N.; Koz'min, A. S.; Caple, R.; Berglund, B. A. Tetrahedron Lett. 1986, 27, 3971. (b) Hembre, R. T.; Scott, C. P.; Norton, J. R. J. Org. Chem. 1987, 52, 3650. (c) Zhdankin, V. V.; Crittell, C. M.; Stang, P. J. Tetrahedron Lett. 1990, 31, 4821. (d) Kitamura, T.; Inoue, D.; Wakimoto, I.; Nakamura, T.; Katsuno, R.; Fujiwara, Y. Tetrahedron 2004, 60, 8855.

19. 19. (a) Yoshida, M.; Fujikawa, K.; Sato, S.; Hara, S. ARKIVOC 2003, (vi), 36. (b) Sato, S.; Yoshida, M.; Hara, S. Synthesis 2005, 2602. (c) Motherwell, W. B.; Greaney, M. F.; Tocher, D. A. J. Chem. Soc., Perkin Trans. 1 2002, 2809. (d) Motherwell, W. B.; Greaney, M. F.; Edmunds, J. J.; Steed, J. W. J. Chem. Soc., Perkin Trans. 1 2002, 2816. (e) Inagaki, T.; Nakamura, Y.; Sawaguchi, M.; Yoneda, N.; Ayuba, S.; Hara, S. Tetrahedron Lett. 2003, 44, 4117. (f) Conte, P.; Panunzi, B.; Tingoli, M. Tetrahedron Lett. 2005, 47, 273. (g) Panunzi, B.; Picardi, A.; Tingoli, M. Synlett 2004, 2339. (f) Ochiai, M.; Hirobe, M.; Yoshimura, A.; Nishi, Y.; Miyamoto, K.; Shiro, M. Org. Lett. 2007, 9, 3335.

20. (a) Yusubov, M. S.; Drygunova, L. A.; Tkachev, A. V.; Zhdankin, V. V. ARKIVOC 2005, (iv), 179. (b) Ibrahim, H.; Kleinbeck, F.; Togni, A. Helv. Chim.Acta 2004, 87, 605. (c) Jin, L.-M.; Yin, J.-J.; Chen, L.; Guo, C.-C.; Chen, Q.-Y. Synlett 2005, 2893. (d) Telvekar, V. N. Synth. Commun. 2007, 37, 2647. (e) Cook, T. R.; Esswein, A. J.; Nocera, D. G. J. Am. Chem. Soc. 2007, 129, 10094. (f) Whitfield, S. R.; Sanford, M. S. J. Am. Chem. Soc. 2007, 129, 15142. (g) Khusniyarov, M. M.; Harms, K.; Sundermeyer, J. J. Fluorine Chem. 2006, 127, 200. (h) Hayton, T. W.; Legzdins, P.; Patrick, B. O. Inorg. Chem. 2002, 41, 5388. (i) Bastian, M.; Morales, D.; Poli, R.; Richard, P.; Sitzmann, H. J. Organomet. Chem. 2002, 654, 109.

21. (a) Hashem, A.; Jung, A.; Ries, M.; Kirschning, A. Synlett 1998, 195. (b) Kirschning, A.; Kunst, E.; Ries, M.; Rose, L.; Schoenberger, A.; Wartchow, R. ARKIVOC 2003, (vi), 145. (c) Xia, J.-J.; Wu, X.-L.; Wang, G.-W. ARKIVOC 2008, (xvi), 22. (d) Panunzi, B.; Rotiroti, L.; Tingoli, M. Tetrahedron Lett. 2003, 44, 8753. (e) Yan, J.; Li, J.; Cheng, D. Synlett 2007, 2442. (f) Karade, N. N.; Tiwari, G. B.; Huple, D. B.; Siddiqui, T. A. J. J. Chem. Res. 2006, 366. (g) Cheng, D.-P.; Chen, Z.-C.; Zheng, Q.-G. Synth. Commun. 2003, 33, 2671. (h) Comins, D. L.; Kuethe, J. T.; Miller, T. M.; Fevrier, F. C.; Brooks, C. A. J. Org. Chem. 2005, 70, 5221. (i) Iglesias-Arteaga, M. A.; Castellanos, E.; Juaristi, E. Tetrahedron: Asymmetry 2003, 14, 577. (j) Diaz-Sanchez, B. R.; Iglesias-Arteaga, M. A.; MelgarFernandez, R.; Juaristi, E. J. Org. Chem. 2007, 72, 4822.

22. (a) Piancatelli, G.; Leonelli, F.; Do, N.; Ragan, J. Org. Synth. 2006, 83, 18. (b) Moroda, A.; Togo, H. Tetrahedron 2006, 62, 12408. (c) Pozzi, G.; Quici, S.; Shepperson, I. Tetrahedron Lett. 2002, 43, 6141. (d) Vatele, J.-M. Tetrahedron Lett. 2006, 47, 715. (e) Vugts, D. J.; Veum, L.; al-Mafraji, K.; Lemmens, R.; Schmitz, R. F.; de Kanter, F. J. J.; Groen, M. B.; Hanefeld, U.; Orru, R. V. A. Eur. J. Org. Chem. 2006, 1672. (f) Zhao, X.-F.; Zhang, C. Synthesis 2007, 551. (g) Hansen, T. M.; Florence, G. J.; Lugo-Mas, P.; Chen, J.; Abrams, J. 
N.; Forsyth, C. J. Tetrahedron Lett. 2002, 44, 57. (h) Li, Y.; Hale, K. J. Org. Lett. 2007, 9, 1267.

23. (a) Tohma, H.; Takizawa, S.; Maegawa, T.; Kita, Y. Angew. Chem., Int. Ed. 2000, 39, 1306.

(b) Tohma, H.; Maegawa, T.; Takizawa, S.; Kita, Y. Adv. Synth. Catal. 2002, 344, 328. (c) Karade, N. N.; Shirodkar, S. G.; Dhoot, B. M.; Waghmare, P. B. J. Chem. Res. 2005, 274.

24. (a) Karade, N. N.; Tiwari, G. B.; Huple, D. B. Synlett 2005, 2039. (b) Karade, N. N.; Budhewar, V. H.; Katkar, A. N.; Tiwari, G. B. ARKIVOC 2006, (xi), 162. (c) Lee, J. C.; Lee, J. Y.; Lee, S. J. Tetrahedron Lett. 2004, 45, 4939.

25. (a) Moriarty, R. M.; Hu, H. Tetrahedron Lett. 1981, 22, 2747. (b) Moriarty, R. M.; Prakash, O.; Karalis, P.; Prakash, I. Tetrahedron Lett. 1984, 25, 4745. (c) Moriarty, R. M.; Prakash, O. J. Org. Chem. 1985, 50, 151. (c) Moriarty, R. M. J. Org. Chem. 2005, 70, 2893. (d) Moriarty, R. M.; Prakash, O. Adv. Heterocycl. Chem. 1998, 69, 1. (e) Moriarty, R. M.; Prakash, O. Org. React. 1999, 54, 273.

26. (a) Koser, G. F. Aldrichimica Acta 2001, 34, 89. (b) Wessig, P.; Muhling, O. Helv. Chim. Acta 2003, 86, 865. (c) Kumar, D.; Sundaree, S.; Rao, V. S.; Varma, R. S. Tetrahedron Lett. 2006, 47, 4197. (d) Kumar, D.; Sundaree, M. S.; Patel, G.; Rao, V. S.; Varma, R. S. Tetrahedron Lett. 2006, 47, 8239. (e) Prakash, O.; Batra, A.; Chaudhri, V.; Prakash, R. Tetrahedron Lett. 2005, 46, 2877. (f) Aggarwal, R.; Sumran, G. Synth. Commun. 2006, 36, 875. (g) Lee, J. C.; Seo, J.-W.; Baek, J. W. Synth. Commun. 2007, 37, 2159. (h) Kawano, Y.; Togo, H. Synlett 2008, 217. (i) Muthukrishnan, M.; Patil, P. S.; More, S. V.; Joshi, R. A. Mendeleev Commun. 2005, 100. (j) Patonay, T.; Levai, A.; Riman, E.; Varma, R. S. ARKIVOC 2004, (vii), 183. (k) Karade, N. N.; Gampawar, S. V.; Kondre, J. M.; Shinde, S. V. Tetrahedron Lett. 2008, 49, 4402. (1) Zhou, G.-B.; Guan, Y.-Q.; Shen, C.; Wang, Q.; Liu, X.-M.; Zhang, P.-F.; Li, L.-L. Synthesis 2008, 1994. (m) Koser, G. F.; Telu, S.; Laali, K. K. Tetrahedron Lett. 2006, 47, 7011.

27. (a) Celik, M.; Alp, C.; Coskun, B.; Gueltekin, M. S.; Balci, M. Tetrahedron Lett. 2006, 47, 3659. (b) Tellitu, I.; Dominguez, E. Tetrahedron 2008, 64, 2465. (c) Yusubov, M. S.; Zholobova, G. A.; Filimonova, I. L.; Chi, K.-W. Russ. Chem. Bull. 2004, 53, 1735. (d) Lee, S.; MacMillan, D. W. C. Tetrahedron 2006, 62, 11413. (e) Alvarez, H. M.; Barbosa, D. P.; Fricks, A. T.; Aranda, D. A. G.; Valdes, R. H.; Antunes, O. A. C. Org. Process Res. Dev. 2006, 10, 941. (f) Dohi, T.; Takenaga, N.; Goto, A.; Fujioka, H.; Kita, Y. J. Org. Chem. 2008, 73, 7365 .

28. (a) Prakash, O.; Batra, H.; Kaur, H.; Sharma, P. K.; Sharma, V.; Singh, S. P.; Moriarty, R. M. Synthesis 2001, 541. (b) Song, H.; Chen, W.; Wang, Y.; Qin, Y. Synth. Commun. 2005, 35, 2735. (c) Davis, M. C.; Stasko, D.; Chapman, R. D. Synth. Commun. 2003, 33, 2677. (d) Berkessel, A.; Glaubitz, K.; Lex, J. Eur. J. Org. Chem. 2002, 2948.

29. (a) Tellitu, I.; Urrejola, A.; Serna, S.; Moreno, I.; Herrero, M. T.; Dominguez, E.; SanMartin, R.; Correa, A. Eur. J. Org. Chem. 2007, 437. (b) Correa, A.; Tellitu, I.; Dominguez, E.; Moreno, I.; SanMartin, R. J. Org. Chem. 2005, 70, 2256. (c) Churruca, F.; SanMartin, R.; Tellitu, I.; Dominguez, E. Eur. J. Org. Chem. 2005, 2481. (d) Serna, S.; Tellitu, I.; 
Dominguez, E.; Moreno, I.; SanMartin, R. Tetrahedron 2004, 60, 6533. (e) Churruca, F.; SanMartin, R.; Carril, M.; Urtiaga, M. K.; Solans, X.; Tellitu, I.; Dominguez, E. J. Org. Chem. 2005, 70, 3178. (f) Herrero, M. T.; Tellitu, I.; Hernandez, S.; Dominguez, E.; Moreno, I.; SanMartin, R. ARKIVOC 2002, (v), 31. (g) Correa, A.; Tellitu, I.; Dominguez, E.; SanMartin, R. J. Org. Chem. 2006, 71, 8316. (h) Tellitu, I.; Serna, S.; Herrero, M. T.; Moreno, I.; Dominguez, E.; SanMartin, R. J. Org. Chem. 2007, 72, 1526. (i) Correa, A.; Tellitu, I.; Dominguez, E.; SanMartin, R. Tetrahedron 2006, 62, 11100.

30. (a) Huang, J.; Liang, Y.; Pan, W.; Yang, Y.; Dong, D. Org. Lett. 2007, 9, 5345. (b) Fan, R.; Wen, F.; Qin, L.; Pu, D.; Wang, B. Tetrahedron Lett. 2007, 48, 7444. (c) Huang, X.; Shao, N.; Palani, A.; Aslanian, R. Tetrahedron Lett. 2007, 48, 1967. (d) Wardrop, D. J.; Burge, M. S. J. Org. Chem. 2005, 70, 10271. (e) Prakash, O.; Kumar, R.; Kumar, R.; Tyagi, P.; Kuhad, R. C. Eur. J. Med. Chem. 2007, 42, 868. (f) Somogyi, L. J. Heterocycl. Chem. 2007, 44, 1235. (g) Du, Y.; Liu, R.; Linn, G.; Zhao, K. Org. Lett. 2006, 8, 5919. (h) Bose, D. S.; Idrees, M. J. Org. Chem. 2006, 71, 8261. (i) Karade, N. N.; Tiwari, G. B.; Gampawar, S. V. Synlett 2007, 1921. (j) Prakash, O.; Pannu, K. ARKIVOC 2007, (xiii), 28. (k) Du, L.-H.; Wang, Y.-G. Synthesis 2007, 675. (k) Das, B.; Srinivas, Y.; Holla, H.; Krishnaiah, M.; Narender, R. Chem. Lett. 2007, 36, 1270. (1) Liu, L.-P.; Lu, J.-M.; Shi, M. Org. Lett. 2007, 9, 1303. (m) Huang, X.; Shao, N.; Palani, A.; Aslanian, R.; Buevich, A.; Seidel-Dugan, C.; Huryk, R. Tetrahedron Lett. 2008, 49, 3592. (n) Amano, Y.; Inoue, K.; Nishiyama, S. Synlett 2008, 134. (o) Chatterjee, N.; Pandit, P.; Halder, S.; Patra, A.; Maiti, D. K. J. Org. Chem. 2008, 73, 7775. (p) Cochran, B. M.; Michael, F. E. Org. Lett. 2008, 10, 5039.

31. (a) Kikugawa, Y.; Nagashima, A.; Sakamoto, T.; Miyazawa, E.; Shiiya, M. J. Org. Chem. 2003, 68, 6739. (b) Miyazawa, E.; Sakamoto, T.; Kikugawa, Y. J. Org. Chem. 2003, 68, 5429. (c) Misu, Y.; Togo, H. Org. Biomol. Chem. 2003, 1, 1342. (d) Walker, S. J.; Hart, D. J. Tetrahedron Lett. 2007, 48, 6214.

32. (a) Boye, A. C.; Meyer, D.; Ingison, C. K.; French, A. N.; Wirth, T. Org. Lett. 2003, 5, 2157. (b) Biland, A. S.; Altermann, S.; Wirth, T. ARKIVOC 2003, (vi), 164. (c) Fujioka, H.; Matsuda, S.; Horai, M.; Fujii, E.; Morishita, M.; Nishiguchi, N.; Hata, K.; Kita, Y. Chem. Eur. J. 2007, 13, 5238. (d) Chanu, A.; Safir, I.; Basak, R.; Chiaroni, A.; Arseniyadis, S. Eur. J. Org. Chem. 2007, 4305.

33. (a) Iglesias-Arteaga, M. A.; Velazquez-Huerta, G. A. Tetrahedron Lett. 2005, 46, 6897. (b) Iglesias-Arteaga, M. A.; Arcos-Ramos, R. O. Tetrahedron Lett. 2006, 47, 8029. (c) IglesiasArteaga, M. A.; Arcos-Ramos, R. O.; Mendez-Stivalet, J. M. Tetrahedron Lett. 2007, 48, 7485 .

34. (a) Harayama, Y.; Yoshida, M.; Kamimura, D.; Wada, Y.; Kita, Y. Chem. Eur. J. 2006, 12, 4893. (b) Harayama, Y.; Yoshida, M.; Kamimura, D.; Kita, Y. Chem. Commun. 2005, 1764.

35. (a) Justik, M. W.; Koser, G. F. Tetrahedron Lett. 2004, 45, 6159. (b) Hossain, M. M.; Tokuoka, T.; Yamashita, K.; Kawamura, Y.; Tsukayama, M. Synth. Commun. 2006, 36, 1201. (c) Silva, L. F., Jr.; Siqueira, F. A.; Pedrozo, E. C.; Vieira, F. Y. M.; Doriguetto, A. C. Org. Lett. 2007, 9, 1433. (d) Justik, M. W.; Koser, G. F. Molecules 2005, 10, 217. (e) Silva, 
L. F., Jr.; Vasconcelos, R. S.; Nogueira, M. A. Org. Lett. 2008, 10, 1017. (f) Lee, J.; Lee, J. Synth. Commun. 2006, 36, 1071. (g) Vatele, J.-M. Synlett 2008, 1785. (h) Kansara, A.; Sharma, P. K.; Banerji, K. K. J. Chem. Res. 2004, 315. (i) ter Wiel, M. K. J.; Vicario, J.; Davey, S. G.; Meetsma, A.; Feringa, B. L. Org. Biomol. Chem. 2005, 3, 28. (j) Shang, Z.; Reiner, J.; Zhao, K. Synth. Commun. 2006, 36, 1529. (k) Prakash, O.; Gujral, H. K.; Rani, N.; Singh, S. P. Synth. Commun. 2000, 30, 417.

36. (a) Sabot, C.; Commare, B.; Duceppe, M.-A.; Nahi, S.; Guérard, K. C.; Canesi, S. Synlett 2008, 3226. (b) Karam, O.; Martin-Mingot, A.; Jouannetaud, M.-P.; Jacquesy, J.-C.; Cousson, A. Tetrahedron 2004, 60, 6629. (c) Basset, L.; Martin-Mingot, A.; Jouannetaud, M.-P.; Jacquesy, J.-C. Tetrahedron Lett. 2008, 49, 1551. (d) Felpin, F.-X. Tetrahedron Lett. 2007, 48, 409.

37. (a) Lebrasseur, N.; Fan, G.-J.; Quideau, S. ARKIVOC 2004, (xiii), 5. (b) Lebrasseur, N.; Fan, G.-J.; Oxoby, M.; Looney, M. A.; Quideau, S. Tetrahedron 2005, 61, 1551. (c) Quideau, S.; Pouysegu, L.; Oxoby, M.; Looney, M. A. Tetrahedron 2001, 57, 319.

38. (a) Ciufolini, M. A.; Braun, N. A.; Canesi, S.; Ousmer, M.; Chang, J.; Chai, D. Synthesis 2007, 3759. (b) Shigehisa, H.; Takayama, J.; Honda, T. Tetrahedron Lett. 2006, 47, 7301. (c) Quideau, S.; Lebon, M.; Lamidey, A.-M. Org. Lett. 2002, 4, 3975.

39. (a) Berard, D.; Giroux, M.-A.; Racicot, L.; Sabot, C.; Canesi, S. Tetrahedron 2008, 64, 7537.

(b) Wipf, P.; Spencer, S. R. J. Am. Chem. Soc. 2005, 127, 225. (c) Canesi, S.; Bouchu, D.; Ciufolini, M. A. Angew. Chem., Int. Ed. 2004, 43, 4336. (d) Nicolaou, K. C.; Edmonds, D. J.; Li, A.; Tria, G. S. Angew. Chem., Int. Ed. 2007, 46, 3942. (e) Tohma, H.; Harayama, Y.; Hashizume, M.; Iwata, M.; Kiyono, Y.; Egi, M.; Kita, Y. J. Am. Chem. Soc. 2003, 125, 11235. (f) Baxendale, I. R.; Ley, S. V.; Nessi, M.; Piutti, C. Tetrahedron 2002, 58, 6285. (g) Vo, N. T.; Pace, R. D. M.; O'Hara, F.; Gaunt, M. J. J. Am. Chem. Soc. 2008, 130, 404. (h) Baxendale, I. R.; Deeley, J.; Griffiths-Jones, C. M.; Ley, S. V.; Saaby, S.; Tranmer, G. K. Chem. Commun. 2006, 2566. (i) Baxendale, I. R.; Lee, A.-L.; Ley, S. V. J. Chem. Soc., Perkin Trans. 1 2002, 1850. (j) Moisan, L.; Wagner, M.; Comesse, S.; Doris, E. Tetrahedron Lett. 2006, 47, 9093. (k) Dohi, T.; Maruyama, A.; Takenage, N.; Senami, K.; Minamitsuji, Y.; Fujioka, H.; Caemmerer, S.; Kita, Y. Angew. Chem., Int. Ed. 2008, 47, 3787.

40. (a) Quideau, S.; Pouysegu, L.; Deffieux, D.; Ozanne, A.; Gagnepain, J.; Fabre, I.; Oxoby, M. ARKIVOC 2003, (vi), 106. (b) Gagnepain, J.; Mereau, R.; Dejugnac, D.; Leger, J.-M.; Castet, F.; Deffieux, D.; Pouysegu, L.; Quideau, S. Tetrahedron 2007, 63, 6493.

41. (a) Lai, C.-H.; Lin, P.-Y.; Peddinti, R. K.; Liao, C.-C. Synlett 2002, 1520. (b) Cook, S. P.; Danishefsky, S. J. Org. Lett. 2006, 8, 5693. (c) Berube, A.; Drutu, I.; Wood, J. L. Org. Lett. 2006, 8, 5421.

42. Boldron, C.; Aromi, G.; Challa, G.; Gamez, P.; Reedijk, J. Chem. Commun. 2005, 5808.

43. (a) Hata, K.; Hamamoto, H.; Shiozaki, Y.; Caemmerer, S. B.; Kita, Y. Tetrahedron 2007, 63, 4052. (b) Kita, Y.; Tohma, H.; Hatanaka, K.; Takada, T.; Fujita, S.; Mitoh, S.; Sakurai, H.; Oka, S. J. Am. Chem. Soc. 1994, 116, 3684. (c) Dohi, T.; Ito, M.; Morimoto, K.; Iwata, M.; Kita, Y. Angew. Chem., Int. Ed. 2008, 47, 1301. (d) Pingaew, R.; Ruchirawat, S. Synlett 
2007, 2363. (e) Taylor, S. R.; Ung, A. T.; Pyne, S. G.; Skelton, B. W.; White, A. H. Tetrahedron 2007, 63, 11377. (f) Hata, K.; Hamamoto, H.; Shiozaki, Y.; Kita, Y. Chem. Commun. 2005, 2465. (g) Huang, W.-J.; Singh, O. V.; Chen, C.-H.; Lee, S.-S. Helv. Chim. Acta 2004, 87, 167. (h) Hamamoto, H.; Hata, K.; Nambu, H.; Shiozaki, Y.; Tohma, H.; Kita, Y. Tetrahedron Lett. 2004, 45, 2293.

44. (a) Tohma, H.; Iwata, M.; Maegawa, T.; Kita, Y. Tetrahedron Lett. 2002, 43, 9241. (b) Mirk, D.; Willner, A.; Froehlich, R.; Waldvogel, S. R. Adv. Synth. Catal. 2004, 346, 675.

45. (a) Jean, A.; Cantat, J.; Berard, D.; Bouchu, D.; Canesi, S. Org. Lett. 2007, 9, 2553. (b) Dohi, T.; Morimoto, K.; Kiyono, Y.; Maruyama, A.; Tohma, H.; Kita, Y. Chem. Commun. 2005, 2930. (c) Tohma, H.; Iwata, M.; Maegawa, T.; Kiyono, Y.; Maruyama, A.; Kita, Y. Org. Biomol. Chem. 2003, 1, 1647. (d) Dohi, T.; Morimoto, K.; Maruyama, A.; Kita, Y. Org. Lett. 2006, 8, 2007. (e) Yoshimura, Y.; Ohta, M.; Imahori, T.; Imamichi, T.; Takahata, H. Org. Lett. 2008, 10, 3449.

46. (a) Francisco, C. G.; Herrera, A. J.; Suarez, E. J. Org. Chem. 2002, 67, 7439. (b) Francisco, C. G.; Herrera, A. J.; Suarez, E. J. Org. Chem. 2003, 68, 1012. (c) Francisco, C. G.; Gonzalez, C. C.; Paz, N. R.; Suarez, E. Org. Lett. 2003, 5, 4171. (d) Alonso-Cruz, C. R.; Kennedy, A. R.; Rodriguez, M. S.; Suarez, E. Org. Lett. 2003, 5, 3729. (e) Alonso-Cruz, C. R.; Kennedy, A. R.; Rodriguez, M. S.; Suarez, E. Tetrahedron Lett. 2007, 48, 7207. (f) Alonso-Cruz, C. R.; Leon, E. I.; Ortiz-Lopez, F. J.; Rodriguez, M. S.; Suarez, E. Tetrahedron Lett. 2005, 46, 5265. (g) Francisco, C. G.; Herrera, A. J.; Kennedy, A. R.; Melian, D.; Suarez, E. Ang.Chem., Int. Ed. 2002, 41, 856. (h) Francisco, C. G.; Freire, R.; Herrera, A. J.; Perez-Martin, I.; Suarez, E. Tetrahedron 2007, 63, 8910. (i) Francisco, C. G.; Freire, R.; Herrera, A. J.; Perez-Martin, I.; Suarez, E. Org. Lett. 2002, 4, 1959. (j) Martin, A.; Quintanal, L. M.; Suarez, E. Tetrahedron Lett. 2007, 48, 5507.

47. (a) Boto, A.; Hernandez, D.; Hernandez, R. Org. Lett. 2007, 9, 1721. (b) Boto, A.; Hernandez, D.; Hernandez, R.; Suarez, E. Org. Lett. 2004, 6, 3785. (c) Boto, A.; Gallardo, J. A.; Hernandez, R.; Saavedra, C. J. Tetrahedron Lett. 2005, 46, 7807.

48. (a) Dohi, T.; Takenaga, N.; Goto, A.; Maruyama, A.; Kita, Y. Org. Lett. 2007, 9, 3129. (b) Pradhan, T. K.; Hassner, A. Synthesis 2007, 3361.

49. (a) Martin, A.; Perez-Martin, I.; Suarez, E. Org. Lett. 2005, 7, 2027. (b) Francisco, C. G.; Herrera, A. J.; Martin, A.; Perez-Martin, I.; Suarez, E. Tetrahedron Lett. 2007, 48, 6384. (c) Fan, R.; Pu, D.; Wen, F.; Wu, J. J. Org. Chem. 2007, 72, 8994.

50. (a) Prakash, O.; Kaur, H.; Pundeer, R.; Dhillon, R. S.; Singh, S. P. Synth. Commun. 2003, 33, 4037. (b) Koser, G. F.; Telu, S.; Laali, K. K. Tetrahedron Lett. 2006, 47, 7011.

51. (a) Pedersen, C. M.; Marinescu, L. G.; Bols, M. Org. Biomol. Chem. 2005, 3, 816. (b) Li, X.Q.; Zhao, X.-F.; Zhang, C. Synthesis 2008, 2589. (c) Chung, R.; Yu, E.; Incarvito, C. D.; Austin, D. J. Org. Lett. 2004, 6, 3881. (d) Kumar, D.; Sundaree, S.; Rao, V. S. Synth. Commun. 2006, 36, 1893. (e) Prakash, O.; Pannu, K.; Prakash, R.; Batra, A. Molecules 2006, 11, 523. 
52. (a) Tingoli, M.; Tiecco, M.; Testaferri, L.; Temperini, A. Chem. Commun. 1994, 1883. (b) Tingoli, M.; Tiecco, M.; Testaferri, L.; Temperini, A. Synth. Commun. 1998, 28, 1769. (c) Shi, M.; Wang, B.-Y.; Li, J. Eur. J. Org. Chem. 2005, 759. (d) Yu, L.; Chen, B.; Huang, X. Tetrahedron Lett. 2007, 48, 925. (e) Mironov, Y. V.; Sherman, A. A.; Nifantiev, N. E. Tetrahedron Lett. 2004, 45, 9107. (f) Mironov, Y. V.; Sherman, A. A.; Nifantiev, N. E. Mendeleev Commun. 2008, 18, 241. (g) Das, J. P.; Roy, U. K.; Roy, S. Organometallics 2005, 24, 6136. (h) Chen, J.-M.; Huang, X. Synth. Commun. 2004, 34, 1745.

53. (a) Simonneaux, G.; Tagliatesta, P. J. Porphyrins Phthalocyanines 2004, 8, 1166. (b) Groves, J. T. J. Porphyrins Phthalocyanines 2000, 4, 350. (c) Rose, E.; Andrioletti, B.; Zrig, S.; Quelquejeu-Etheve, M. Chem. Soc. Rev. 2005, 34, 573. (d) Bernadou, J.; Meunier, B. Adv. Synth. Catal. 2004, 346, 171. (e) Vinhado, F. S.; Martins, P. R.; Iamamoto, Y. Curr. Top. Catal. 2002, 3, 199. (f) Zhdankin, V. V.; Stang, P. J. Chem. Rev. 2002, 102, 2523.

54. (a) Kang, M.-J.; Song, W. J.; Han, A.-R.; Choi, Y. S.; Jang, H. G.; Nam, W. J. Org. Chem. 2007, 72, 6301. (b) de Visser, S. P.; Oh, K.; Han, A.-R.; Nam, W. Inorg. Chem. 2007, 46, 4632. (c) Silva, G. d. F.; Carvalho da Silva, D.; Guimaraes, A. S.; do Nascimento, E.; Reboucas, J. S.; Peres de Araujo, M.; Dai de Carvalho, M. E. M.; Idemori, Y. M. J. Mol. Cat. A 2007, 266, 274. (d) Song, W. J.; Seo, M. S.; DeBeer George, S.; Ohta, T.; Song, R.; Kang, M.-J.; Tosha, T.; Kitagawa, T.; Solomon, E. I.; Nam, W. J. Am. Chem. Soc. 2007, 129, 1268. (e) Lindsay Smith, J. R.; Iamamoto, Y.; Vinhado, F. S. J. Mol. Cat. A 2006, 252, 23.

55. (a) Murakami, Y.; Konishi, K. J. Am. Chem. Soc. 2007, 129, 14401. (b) Santos, M. M. C.; Silva, A. M. S.; Cavaleiro, J. A. S.; Levai, A.; Ptonay, T. Eur. J. Org. Chem. 2007, 2877. (c) Babakhania, R.; Bahadoran, F.; Safari, N. J. Porphyrins Phthalocyanines 2007, 11, 95. (d) Pouralimardan, O.; Chamayou, A.-C.; Janiak, C.; Hosseini-Monfared, H. Inorg. Chim. Acta 2007, 360, 1599.

56. (a) Yang, Z. W.; Kang, Q. X.; Quan, F.; Lei, Z. Q. J. Mol. Cat. A 2007, 261, 190. (b) Vatele, J.-M. Synlett 2006, 2055. (c) Geraskin, I. M.; Luedtke, M. W.; Neu, H. M.; Nemykin, V. N.; Zhdankin, V. V. Tetrahedron Lett. 2008, 49, 7410.

57. (a) Wolckenhauer, S. A.; Devlin, A. S.; Du Bois, J. Org. Lett. 2007, 9, 4363. (b) Ferrand, Y.; Daviaud, R.; Le Maux, P.; Simonneaux, G. Tetrahedron: Asymmetry 2006, 17, 952. (c) Bryliakov, K. P.; Talsi, E. P. Chem. Eur. J. 2007, 13, 8045.

58. (a) Young, K. J. H.; Mironov, O. A.; Periana, R. A. Organometallics 2007, 26, 2137. (b) Li, Z.; Xia, C.-G. J. Mol. Catal. A 2004, 214, 95. (c) In, J.-H.; Park, S.-E.; Song, R.; Nam, W. Inorg. Chim. Acta 2003, 343, 373.

59. (a) Yusubov, M. S.; Gilmkhanova, M. P.; Zhdankin, V. V.; Kirschning, A. Synlett 2007, 563.

(b) Yusubov, M. S.; Chi, K.-W.; Park, J. Y.; Karimov, R.; Zhdankin, V. V. Tetrahedron Lett. 2006, 47, 6305.

60. (a) Miyamura, H.; Akiyama, R.; Ishida, T.; Matsubara, R.; Takeuchi, M.; Kobayashi, S. Tetrahedron 2005, 61, 12177. (b) Sun, W.; Wang, H.; Xia, C.; Li, J.; Zhao, P. Angew. Chem., Int. Ed. 2003, 42, 1042. (c) Li, Z.; Tang, Z. H.; Hu, X. X.; Xia, C. G. Chem. Eur. J. 
2005, 11, 1210. (d) Karimipour, G. R.; Shadegan, H. A.; Ahmadpour, R. J. Chem. Res. 2007, 252. (e) Adam, W.; Hajra, S.; Herderich, M.; Saha-Moeller, C. R. Org. Lett. 2000, 2 , 2773. (f) Provins, L.; Murahashi, S.-I. ARKIVOC 2007, (x), 107.

61. (a) Deprez, N. R.; Sanford, M. S. Inorg. Chem. 2007, 46, 1924. (b) Dick, A. R.; Hull, K. L.; Sanford, M. S. J. Am. Chem. Soc. 2004, 126, 2300. (c) Alexanian, E. J.; Lee, C.; Sorensen, E. J. J. Am. Chem. Soc. 2005, 127, 7690. (d) Desai, L. V.; Hull, K. L.; Sanford, M. S. J. Am. Chem. Soc. 2004, 126, 9542. (e) Kalyani, D.; Sanford, M. S. Org. Lett. 2005, 7, 4149. (f) Kalyani, D.; Dick, A. R.; Anani, W. Q.; Sanford, M. S. Org. Lett. 2006, 8, 2523. (g) Wang, D.-H.; Hao, X.-S.; Wu, D.-F.; Yu, J.-Q. Org. Lett. 2006, 8, 3387. (e) Welbes, L. L.; Lyons, T. W.; Cychosz, K. A.; Sanford, M. S. J. Am. Chem. Soc. 2007, 129, 5836. (f) Desai, L. V.; Sanford, M. S. Angew. Chem., Int. Ed. 2007, 46, 5737. (h) Liu, G.; Stahl, S. S. J. Am. Chem. Soc. 2006, 128, 7179. (i) Streuff, J.; Hoevelmann, C. H.; Nieger, M.; Muniz, K. J. Am. Chem. Soc. 2005, 127, 14586. (j) Muniz, K.; Hoevelmann, C. H.; Streuff, J. J. Am. Chem. Soc. 2008, 130, 763. (k) Giri, R.; Chen, X.; Yu, J.-Q. Angew. Chem., Int. Ed. 2005, 44, 2112. (1) Daugulis, O.; Zaitsev, V. G. Angew. Chem., Int. Ed. 2005, 44, 4046. (m) Dick, A. R.; Kampf, J. W.; Sanford, M. S. J. Am. Chem. Soc. 2005, 127, 12790. (n) Kalyani, D.; Sanford, M. S. J. Am. Chem. Soc. 2008, 130, 2150. (o) Kalyani, D.; Dick, A. R.; Anani, W. Q.; Sanford, M. S. Tetrahedron 2006, 62, 11483.

62. (a) Yan, J.; Wu, J.; Jin, H. J. Organomet. Chem. 2007, 692, 3636. (b) Yan, J.; Lin, F.; Yang, Z. Synthesis 2007, 1301. (c) Zhu, M.; Jin, J. C.; Tong, J. Y. J. Chem. Res. 2008, 218.

63. (a) Richardson, R. D.; Wirth, T. Angew. Chem., Int. Ed. 2006, 45, 4402. (b) Ochiai, M. Chem. Rec. 2007, 7, 12.

64. (a) Thottumkara, A. P.; Bowsher, M. S.; Vinod, T. K. Org. Lett. 2005, 7, 2933. (b) Schulze, A.; Giannis, A. Synthesis 2006, 257. (c) Uyanik, M.; Akakura, M.; Ishihara, K. J. Am. Chem. Soc. 2009, 131, 251.

65. (a) Ochiai, M.; Takeuchi, Y.; Katayama, T.; Sueda, T.; Miyamoto, K. J. Am. Chem.Soc. 2005, 127, 12244. (b) Richardson, R. D.; Page, T. K.; Altermann, S.; Paradine, S. M.; French, A. N.; Wirth, T. Synlett 2007, 538. (c) Yamamoto, Y.; Togo, H. Synlett 2006, 798. (d) Akiike, J.; Yamamoto, Y.; Togo, H. Synlett 2007, 2168. (e) Yamamoto, Y.; Kawano, Y.; Toy, P. H.; Togo, H. Tetrahedron 2007, 63, 4680.

66. (a) Dohi, T.; Maruyama, A.; Yoshimura, M.; Morimoto, K.; Tohma, H.; Kita, Y. Angew. Chem., Int. Ed. 2005, 44, 6193. (b) Dohi, T.; Maruyama, A.; Minamitsuji, Y.; Takenaga, N.; Kita, Y. Chem. Commun. 2007, 1224. (c) Yakura, T.; Konishi, T. Synlett 2007, 765. (d) Dohi, T.; Minamitsuji, Y.; Maruyama, A.; Hirose, S.; Kita, Y. Org. Lett. 2008, 10, 3559. (e) Liu, H.; Tan, C.-H. Tetrahedron Lett. 2007, 48, 8220. (f) Moroda, A.; Togo, H. Synthesis 2008, 1257. (g) Miyamoto, K.; Sei, Y.; Yamaguchi, K.; Ochiai, M. J. Am. Chem. Soc. 2009, $131,1382$.

67. (a) Herrerias, C. I.; Zhang, T. Y.; Li, C.-J. Tetrahedron Lett. 2006, 47, 13. (b) But, T. Y. S.; Tashino, Y.; Togo, H.; Toy, P. H. Org. Biomol. Chem. 2005, 3, 970. (c) Tohma, H.; Maegawa, T.; Kita, Y. Synlett 2003, 723. (d) Tohma, H.; Maegawa, T.; Kita, Y. ARKIVOC 
2003, (vi), 62. (e) Chen, J.-M.; Huang, X. Synthesis 2004, 2459. (f) Liu, S.-J.; Zhang, J.-Z.; Tian, G.-R.; Liu, P. Synth. Commun. 2005, 35, 1753. (g) Huang, H.-Y.; Hou, R.-S.; Wang, H.-M.; Chen, L.-C. Heterocycles 2005, 65, 1881.

68. (a) Liu, S. J.; Zhang, J. Z.; Tian, G. R.; Liu, P. Synth. Commun. 2005, 36, 823. (b) Xie, Y.-Y.; Chen, Z.-C. Synth. Commun. 2002, 32, 1875. (c) Wan, D.-B.; Chen, J.-M. J. Chem. Res. 2006, 32. (d) Kawamura, Y.; Maruyama, M.; Tokuoka, T.; Tsukayama, M. Synthesis 2002, 2490. (e) Chen, J.-M.; Huang, X. Synthesis 2004, 1577.

69. (a) Tesevic, V.; Gladysz, J. A. Green Chem. 2005, 7, 833. (b) Tesevic, V.; Gladysz, J. A. J. Org. Chem. 2006, 71, 7433. (c) Lion, C. J.; Vasselin, D. A.; Schwalbe, C. H.; Matthews, C. S.; Stevens, M. F. G.; Westwell, A. D. Org. Biomol. Chem. 2005, 3, 3996. (d) Rocaboy, C.; Gladysz, J. A. Chem. Eur. J. 2003, 9, 88.

70. (a) Kunst, E.; Gallier, F.; Dujardin, G.; Yusubov, M. S.; Kirschning, A. Org. Lett. 2007, 9, 5199. (b) Yusubov, M. S.; Yusubova, R. Y.; Kirschning, A.; Park, J. Y.; Chi, K.-W. Tetrahedron Lett. 2008, 49, 1506.

\section{Author's biographical data}

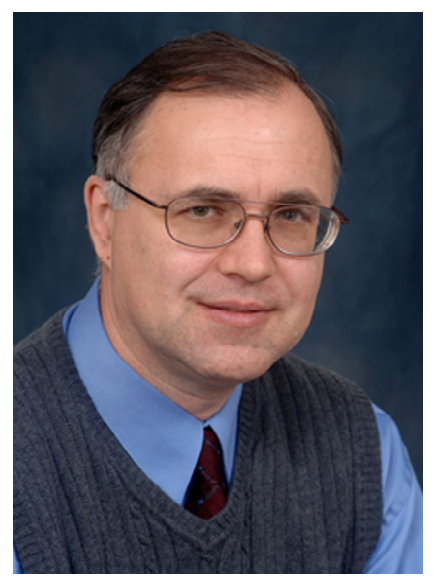

Viktor V. Zhdankin was born in Ekaterinburg, Russian Federation. His M.S. (1978), Ph.D. (1981), and Doctor of Chemical Sciences (1986) degrees were earned at Moscow State University in the research laboratories of Professor Nikolay S. Zefirov. He moved to the University of Utah in 1990, where he worked for three years as Instructor of organic chemistry and Research Associate. In 1993, he joined the faculty of the University of Minnesota Duluth, where he is currently a Professor of Chemistry. He has published over 200 scientific papers including 22 reviews and book chapters. His main research interests are in the fields of synthetic and mechanistic organic chemistry of hypervalent main-group elements (iodine, xenon, selenium, sulfur, and phosphorus) and organofluorine chemistry. Since 2003 he is Scientific Editor and a Member of Control Board of ARKIVOC. 